\title{
The Key Role of Active Sites in the Development of Selective Metal Oxide Sensor Materials
}

\author{
Artem Marikutsa ${ }^{1, *(D)}$, Marina Rumyantseva ${ }^{1}$ (D), Elizaveta A. Konstantinova ${ }^{2,3,4}$ (D) $_{\text {and }}$ Alexander Gaskov ${ }^{1}$ \\ 1 Chemistry Department, Moscow State University, 119991 Moscow, Russia; roum@inorg.chem.msu.ru (M.R.); \\ gaskov@inorg.chem.msu.ru (A.G.) \\ 2 Physics Department, Moscow State University, 119991 Moscow, Russia; liza35@mail.ru \\ 3 Faculty of Nano-, Bio-, Information and Cognitive Technologies, Moscow Institute of Physics and Technology, \\ 141700 Dolgoprudny, Russia \\ 4 National Research Center "Kurchatov Institute", 123182 Moscow, Russia \\ * Correspondence: artem.marikutsa@gmail.com
}

Citation: Marikutsa, A.;

Rumyantseva, M.; Konstantinova,

E.A.; Gaskov, A. The Key Role of

Active Sites in the Development of

Selective Metal Oxide Sensor

Materials. Sensors 2021, 21, 2554.

https://doi.org/10.3390/s21072554

Academic Editor: Victor Sysoev

Received: 16 March 2021

Accepted: 2 April 2021

Published: 6 April 2021

Publisher's Note: MDPI stays neutral with regard to jurisdictional claims in published maps and institutional affiliations.

Copyright: (c) 2021 by the authors. Licensee MDPI, Basel, Switzerland. This article is an open access article distributed under the terms and conditions of the Creative Commons Attribution (CC BY) license (https:// creativecommons.org/licenses/by/ $4.0 /)$.

\begin{abstract}
Development of sensor materials based on metal oxide semiconductors (MOS) for selective gas sensors is challenging for the tasks of air quality monitoring, early fire detection, gas leaks search, breath analysis, etc. An extensive range of sensor materials has been elaborated, but no consistent guidelines can be found for choosing a material composition targeting the selective detection of specific gases. Fundamental relations between material composition and sensing behavior have not been unambiguously established. In the present review, we summarize our recent works on the research of active sites and gas sensing behavior of $n$-type semiconductor metal oxides with different composition (simple oxides $\mathrm{ZnO}, \mathrm{In}_{2} \mathrm{O}_{3}, \mathrm{SnO}_{2}, \mathrm{WO}_{3}$; mixed-metal oxides $\mathrm{BaSnO}_{3}, \mathrm{Bi}_{2} \mathrm{WO}_{6}$ ), and functionalized by catalytic noble metals $(\mathrm{Ru}, \mathrm{Pd}, \mathrm{Au})$. The materials were variously characterized. The composition, metal-oxygen bonding, microstructure, active sites, sensing behavior, and interaction routes with gases $\left(\mathrm{CO}, \mathrm{NH}_{3}, \mathrm{SO}_{2}, \mathrm{VOC}, \mathrm{NO}_{2}\right)$ were examined. The key role of active sites in determining the selectivity of sensor materials is substantiated. It was shown that the metal-oxygen bond energy of the MOS correlates with the surface acidity and the concentration of surface oxygen species and oxygen vacancies, which control the adsorption and redox conversion of analyte gas molecules. The effects of cations in mixed-metal oxides on the sensitivity and selectivity of $\mathrm{BaSnO}_{3}$ and $\mathrm{Bi}_{2} \mathrm{WO}_{6}$ to $\mathrm{SO}_{2}$ and VOCs, respectively, are rationalized. The determining role of catalytic noble metals in oxidation of reducing analyte gases and the impact of acid sites of MOS to gas adsorption are demonstrated.
\end{abstract}

Keywords: active sites; metal oxide semiconductor; gas sensor; gas-solid interaction; selectivity; nanoparticles

\section{Introduction \\ 1.1. Issues in the Design of Metal Oxide Sensors}

Nanomaterials based on metal oxide semiconductors (MOS) have been extensively investigated for use in resistive gas sensors. The electronic properties of MOS are sensitive to chemical processes occurring at the surface, which enables the detection of gas molecules in the ppb-ppm concentration range in the environment [1-3]. Thermal stability in air, miniaturization, low cost and ability of integration into wireless devices are the main advantages of resistive sensors. The main drawback is the low selectivity, which is due to the sensing principle. Redox conversion of reducing or oxidizing gas molecules at the surface of MOS controls the thickness of a space charge region and electric conduction in the semiconductor $[2,4]$. Therefore, gas molecules with distinct compositions but similar redox properties are indistinguishable by the sensor response. A number of approaches to improve the selectivity of MOS sensors were elaborated. Those include technological ones, e.g., using preconcentration or filtering membranes $[5,6]$, modulation of the operation temperature 
regime, use of multisensor arrays with appropriate data treatment algorithms ("electronic nose") [7-9]. The fundamental approach is modification of the chemical composition of the sensor material. It can be performed by functionalization of MOS surfaces [9-12], bulk doping of MOS $[13,14]$, use of $p$-type MOS and mixed-metal oxides instead of conventionally employed $n$-type $\mathrm{MOS}\left(\mathrm{SnO}_{2}, \mathrm{ZnO}, \mathrm{WO}_{3}, \mathrm{TiO}_{2}, \mathrm{Ga}_{2} \mathrm{O}_{3}, \mathrm{In}_{2} \mathrm{O}_{3}\right.$, etc.) [15-17], or MOS-based composites with different additives, e.g., noble metals, metal oxides, graphene and carbon nanotubes, polymers [18-21]. Although there are numerous reviews available on MOS-based materials for gas sensors, a comprehensive materials design concept for the creation of sensors with predetermined selectivity for a desired analyte gas or a group of gases can hardly be found. In a recent review by Korotcenkov, et.al., the criteria for choosing the chemical composition of a gas-sensitive MOS were proposed [22]. For example, simple metal oxides conventionally used in sensors combine thermal stability (high melting and decomposition points above $1200^{\circ} \mathrm{C}$ ), and electronic configuration $\mathrm{d}^{0}$ for transition metal cations (in $\mathrm{TiO}_{2}, \mathrm{WO}_{3}$ ) or $\mathrm{d}^{10}$ for post-transition metal cations (in $\mathrm{In}_{2} \mathrm{O}_{3}, \mathrm{ZnO}, \mathrm{SnO}_{2}$ ) that conditions the wide bandgap $n$-type semiconductor behavior. These cations may be partially reduced through the formation of oxygen vacancies, and the concentration of point defects in these metal oxides falls in the $10^{16}-10^{19} \mathrm{~cm}^{-3}$ range, which is appropriate for the sensitivity of bulk conduction of localized charges at the surface [22]. However, no guidelines can be found for choosing the chemical composition of a sensor material. Even the choice between the listed simple MOS is an issue when the selectivity of analyte gas adsorption and redox interaction with the surface is considered. A more sophisticated problem is an appropriate selection of constituents when gas sensitive mixed-metal oxides or composites are elaborated. Besides the predictable effect on electronic properties of the semiconductor, the additives influence the adsorption capacity and chemical reactivity of the material surface, and the latter has often been disregarded in the gas sensor studies.

\subsection{Gas Sensing Principles of Metal Oxide Sensors}

The mechanism of gas sensing consists of three principle steps: (i) adsorption and redox interaction of gas molecules with the MOS surface ("reception"); (ii) transduction of the electric signal produced by the redox reaction from the surface to the bulk of MOS; and (iii) transduction of the electric signal through the network of contacting MOS particles $[1,2,23]$. The reception is a chemical process involving the active sites at MOS surface and is discussed in detail below.

\subsubsection{Oxygen Vacancy Formation and Oxygen Chemisorption}

Oxygen vacancies are formed due to partial oxygen loss from the surface of oxides in which metals have the highest oxidation states for the respective elements group:

$$
\mathrm{O}^{2-}{ }_{\text {(bulk) }} \leftrightarrow \frac{1}{2} \mathrm{O}_{2(\mathrm{~g})}+\mathrm{V}_{\mathrm{O}}{ }^{2-} \leftrightarrow \frac{1}{2} \mathrm{O}_{2(\mathrm{~g})}+\mathrm{V}_{\mathrm{O}}{ }^{-}+e^{-} \leftrightarrow \frac{1}{2} \mathrm{O}_{2(\mathrm{~g})}+\mathrm{V}_{\mathrm{O}}+2 e^{-}
$$

Electron donor states associated with oxygen vacancies (or, reduced metal cations) are available for oxygen chemisorption in air yielding chemisorbed species (Equation (2)), or restoring the lattice $\mathrm{O}^{2-}$ anions on the oxide surface (Equation (3)):

$$
\begin{gathered}
\mathrm{O}_{2(\mathrm{~g})}+4 e^{-} \leftrightarrow \mathrm{O}_{2}{ }^{-}{ }_{\text {(ads) }}+3 e^{-} \leftrightarrow 2 \mathrm{O}^{-}{ }_{\text {(ads) }}+2 e^{-} \leftrightarrow 2 \mathrm{O}^{2-}{ }_{\text {(ads) }} \\
\mathrm{O}_{2(\mathrm{~g})}+2 \mathrm{~V}_{\mathrm{O}}+4 e^{-} \leftrightarrow 2 \mathrm{O}^{2-}{ }_{\text {(bulk) }}
\end{gathered}
$$

As a result, in the subsurface region the donor states become less occupied by electrons, negative charge is localized at the chemisorbed oxygen and surface potential barrier arises leading to reduced conductivity of the $n$-type MOS decrease (Figure 1). The chemisorption equilibria described in Equation (2) shift to the right at increasing temperature, so that predominant chemisorbed oxygen species changes from molecular $\mathrm{O}_{2}{ }^{-}\left(160-200{ }^{\circ} \mathrm{C}\right)$ to atomic $\mathrm{O}^{-}\left(200-350{ }^{\circ} \mathrm{C}\right.$ ) and $\mathrm{O}^{2-}$ ones (above $\left.350^{\circ} \mathrm{C}\right)$. It was established for polycrystalline $\mathrm{SnO}_{2}$ using numerous spectroscopic techniques and indirect measurements $[5,24,25]$, and 
the agreeing conclusions were done for other $n$-type $\mathrm{MOS}\left(\mathrm{ZnO}, \mathrm{In}_{2} \mathrm{O}_{3}, \mathrm{WO}_{3}\right)$ using the conduction measurements under variable oxygen pressure [26-28].

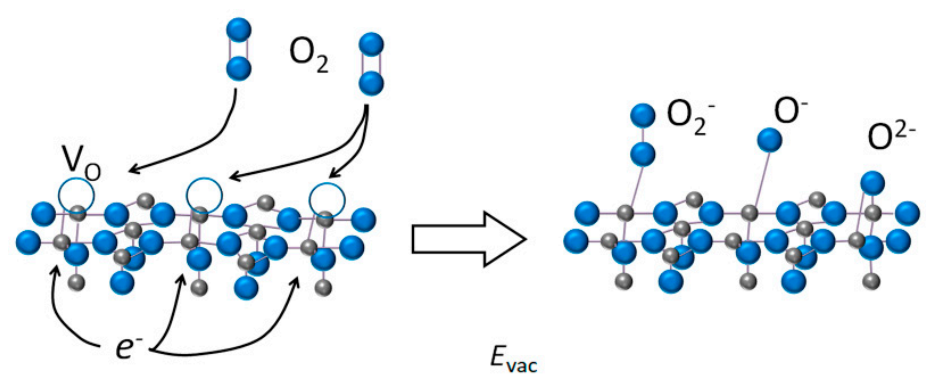

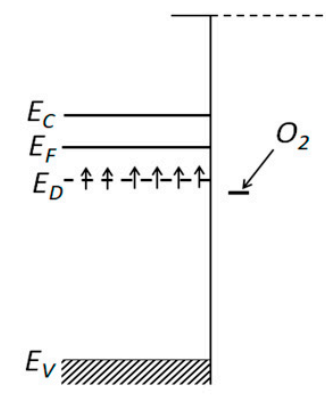

(a)

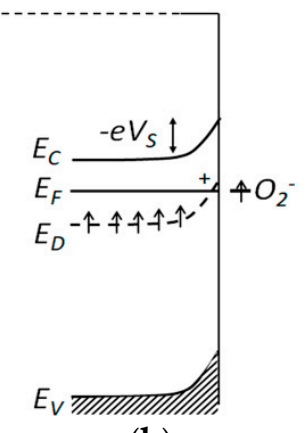

(b)

Figure 1. Schematic of representation (top) of the surface of MOS possessing oxygen vacancies $\left(\mathrm{V}_{\mathrm{O}}\right)$ before (a) and after oxygen ionosorption (b); and the corresponding modulation of band energy levels (bottom): vacuum level $\left(E_{\mathrm{vac}}\right)$, conduction band bottom $\left(E_{C}\right)$, Fermi level $\left(E_{F}\right)$, donor states level $\left(E_{D}\right)$, valence band top $\left(E_{V}\right)$, potential energy surface barrier $\left(-e V_{S}\right)$.

There are two models describing the sensor response as the interaction of analyte gases with: (i) chemisorbed oxygen species (ionosorption model), and (ii) lattice oxygen anions at the oxide surface (oxygen vacancy model) [29,30].

\subsubsection{The Ionosorption Model of Sensor Response}

Within the ionosorption model, sensor response to a reducing gas (Red) is due to oxidation of gas molecules by chemisorbed oxygen species $\left(\mathrm{O}_{n}{ }^{\mathrm{m}-}\right)[4,6-8,29,30]$ :

$$
\operatorname{Red}_{(\mathrm{g})}+\mathrm{O}_{\mathrm{n}}{ }^{\mathrm{m}-}{ }_{(\mathrm{ads})} \rightarrow \mathrm{RO}_{\mathrm{n}(\mathrm{g})}+m e^{-}
$$

where $\mathrm{RO}_{\mathrm{n}}$ is the oxidation product. The removal of chemisorbed oxygen species releases the trapped electrons back to the semiconductor and decreases the surface potential barrier (Figure 2), which results in increasing conductivity. For example, the reducing gases $\mathrm{H}_{2}, \mathrm{CO}, \mathrm{H}_{2} \mathrm{~S}, \mathrm{NH}_{3}$, and VOCs are commonly considered to be oxidized to $\mathrm{H}_{2} \mathrm{O}, \mathrm{CO}_{2}$, $\mathrm{H}_{2} \mathrm{O}+\mathrm{SO}_{2}, \mathrm{H}_{2} \mathrm{O}+\mathrm{N}_{2}$, and $\mathrm{H}_{2} \mathrm{O}+\mathrm{CO}_{2}$, respectively [2,4,5,31-35]. The surface reaction is described similarly as the mechanisms of heterogeneous oxidation catalysis within the Langmuir-Hinshelwood model (reaction between co-adsorbed Red molecule and oxygen) or Iley-Rideal model (reaction of gas-phase Red and adsorbed oxygen) [36,37]. Unlike the mechanisms of catalysis which have been the subject for careful kinetic studies, the interaction of reducing gases with chemisorbed oxygen at the sensors surfaces has hardly been experimentally proven. The ionosorption model, i.e., oxidation by ionosorbed oxygen species, has often been speculatively used to describe the sensing mechanisms of reducing gases [32-35,38-40]. The major issue is the lack of techniques for the observation of chemisorbed oxygen species, especially under in situ reaction conditions [25]. The response to an oxidizing gas $(\mathrm{Ox})$ is attributed to the competitive chemisorption of target molecules (e.g., $\mathrm{NO}_{2}, \mathrm{O}_{3}, \mathrm{Cl}_{2}$ ) which are stronger electron acceptors than $\mathrm{O}_{2}$ :

$$
\mathrm{Ox}_{(\mathrm{g})}+m e^{-} \rightarrow \mathrm{Ox}^{\mathrm{m}-} \text { (ads) }
$$




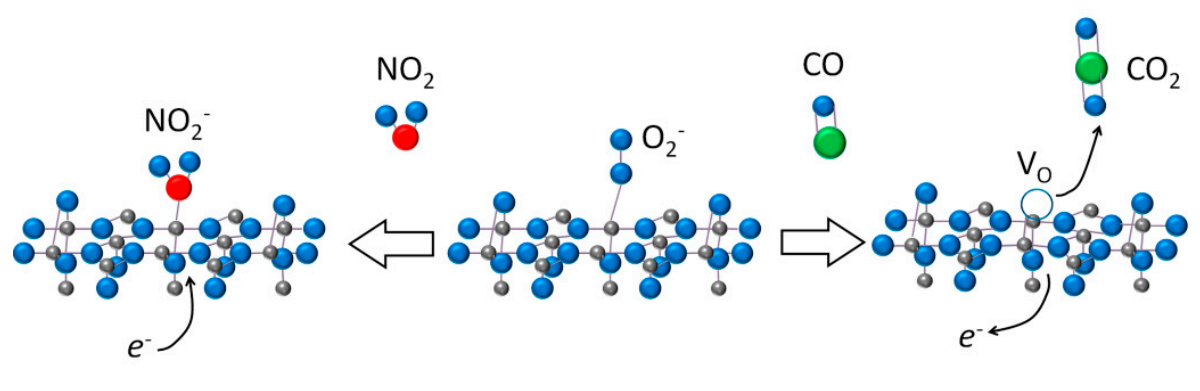

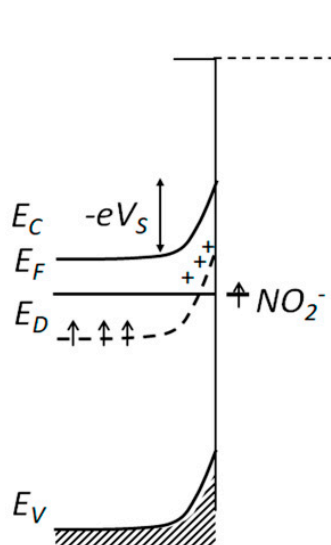

(a)

$E_{\text {vac }}$

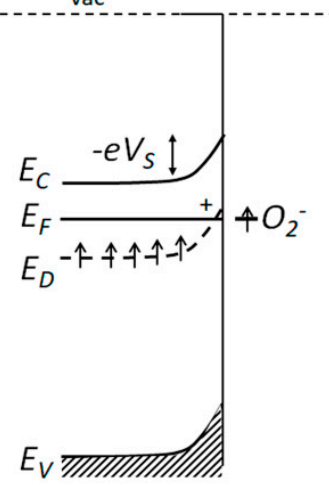

(b)

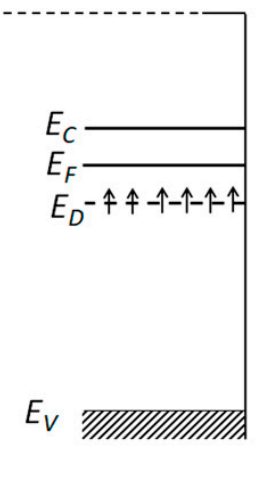

(c)

Figure 2. Schematic representation of the surface of $n$-type MOS with ionosorbed oxygen species (b) and after its interaction with reducing gas $\mathrm{CO}$ (c) and oxidizing gas $\mathrm{NO}_{2}$ (a) within the chemisorption model of sensor response (top); and the corresponding modulation of band energy levels (bottom).

This leads to trapping of more electrons in the surface states and a higher potential barrier at the MOS surface, resulting in decreased conductivity in the presence of oxidizing gases (Figure 2). The sensing mechanism related to chemisorption of oxidizing gases (Equation (5)) was experimentally proven by spectroscopy studies, e.g., $\mathrm{NO}_{2}$ adsorption on the MOS surfaces with the formation of $\mathrm{NO}_{2}{ }^{-}$was observed by in situ Raman measurements [41] and diffuse reflectance infrared Fourier-transform (DRIFT) spectroscopy [42].

\subsubsection{The Oxygen Vacancy Model of Sensor Response}

The oxygen vacancy model describes the sensor response of $n$-type MOS in terms of reversible shift of equilibria between bulk oxygen anions and oxygen vacancy formation (Equation (1)) depending on the ambient gas composition [29,30]. The reducing gas (Red) favors the formation of oxygen vacancies via the binding with lattice $\mathrm{O}^{2-}$ anions at the oxide surface and desorption of the oxidation product $\left(\mathrm{RO}_{\mathrm{n}}\right)$ :

$\operatorname{Red}_{(\mathrm{g})}+n \mathrm{O}^{2-}{ }_{\text {(lat) }} \rightarrow \mathrm{RO}_{\mathrm{n}(\mathrm{g})}+n \mathrm{~V}_{\mathrm{O}}^{2-} \leftrightarrow \mathrm{RO}_{\mathrm{n}(\mathrm{g})}+n \mathrm{~V}_{\mathrm{O}}^{-}+n e^{-} \leftrightarrow \mathrm{RO}_{\mathrm{n}(\mathrm{g})}+n \mathrm{~V}_{\mathrm{O}}+2 n e^{-}$

As a result, the concentration of donor states with loosely bound electrons increases (Figure 3), and the conductivity of $n$-type MOS rises. The reaction of target gas with lattice $\mathrm{O}^{2-}$ anions (Equation (6)) with simultaneous cleavage of metal-oxygen bonds is considered within the Mars-van Krevelen model of catalytic oxidation over metal oxide catalysts [36]. It has been accepted that the oxygen vacancy mechanism of sensor response takes place under oxygen-lean conditions, e.g., when the reducing gases $\left(\mathrm{CO}\right.$, hydrocarbons, $\left.\mathrm{H}_{2}\right)$ are detected in inert gases $[43,44]$. Such conditions are unfavorable for oxygen chemisorption at the MOS surface, and the ionosorption model of sensor response is unsuitable. Response 
to an oxidizing gas $(\mathrm{Ox})$ is attributed to the fulfilment of an oxygen vacancy by an oxygen atom and restoration of lattice $\mathrm{O}^{2-}$ anions and metal-oxygen bonds:

$$
\mathrm{Ox}_{(\mathrm{g})}+\mathrm{V}_{\mathrm{O}}+2 e^{-} \rightarrow \mathrm{R}_{(\mathrm{g})}+\mathrm{O}^{2-}{ }_{(\text {lat })}
$$

where the Ox molecule contains oxygen atoms and $\mathrm{R}$ is the reduction product. The participation of oxide anions in the interaction of MOS with analyte gases was confirmed experimentally in a number of works. The evolution of $\mathrm{Sn}^{2+}$ cations was observed by Mossbauer spectroscopy as a result of partial lattice oxygen reduction in $\mathrm{SnO}_{2}$ during the interaction with $\mathrm{CO}$ in inert atmosphere [45]. By DRIFT spectroscopy it was established that the $\mathrm{W}-\mathrm{O}$ bonds were cleaved on the surface of $\mathrm{WO}_{3}$ in presence of $\mathrm{CO}$ in air [46]. On the contrary, the $\mathrm{W}-\mathrm{O}$ bonds restored when $\mathrm{WO}_{3}$ was oxidized by $\mathrm{NO}_{2}$ or even $\mathrm{H}_{2} \mathrm{O}$ molecules in humid air $[46,47]$. Thus, the sensor response of tungsten oxide has been appropriately described by the oxygen vacancy model.

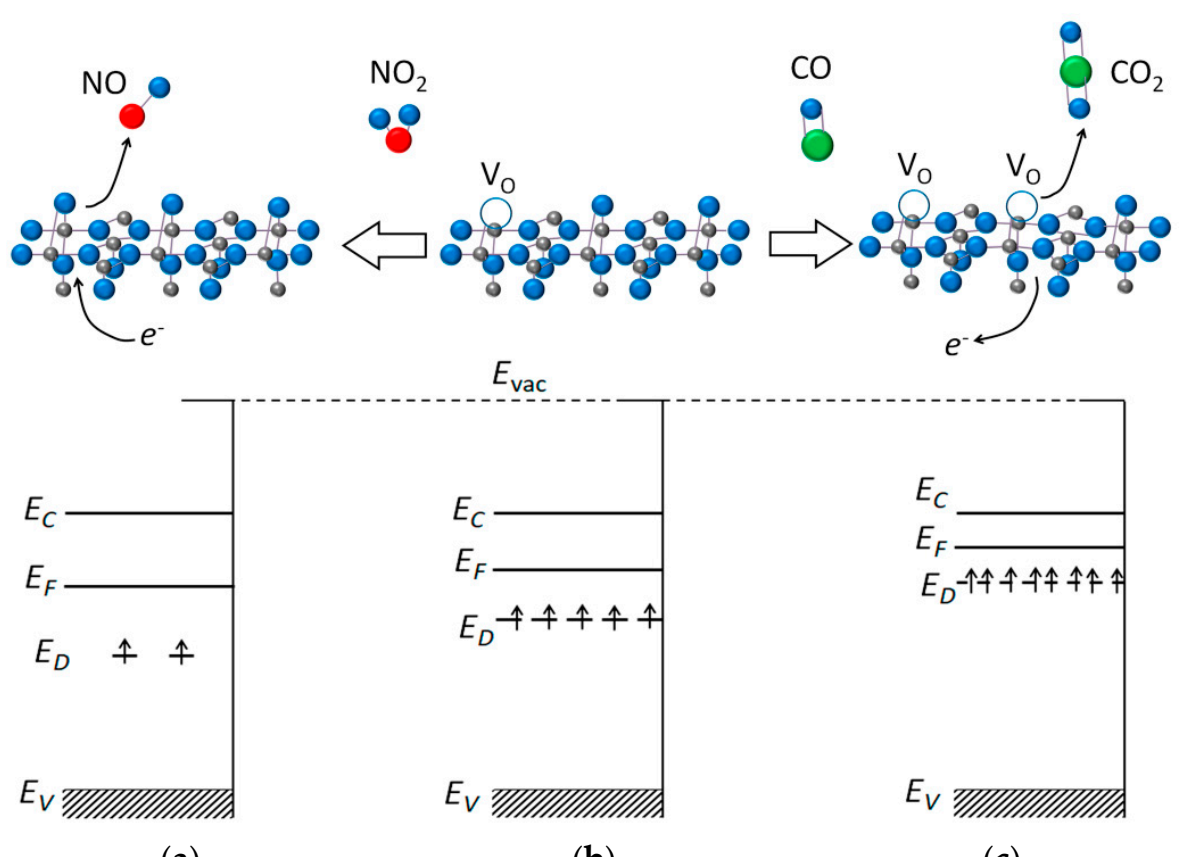

(a)

(b)

(c)

Figure 3. Schematic representation of the $n$-type MOS with oxygen vacancies and lattice oxygen anions (b), and after its interaction with reducing gas $\mathrm{CO}(\mathbf{c})$ and oxidizing gas $\mathrm{NO}_{2}(\mathbf{a})$ within the oxygen vacancy model of sensor response (top); and the assumed changes in donor states population $\left(E_{\mathrm{D}}\right)$ and Fermi level positions $\left(E_{\mathrm{F}}\right)$ (bottom).

\subsection{The Concerns on Sensor Materilals from Heterogeneous Catalysis}

The reception of gas molecules at the sensor surface consists of same processes as on the surface of heterogeneous catalysts: adsorption and redox conversion of gas molecules. The correlations of sensitivity with catalytic activity of MOS have been observed experimentally [48-50]. Typical studies of heterogeneous catalysts consist of in-depth materials characterization, including the determination of active surface sites and the investigation of gas-solid interactions (adsorption, redox conversion) which are controlled by the surface sites [36,51]. On the contrary, in studies of sensors the greater attention has been paid to electrophysical phenomena (charge transfer, surface charging, band bending, conduction paths); and the sensitivity was successfully modelled depending on semiconductor type, donor states concentration, particle size, materials morphology, heterojunctions etc. $[1-4,8,23,52,53]$. Characterization of active sites at sensors surfaces was hardly performed, therefore, the chemical routes of analyte gas adsorption and redox interaction with the surface was incompletely understood. Catalytic activity of MOS and additives used in the composites is often referred to when gas sensing is discussed; however, the 
characterization of the surface sites and the direct experimental evidences for the catalytic interaction with gases was most often missing. The additives utilized in MOS-based sensors have traditionally been grouped as the catalytic (chemical) and the electronic ones [4,8,21]. The disadvantage of such classification is that the origin and mechanism of the catalytic activity in the process of target gas conversion is disregarded, and, consequently, the improvement of selectivity is not substantiated from the viewpoint of surface chemistry. Moreover, the additives (noble metals, metal oxides, carbon nanomaterials, polymers) can simultaneously exhibit the catalytic behavior and electronic interaction, i.e., heterojunction formation with MOS.

\subsection{The Comparison of Energetic Parameters of n-Type Metal Oxide Semiconductors}

In this review, we summarize our recent works aimed at reveling the active sites at the surface of gas sensitive MOS-based materials and the impact of surface sites on the adsorption and redox interactions with gas molecules which influence the sensing behavior. We show that the paradigm of heterogeneous catalysts research is worth applying for the investigation of sensor materials, since the reasons for selectivity in gas sensing may be fundamentally rationalized in terms of surface chemical reactivity. The approaches conventionally used for catalysts research were successfully transferred to the studies of gas sensors, including the qualitative and quantitative determination of active sites by surface science techniques such as temperature-programmed reduction and temperatureprogrammed desorption of probe molecules. Using in situ infrared spectroscopy the roles of adsorption sites and redox sites were revealed in the processes of gas molecules interaction with the sensors surfaces. The dependence of materials functional behavior on gas-solid interaction is the common point for heterogeneous catalysts and sensors. The sensitivity of sensors is much influenced also by the transduction of charge carriers between the surface and bulk of semiconductor and through the network of conduction paths. However, in the present review we propose that the selectivity of sensor response is mainly controlled by gas molecules reception, which in turn depends on active sites at the sensor surface. The nature and concentration of active sites depend on the chemical composition of sensing materials. Revealing these correlations will be useful for predictable control of sensors selectivity through appropriate tailoring the materials composition. Herein, the effect of chemical composition of simple $n$-type $\mathrm{MOS}\left(\mathrm{In}_{2} \mathrm{O}_{3}, \mathrm{ZnO}, \mathrm{SnO}_{2}, \mathrm{TiO}_{2}, \mathrm{WO}_{3}\right)$ and mixedmetal oxides $\left(\mathrm{BaSnO}_{3}, \mathrm{Bi}_{2} \mathrm{WO}_{6}\right)$ on the acid sites, oxidizing sites (surface oxygen species) and donor sites (oxygen vacancies) is discussed. The materials are wide-bandgap $n$-type semiconductors and differ in energetic parameters of the oxides and constituent cations (Table 1) [54,55]. Electronegativity of the cations increases in the order $\mathrm{Zn}^{2+}, \mathrm{In}^{3+}, \mathrm{Sn}^{4+}$, $\mathrm{Ti}^{4+}, \mathrm{W}^{6+}$; it agrees with the increment of charge/radius ratio. Accordingly, the metaloxygen bond energy ( $\left.E_{\mathrm{M}-\mathrm{O}}\right)$ increases in respective metal oxides (Table 1$)$ [54,56], and electron energy band positions (valence band top $E_{\mathrm{v}}$, conduction band bottom $E_{\mathrm{c}}$, middle of bandgap $\chi$ ) decrease (Figure 4 ). The conduction band minima are mainly contributed by empty cationic s-orbitals $\left(\mathrm{In}^{3+}, \mathrm{Zn}^{2+}, \mathrm{Sn}^{4+}\right)$ or d-orbitals $\left(\mathrm{Ti}^{4+}, \mathrm{W}^{6+}\right)$, and the valence band maxima-by filled oxygen 2p-orbitals $[57,58]$. Energy levels of the orbitals shift deeper below the vacuum level as the electronegativity of cations increases (Figure 4). Bandgap width of oxides is related to cationic Pearson's hardness (or, ionic-covalent parameter), which is close for the mentioned cations (intermediately hard) and, therefore, the oxides have wide bandgaps $\left(E_{\mathrm{g}}=2.8-3.6 \mathrm{eV}\right)$ [54]. In the following, we use M-O bond energy as the fundamental descriptor parameter of the active sites and gas sensitivity of metal oxides. The roles of acid sites, chemisorbed oxygen and oxygen vacancies in adsorption and redox conversion of gas molecules $\mathrm{NH}_{3}, \mathrm{SO}_{2}, \mathrm{H}_{2} \mathrm{~S}$, volatile organic compounds (VOCs), and $\mathrm{NO}_{2}$ is discussed in relation to sensing behavior. The key role of noble metal clusters $(\mathrm{Pd}, \mathrm{Ru})$ in specific catalytic oxidation of analyte molecules $\left(\mathrm{CO}, \mathrm{NH}_{3}\right)$ improving the selectivity of sensor response of catalytically functionalized MOS is discussed. 
Table 1. Parameters of $n$-type metal oxide semiconductors (MOS): cationic radius r, electronegativity $\chi$ and ionic-covalent parameter ICP; metal-oxygen bond energy $E_{\mathrm{M}-\mathrm{O}}$ and bond distance $d_{\mathrm{M}-\mathrm{O}}$; negative formation enthalpy per oxygen atom $-1 / x \cdot \Delta_{\mathrm{f}} \mathrm{H}$; bandgap width $E_{\mathrm{g}}$.

\begin{tabular}{|c|c|c|c|c|c|c|c|}
\hline MOS & r, Å [59] & $\chi,{ }^{1}$ P.u. [54] & $\mathrm{ICP}^{2}$ [54] & $E_{\mathrm{M}-\mathrm{O}^{3}}, \mathrm{eV}[55]$ & $d_{\mathrm{M}-\mathrm{O}}, \AA$ & $-1 / x \cdot \Delta_{\mathrm{f}} \mathrm{H}[55], \mathrm{eV}$ & $E_{\mathrm{g}}[54], \mathrm{eV}$ \\
\hline $\mathrm{ZnO}$ & 0.74 & 1.65 & 0.45 & 10.4 & $1.96-1.98$ [57] & 3.6 & 3.4 \\
\hline $\mathrm{In}_{2} \mathrm{O}_{3}$ & 0.79 & 1.78 & 0.53 & 12.4 & $2.18[60]$ & 3.2 & 2.8 \\
\hline $\mathrm{SnO}_{2}$ & 0.69 & 1.96 & 0.61 & 15.5 & $2.02[61]$ & 6.0 & 3.6 \\
\hline $\mathrm{TiO}_{2}$ & 0.61 & 2.01 & 0.52 & 20.7 & $\begin{array}{c}1.95 \text { (rutile) } \\
1.96 \text { (anatase) [62] }\end{array}$ & 9.8 & 3.4 \\
\hline $\mathrm{WO}_{3}$ & 0.58 & 2.36 & 0.49 & 36.6 & $1.74-2.17$ [63] & 8.7 & 2.8 \\
\hline
\end{tabular}

${ }^{1}$ P.u. is Pauling units; ${ }^{2}$ Ionic-covalent parameter (dimensionless) correlates to Pearson's hardness of cations [54]; ${ }^{3}$ Bond energy in metal oxides $\mathrm{MO}_{\mathrm{x}}$ estimated from thermodynamic parameters [55]: $E_{\mathrm{M}-\mathrm{O}}=\left\{-\Delta_{\mathrm{f}} \mathrm{H}^{\circ}\left(\mathrm{MO}_{\mathrm{x}}\right)+\Delta_{\mathrm{sub}} \mathrm{H}^{\circ}(\mathrm{M})+x / 2 \cdot \Delta_{\text {dis }} \mathrm{H}^{\circ}\left(\mathrm{O}_{2}\right)+x \cdot \Delta_{\mathrm{el} . \text { af. }} \mathrm{H}^{\circ}(\mathrm{O})\right.$ $\left.+\Sigma \Delta_{\text {ion. }} \mathrm{H}^{\circ}(\mathrm{M})\right\} /\left(x \cdot \mathrm{CN}_{\mathrm{O}}\right)$, where $\Delta_{\mathrm{sub}} \mathrm{H}^{\circ}(\mathrm{M})$ - sublimation enthalpy of metal, $\Delta_{\mathrm{dis}} \mathrm{H}^{\circ}\left(\mathrm{O}_{2}\right)$ - dissociation enthalpy of oxygen molecule, $\Delta_{\text {el.af. }} \mathrm{H}^{\circ}(\mathrm{O})$ - electron affinity of oxygen atom, $\Sigma \Delta_{\text {ion. }} \mathrm{H}^{\circ}(\mathrm{M})$-sum of ionization potentials of metal cation, $\mathrm{CN}_{\mathrm{O}}$-coordination number of oxygen in the oxide.

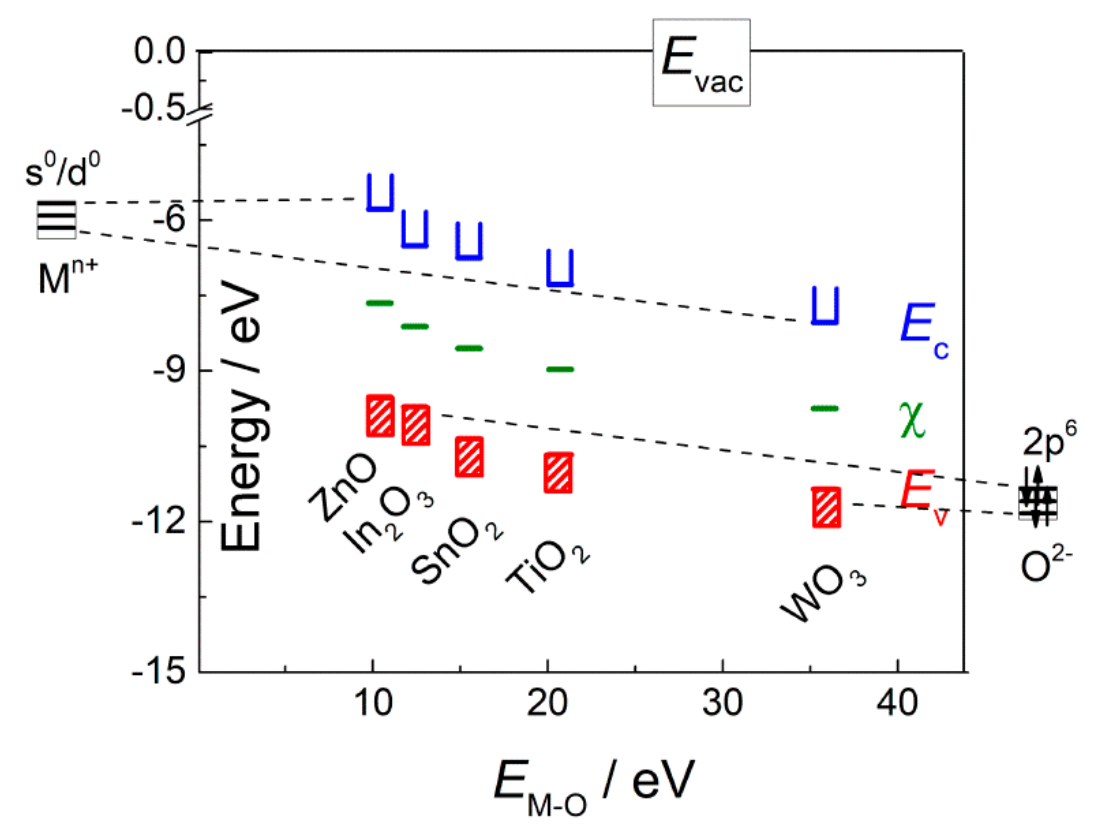

Figure 4. Positions of conduction band minima $\left(E_{\mathrm{c}}\right)$, valence band maxima $\left(E_{\mathrm{v}}\right)$ and electronegativity $(\chi)$ of $n$-type MOS, respective to vacuum level $\left(E_{\mathrm{vac}}\right)$. Adapted with permission using numeric data from ref. [54]. Copyright 2011 Elsevier. The oxides electronegativity corresponds to middle bandgap position. The levels of atomic orbitals for metal cations $\left(\mathrm{M}^{\mathrm{n}+} \mathrm{s}^{0} / \mathrm{d}^{0}\right)$ and oxygen anions $\left(\mathrm{O}^{2-} 2 \mathrm{p}^{6}\right)$ are shown schematically.

\section{Types of Active Sites at the MOS Surface}

In the literature there is no strict definition of an active site at the metal oxide surface; rather, it is conditional according to the materials and processes under consideration. In catalysts, the proper representation of an active site is the surface atom or ensemble which binds to a foreign molecule, thus loosening the intramolecular chemical bonds and forming the intermediates and/or final products of the catalytic reaction [36,64]. Yet, such defined active sites are hardly observable experimentally and unmeasurable due to their low fraction in the overall number of surface atoms, the specificity of catalytic reaction and the dynamic lability of active species in course of reaction. The other way demonstrated in some works was to regard the active sites as the adsorption sites for the specific reactant or probe molecule (e.g., isopropanol [65], aromatics [66,67]). Such defined active sites, i.e., adsorption sites, were quantified by the adsorption measurements and their concentration 
correlated with the catalytic activity; yet, no observations under in situ reaction conditions were available.

Herein, we use the conditional term of an active site as the surface species that possess a definite chemical behavior, like acidity/basicity, redox reactivity, electron donor/acceptor behavior, specific chemisorption capacity for probe molecules [64-68]. The observation of actual reactivity of surface sites under in situ reaction conditions is an unresolved problem; and the above definition refers to a potential participation of certain types of active sites in real-life chemical reactions that determine the functionality of catalytic and sensing materials.

In general, the active sites at a metal oxide surface can be constituted by coordinately unsaturated cations and oxygen anions, atomic ensembles, molecular and atomic adsorbates $[69,70]$. Defects are also considered as important active sites in catalytic reactions; including the point defects (cationic or anionic vacancies, atomic interstitials), and the extended defects like steps, corners, edges, dislocations, perimeter between metal oxide support and catalytic clusters [71-73]. The adsorption capacity and reactivity of surface sites is due to dangling bonds and unsaturated coordination of the peripheral atoms. The surface sites can form localized electron energy states and influence the band energy levels in MOS, thus influencing the electric response to surface processes. Coordinately unsaturated cations, oxygen anions and defects (vacancies, interstitials, dislocations, etc.) are the possible intrinsic active sites. Adsorbed oxygen, OH-groups, hydrogen adatoms resulting from spontaneous adsorption of oxygen and humidity represent the intrinsic adsorbate sites at the surface of pristine metal oxides. The extrinsic active sites can be created via the introduction of additives: atoms, atomic groups, clusters, nanoparticles of metals or metal oxides. In accordance with the chemical reactivity, the intrinsic active sites can be grouped into acid/base and reducing/oxidizing (or, donor/acceptor) ones [68] The distinct chemical reactivity allows for the experimental determination of these species using appropriate techniques. In Figure 5 the types of active sites at the surface of tin oxide are shown schematically.

The concentration of different active sites depends on the nature of metal oxide (cationic charge and size, metal-oxygen bond energy), the synthesis conditions, microstructure, and additives. In the following sections, these relationships are reviewed based on our experimental studies of nanocrystalline $n$-type MOS: $\mathrm{ZnO}, \mathrm{In}_{2} \mathrm{O}_{3}, \mathrm{SnO}_{2}, \mathrm{BaSnO}_{3}, \mathrm{TiO}_{2}$, $\mathrm{WO}_{3}, \mathrm{Bi}_{2} \mathrm{WO}_{6}$. The materials were synthesized via the standardized aqueous precipitation of metal hydroxides followed by calcination at temperature $300-700{ }^{\circ} \mathrm{C}[63,74-78]$.

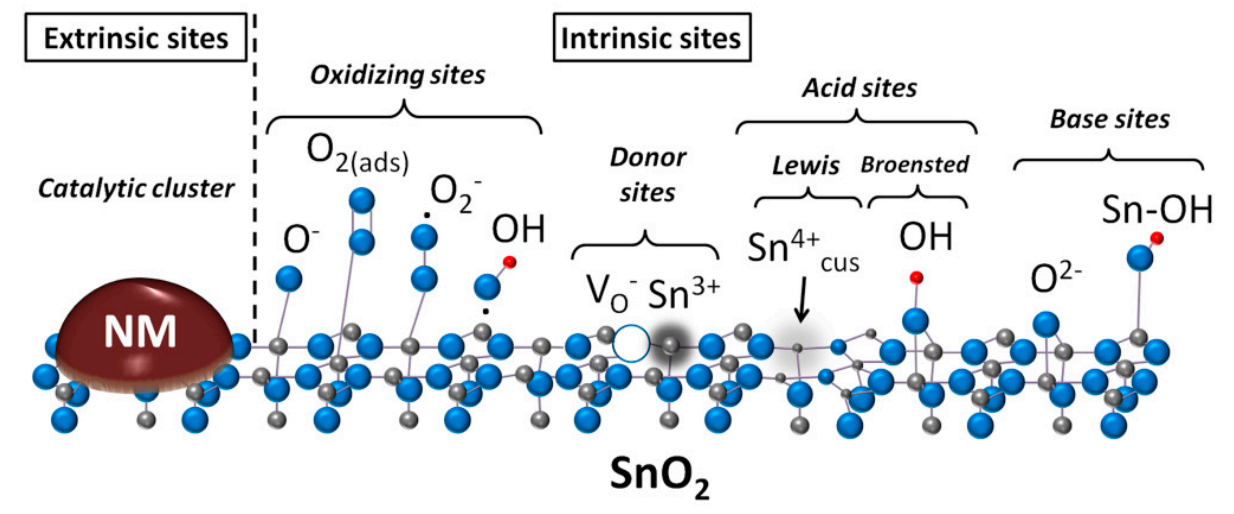

Figure 5. Types of active sites at the surface of tin oxide: noble metal cluster (NM), chemisorbed oxygen species $\left(\mathrm{O}_{2(\mathrm{ads})}, \mathrm{O}_{2}{ }^{-}, \mathrm{O}^{-}\right)$, charged oxygen vacancies $\left(\mathrm{V}_{\mathrm{O}}{ }^{-}\right)$, partially reduced cations $\left(\mathrm{Sn}^{3+}\right)$, coordinately unsaturated cations $\left(\mathrm{Sn}^{4+}\right.$ cus $)$, hydroxyl species $(\mathrm{OH}, \mathrm{Sn}-\mathrm{OH})$, surface oxygen anions $\left(\mathrm{O}^{2-}\right)$. Adapted with permission from ref. [79]. Copyright 2014 American Chemical Society. 


\subsection{Acid/Base Sites}

Surface metal cations are the Lewis acid sites, since the positive charge and unsaturated coordination favor the acceptation of lone electron pairs from the adsorbate to the cationic empty orbitals. From the electrostatic attraction law, Lewis acidity is expected to increase with increasing charge/radius ratio of the cation. On the contrary, the covalent contribution to cation-adsorbate bonding can be crucial for the acid-base bond strength. For example, it was shown that $\mathrm{Sn}^{2+}$ cations at the surface of partially reduced $\mathrm{SnO}_{2}$ are formally stronger Lewis acid sites than $\mathrm{Sn}^{4+}$ due to more covalent binding with adsorbed ammonia [80]. An alternative approach to quantitative scaling of the Lewis acidity is based on the concept of optical basicity $(\Lambda)$; it is related to the ability of cations to shift electron density from oxygen anions in metal oxides [81].

Adsorption of $\mathrm{H}_{2} \mathrm{O}$ molecules (Lewis base) and strong binding to surface cation (Lewis acid) results in water molecule dissociation producing the OH-groups (Figure 6). In case of binding to strongly Lewis acidic cations and/or binding to more than one cation in a bridging conformation, the OH-group possesses an acidic proton and behaves as Brønsted acid site. Hydroxyl groups which are loosely bound to weakly acidic cations in a terminal conformation can behave as Brønsted base or acid sites depending on the counterpart interacting species. The $\mathrm{OH}$-groups can be distinguished using FTIR spectroscopy: the terminal hydroxyls give rise to separate $\mathrm{O}-\mathrm{H}$ peaks with wavenumbers above $3600 \mathrm{~cm}^{-1}[82,83]$. The broad O-H bands centered at about $3400 \mathrm{~cm}^{-1}$ are indicative of the families of bridging hydroxyls associated via hydrogen bonds (Figure 7).

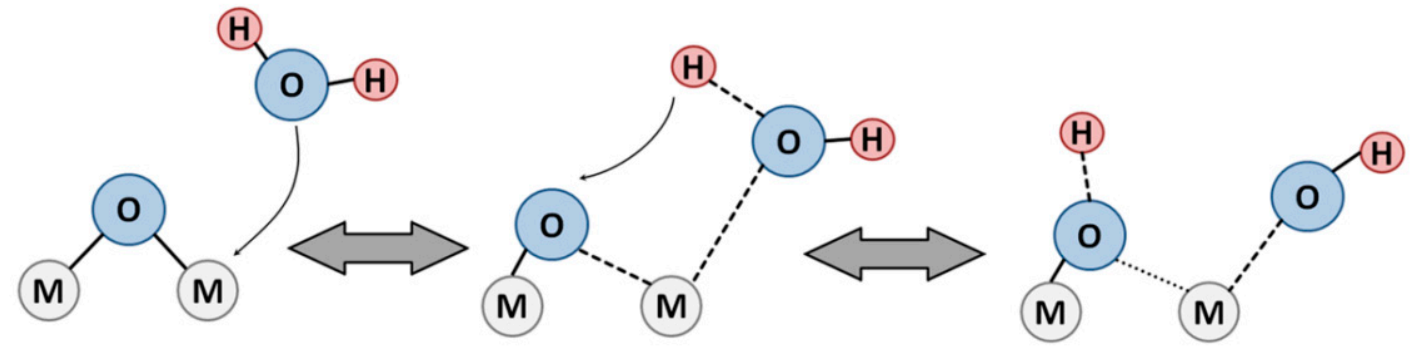

Figure 6. Scheme of water molecule dissociative adsorption at metal oxide surface with the formation of bridging and terminal OH-groups. Reprinted with permission from ref. [84]. Copyright 2018 Springer.

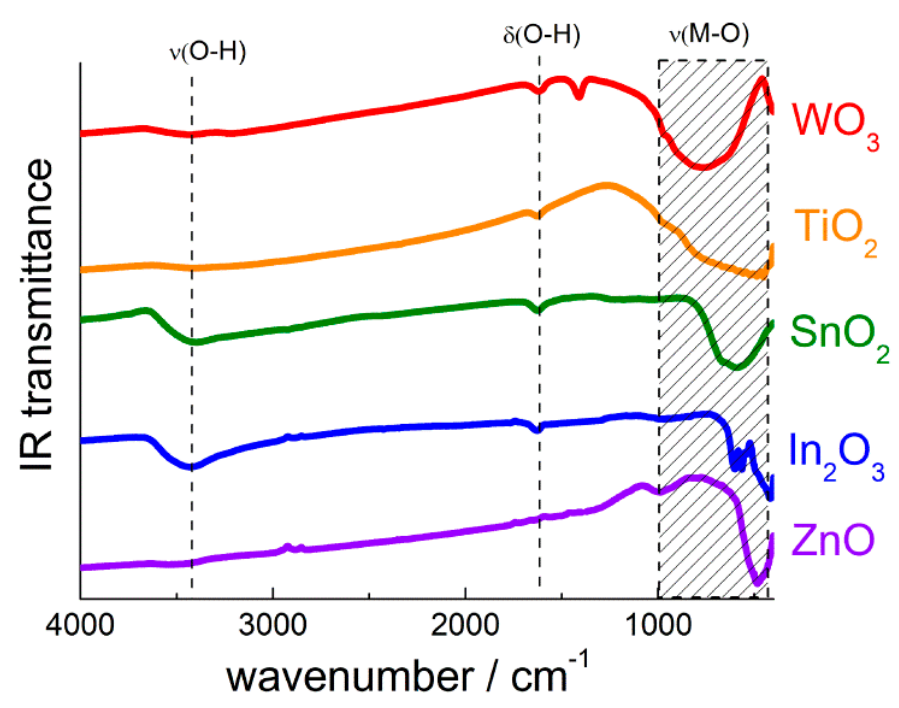

Figure 7. FTIR spectra of nanocrystalline $n$-type MOS. Adapted with permission from ref. [75] copyright 2018 Elsevier; ref. [76] copyright 2019 Marikutsa, Rumyantseva, Gaskov, Batuk, Hadermann, Sarmadian, Saniz, Partoens and Lamoen Creative Commons Attribution License (CC BY); ref. [78] copyright 2021 Elsevier; ref. [79] copyright 2014 American Chemical Society. 
Surface oxygen anions $\mathrm{O}^{2-}$ are the intrinsic base sites at a metal oxide surface, and can act as the Lewis or Brønsted base depending on the adsorbate. The oxide anions can be determined by X-ray photoelectron spectroscopy (XPS). The asymmetric O 1s signal of nanocrystalline metal oxides can be simulated by two components (Figure 8): the major signal with binding energy $530.0-530.5 \mathrm{eV}$ due to bulk $\mathrm{O}^{2-}$ anions and the lower peak of surface oxygen species at higher binding energy $(531.0-533.0 \mathrm{eV})[34,85,86]$.

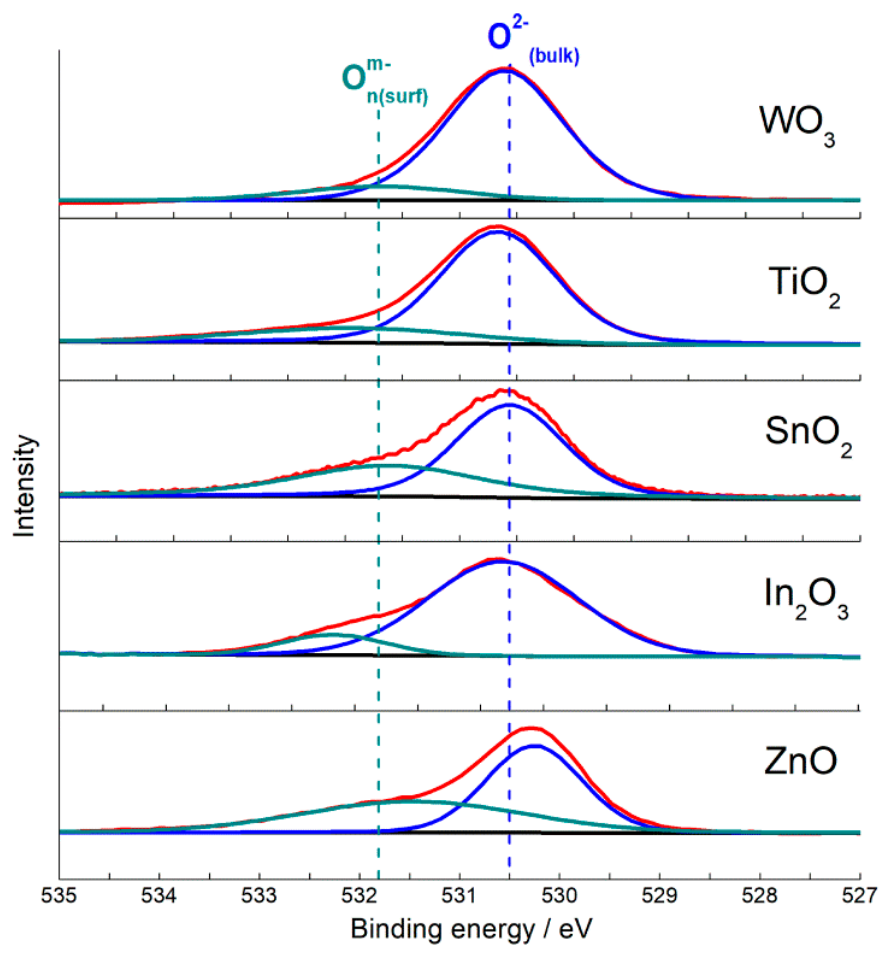

Figure 8. XP-spectra of $\mathrm{O} 1 \mathrm{~s}$ state for nanocrystalline $n$-type MOS. Adapted with permissions from ref. [75] copyright 2018 Elsevier; ref. [78] copyright 2021 Elsevier; [79] copyright 2014 American Chemical Society; ref. [87] copyright 2010 Elsevier.

\subsection{Oxidizing Sites}

The oxidizing surface sites are most often associated with adsorbed oxygen $[2,8,12,85,86,88,89]$. There are several types of adsorbed oxygen species on a metal oxide surface:

- physisorbed $\mathrm{O}_{2}$ molecules held at the surface via van der Waals attraction, the physisoption dominates at temperature below $-70{ }^{\circ} \mathrm{C}$ [90];

- chemisorbed $\mathrm{O}_{2}$ molecules covalently bound with surface cations via a local redistribution of electron density, the chemisorbed oxygen was found to dominate at the surface of tin oxide at temperature below $200{ }^{\circ} \mathrm{C}$ [91];

- $\quad$ ionosorbed species $\mathrm{O}_{2}{ }^{-}, \mathrm{O}^{-}$, and $\mathrm{O}^{2-}$ are formed by molecular and dissociative oxygen adsorption and acceptation of delocalized electrons from the bulk of MOS (Equation (2)) [5].

Besides, hydroxyl species were found to possess oxidizing activity to reducing gases: $\mathrm{CO}, \mathrm{H}_{2}[82,83,92]$. Metal cations in high oxidation states $\left(\mathrm{Sn}^{4+}, \mathrm{Ti}^{4+}, \mathrm{V}^{5+}, \mathrm{Mo}^{6+}, \mathrm{W}^{6+}\right)$ represent the other type of oxidation sites at the surface of respective metal oxides. Of particular interest are the double $\mathrm{M}=\mathrm{O}$ bonds which end up the metal-oxygen framework at the surface of $\mathrm{V}_{2} \mathrm{O}_{5}, \mathrm{MoO}_{3}, \mathrm{WO}_{3}$, and have been considered as the active oxidizing sites on these metal oxides and composites [93]. The reduction of surface metal cations to lower oxidation state proceeds through the cleavage of metal-oxygen bonds leaving oxygen vacancies in the surface structure of metal oxide. It is the so-called Mars-van Krevelen mechanism in heterogeneous oxidation catalysis. 


\subsection{Electron Donor Sites}

Oxygen vacancies $\left(\mathrm{V}_{\mathrm{O}^{2-}}{ }^{2-} \mathrm{V}_{\mathrm{O}}^{-}\right)$and reduced metal cations possess loosely bound electrons and behave like donor sites [4]. Oxygen vacancies which diffuse into the oxide bulk form donor states and account for the $n$-type conductivity of MOS: $\operatorname{In}_{2} \mathrm{O}_{3}, \mathrm{ZnO}$, $\mathrm{SnO}_{2}, \mathrm{TiO}_{2}, \mathrm{WO}_{3}[22,58]$. In these oxides, metals have the highest oxidation states for the respective elements group and, hence, can be reduced to a lower oxidation state by trapping electrons liberated from oxygen desorption and ionization of oxygen vacancies (Equation (1)).

\section{Active Sites Concentrations at the Surface of Nanocrystalline $n$-Type MOS}

In Table 2, we summarized the concentrations of active sites determined in our works on $n$-type simple $\mathrm{MOS}\left(\mathrm{ZnO}, \mathrm{SnO}_{2}, \mathrm{TiO}_{2}, \mathrm{WO}_{3}\right)$ with different phase compositions and microstructure parameters, and mixed-metal oxides $\left(\mathrm{BaSnO}_{3}, \mathrm{Bi}_{2} \mathrm{WO}_{6}\right)$. The simple MOS were synthesized by aqueous deposition of metal hydroxides with subsequent annealing at temperature $300-700{ }^{\circ} \mathrm{C}$. Mixed-metal oxides were obtained by co-precipitation of metal hydroxides and hydrothermal treatment with subsequent annealing at $300-500{ }^{\circ} \mathrm{C}$. The materials consisted of phase-pure nanocrystalline wurtzite-like $\mathrm{ZnO}$, rutile-like $\mathrm{SnO}_{2}$, monoclinic $\gamma-\mathrm{WO}_{3}$, cubic perovskite-like $\mathrm{BaSnO}_{3}$, and Aurivillius phase $\mathrm{Bi}_{2} \mathrm{WO}_{6}$ with the crystallite size in the range $d_{\mathrm{XRD}}=3-50 \mathrm{~nm}$ and specific surface area $4-100 \mathrm{~m}^{2} / \mathrm{g}$ (Table 2) [63,74-78]. Mixed-phase $\mathrm{TiO}_{2}$ with the rutile:anatase ratio of 3:2 was obtained after calcination at $700{ }^{\circ} \mathrm{C}$ [78]. TEM and SEM micrographs of the materials in Figures 9 and 10 demonstrate the random shaped morphology of the nanoparticles of materials. Active sites of different types were determined by electron paramagnetic resonance (EPR) and probe molecules techniques: temperature programmed desorption of ammonia (TPD) and temperature programmed reduction by hydrogen (TPR). The principles and procedures of the active sites determination are described in the Appendix A.

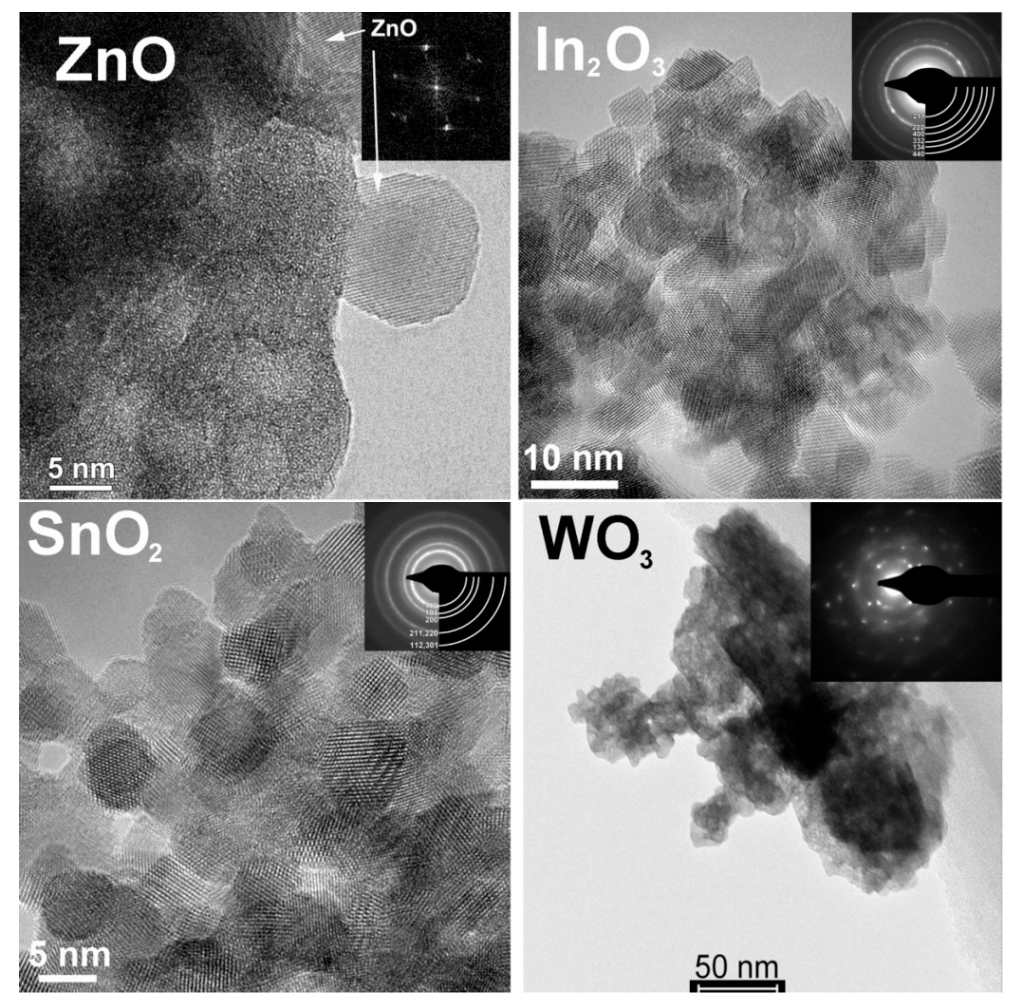

Figure 9. HRTEM images of nanocrystalline $\mathrm{ZnO}, \mathrm{In}_{2} \mathrm{O}_{3}$, and $\mathrm{SnO}_{2}$, and TEM image of $\mathrm{WO}_{3}$; the sample were annealed at $300{ }^{\circ} \mathrm{C}$. The insets show electron diffraction patterns. Adapted with permissions from ref. [42] copyright 2019 by the authors (CC BY); ref. [76] copyright 2019 by the authors (CC BY); ref. [94] copyright 2015 Elsevier; ref. [95] copyright 2013 American Chemical Society. 


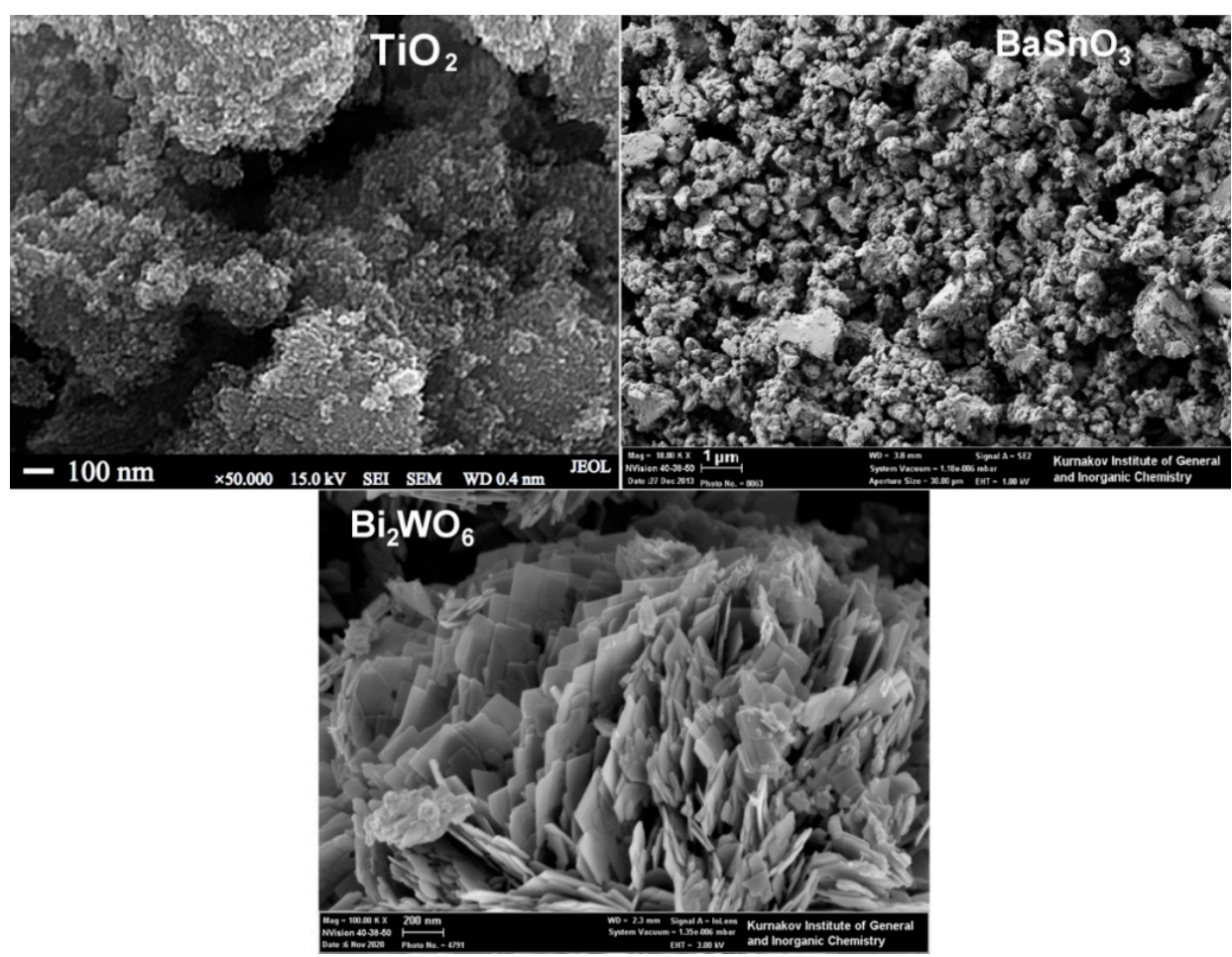

Figure 10. SEM images of nanocrystalline $\mathrm{TiO}_{2}, \mathrm{BaSnO}_{3}$, and $\mathrm{Bi}_{2} \mathrm{WO}_{6}$. Adapted with permissions from ref. [63] copyright 2021 Elsevier; ref. [77] copyright 2015 by the authors (CC BY); ref. [96] copyright 2021 Springer Nature.

Table 2. Concentration of active sites at the surface of $n$-type MOS obtained at different annealing temperature $\left(T_{\text {anneal }}\right)$ and having different mean crystallite size $\left(d_{\mathrm{XRD}}\right)$ and specific surface area (SSA) $[63,76-79,94,96]$.

\begin{tabular}{|c|c|c|c|c|c|c|c|c|}
\hline \multirow{3}{*}{ MOS } & \multirow{3}{*}{$T_{\text {anneal }},{ }^{\circ} \mathrm{C}$} & \multirow{3}{*}{$d_{\mathrm{XRD}}, \mathrm{nm}$} & \multirow{3}{*}{$\mathrm{SSA}, \mathrm{m}^{2} / \mathrm{g}$} & \multicolumn{4}{|c|}{ Active Sites Concentration, $10^{-6} \mathrm{~mole} / \mathrm{m}^{2}$} & \multirow{3}{*}{$\begin{array}{c}\text { Donor Sites } \\
\mathrm{V}_{\mathrm{O}^{-3}}\end{array}$} \\
\hline & & & & \multicolumn{2}{|c|}{ Acid Sites $^{1}$} & \multicolumn{2}{|c|}{ Oxidizing Sites } & \\
\hline & & & & $\begin{array}{c}\text { Weak } \\
\text { (Broensted) }\end{array}$ & $\begin{array}{l}\text { Strong } \\
\text { (Lewis) }\end{array}$ & $\begin{array}{c}\text { Total } \\
n\left(\mathrm{H}_{2, \mathrm{TPR}}\right)^{2}\end{array}$ & $\mathrm{O}_{2}^{-3}$ & \\
\hline $\mathrm{ZnO}$ & 300 & $11-13$ & 45 & $0.4 \pm 0.1$ & $1.8 \pm 0.4$ & $6.6 \pm 0.5$ & $4.4 \times 10^{-5}$ & $8 \times 10^{-6}$ \\
\hline \multirow{2}{*}{$\mathrm{In}_{2} \mathrm{O}_{3}$} & 300 & $7-8$ & 100 & n.d. ${ }^{4}$ & n.d. ${ }^{4}$ & $5.8 \pm 0.4$ & $1.3 \times 10^{-2}$ & - \\
\hline & 500 & $16-19$ & 35 & $0.5 \pm 0.1$ & $1.7 \pm 0.4$ & $4.1 \pm 0.8$ & $1.5 \times 10^{-2}$ & \\
\hline \multirow[t]{3}{*}{$\mathrm{SnO}_{2}$} & 300 & $3-5$ & 95 & $0.6 \pm 0.1$ & $2.4 \pm 0.5$ & $23.6 \pm 0.8$ & $1.4 \times 10^{-5}$ & $3.5 \times 10^{-4}$ \\
\hline & 500 & $10-12$ & 25 & $0.5 \pm 0.2$ & $1.5 \pm 0.4$ & $14.0 \pm 1.2$ & & \\
\hline & 700 & $16-20$ & 10 & $0.5 \pm 0.2$ & $1.2 \pm 0.5$ & $12.6 \pm 2.6$ & & \\
\hline $\mathrm{BaSnO}_{3}$ & 500 & $20-22$ & 8 & $0.4 \pm 0.2$ & $0.7 \pm 0.3$ & $12.2 \pm 2.8$ & $2.5 \times 10^{-4}$ & - \\
\hline \multirow[t]{2}{*}{$\mathrm{TiO}_{2}$} & 700 & $\begin{array}{c}27-30 \text { (rutile), } \\
38-46 \text { (anatase) }\end{array}$ & 5 & $3.3 \pm 0.8$ & $8.2 \pm 1.9$ & $20.8 \pm 3.1$ & $6 \times 10^{-6}$ & $6.8 \times 10^{-4}$ \\
\hline & 300 & 7-9 & 35 & $6.1 \pm 0.2$ & $21.7 \pm 0.9$ & $5.4 \pm 0.6$ & - & $3.1 \times 10^{-3}$ \\
\hline \multirow[t]{2}{*}{$\mathrm{WO}_{3}$} & 450 & $19-22$ & 9 & $5.1 \pm 0.9$ & $15.6 \pm 1.2$ & - & & \\
\hline & 600 & $23-25$ & 4 & $3.1 \pm 0.6$ & $8.9 \pm 2.0$ & - & & \\
\hline $\mathrm{Bi}_{2} \mathrm{WO}_{6}$ & 300 & $14-15$ & 9 & $0.8 \pm 0.3$ & $1.7 \pm 0.6$ & $16.4 \pm 2.0$ & - & - \\
\hline
\end{tabular}

${ }^{1}$ Evaluated by TPD of ammonia. ${ }^{2}$ Evaluated by TPR with hydrogen. ${ }^{3}$ Evaluated by EPR. ${ }^{4}$ No data for TPD from $\operatorname{In}_{2} \mathrm{O}_{3}$ annealed at $300{ }^{\circ} \mathrm{C}$ because of ammonia oxidation caused by residual nitrate species $[78,97]$.

\subsection{Acid Sites}

Acid sites were determined by TPD of ammonia [63,75,78,79,98]. Desorption patterns are shown in Figure 11a. The low-temperature bands at $50-200{ }^{\circ} \mathrm{C}$ were due to desorption of weakly bound probe molecules. Molecular $\mathrm{NH}_{3}$ evolved at this temperature, as was confirmed by mass-spectrometry (Figure 11b). These bands were ascribed to weak (Brønsted) acid sites, i.e., acidic $\mathrm{OH}$-groups. At higher temperature (above $200{ }^{\circ} \mathrm{C}$, Figure 11a) ammonia desorbed from stronger (Lewis) acid sites, i.e., coordinately unsaturated cations at the oxides surfaces. Concentration of Brønsted and Lewis acid sites increased in the 
order $\mathrm{ZnO} \approx \mathrm{In}_{2} \mathrm{O}_{3}<\mathrm{SnO}_{2}<\mathrm{TiO}_{2}<\mathrm{WO}_{3}$ (Figure 12). It agrees with the increment of metal-oxygen bond energy, electronegativity and charge/radius ratio of cations (Table 1). In the same order does the optical basicity of oxides decrease [81]. The coincident trends of surface acidity, $\mathrm{E}_{\mathrm{M}-\mathrm{O}}$ and electronegativity should be due to increasing charge/size ratio for the cations $\mathrm{Zn}^{2+}, \mathrm{In}^{3+}, \mathrm{Sn}^{4+}, \mathrm{Ti}^{4+}, \mathrm{W}^{6+}$. The higher positive charge density at a cation (Lewis acid) favors stronger attraction of lone electron pair donor (Lewis base).

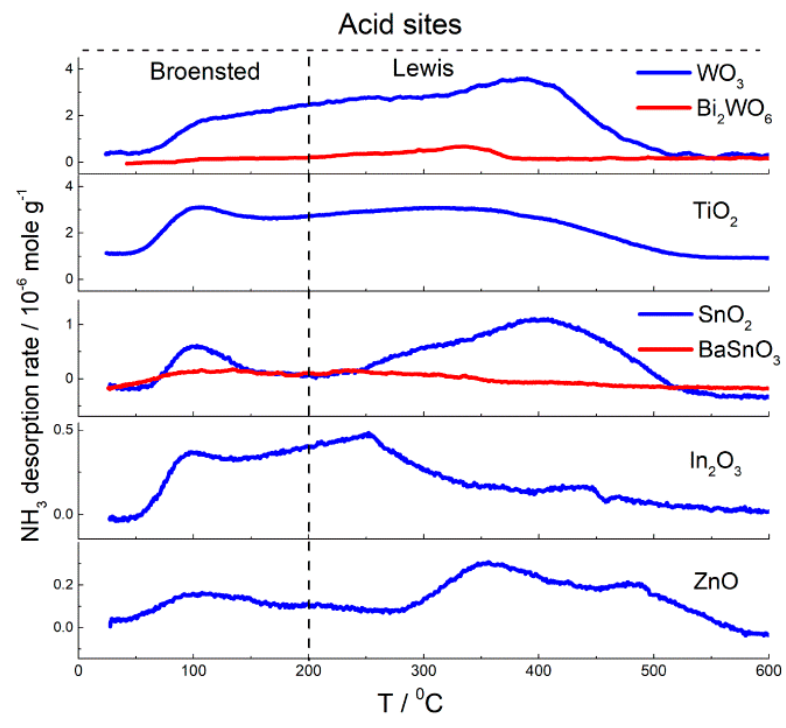

(a)

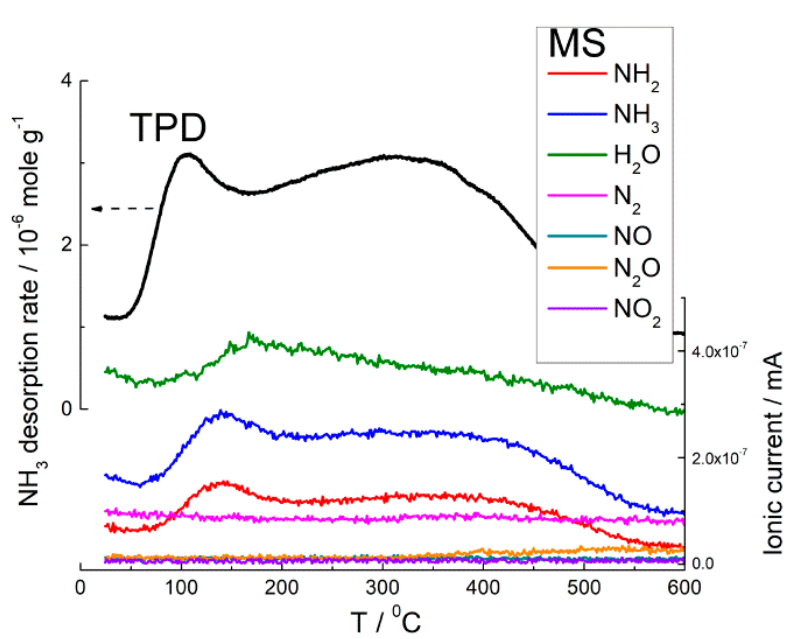

(b)

Figure 11. Temperature plots of ammonia desorption rate from the surface of $n$-type MOS (a). Adapted with permissions from ref. [63] copyright 2021 Elsevier; ref. [75] copyright 2018 Elsevier; ref. [78] copyright 2021 Elsevier; ref. [79] copyright 2014 American Chemical Society. TPD pattern of $\mathrm{TiO}_{2}$ compared with mass-spectral (MS) analysis of desorbed gas (b).

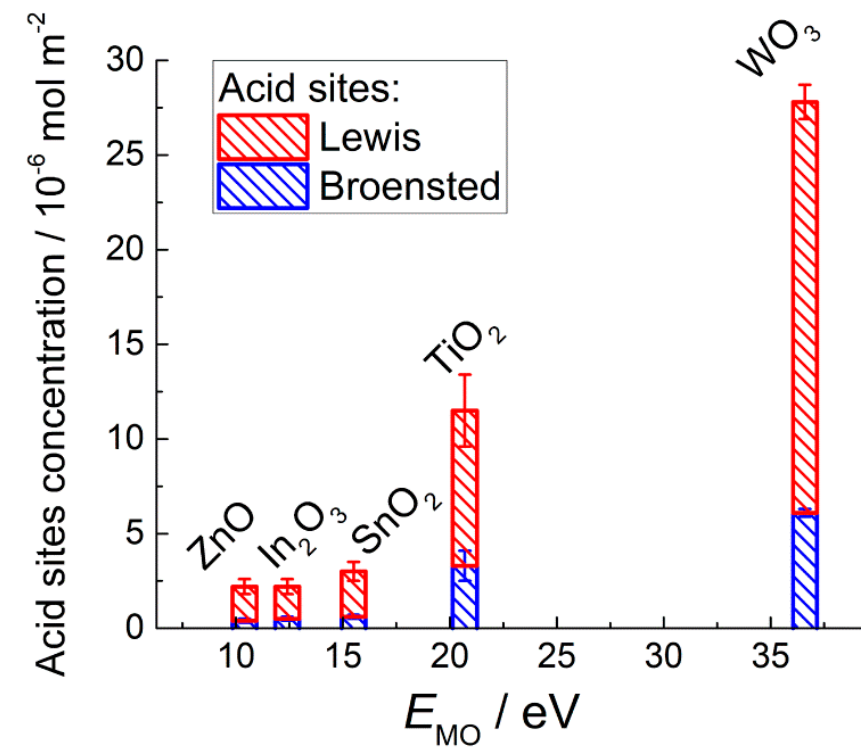

Figure 12. Concentration of Brønsted and Lewis acid sites at the surface of nanocrystalline n-type MOS synthesized at $300{ }^{\circ} \mathrm{C}\left(\mathrm{ZnO}, \mathrm{In}_{2} \mathrm{O}_{3}, \mathrm{SnO}_{2}, \mathrm{WO}_{3}\right)$ and $700{ }^{\circ} \mathrm{C}\left(\mathrm{TiO}_{2}\right)$ in relation to metal-oxygen bond energy. Adapted with permission from reference [78]. Copyright 2021 Elsevier. 


\subsection{Donor Sites (Oxygen Vacancies)}

Donor paramagnetic sites attributed to single charged oxygen vacancies $\mathrm{V}_{\mathrm{O}}{ }^{-}$were recognized on the EPR spectra of $\mathrm{ZnO}, \mathrm{SnO}_{2}, \mathrm{TiO}_{2}, \mathrm{WO}_{3}$, by the signals with $g$-factor below 2.00 (Figure 13). The signal intensity was highly sensitive to temperature because of relaxation of excited $\mathrm{V}_{\mathrm{O}}{ }^{-}$spin states on lattice phonon vibrations [79]. Concentration of $\mathrm{V}_{\mathrm{O}}{ }^{-}$in MOS increases with increasing $E_{\mathrm{M}-\mathrm{O}}$ (Figure 14a). The concentration was calculated per unit surface area (Table 2), although the sensitivity to phonon vibrations suggests that oxygen vacancies are mainly inside the oxide nanoparticles. Nevertheless, the values normalized per 1 mole of MOS followed the same tendency as in Figure 14a. Noteworthy, oxygen vacancies were detected in oxides under ambient conditions. The increasing concentration of $\mathrm{V}_{\mathrm{O}}^{-}$in $\mathrm{SnO}_{2}, \mathrm{TiO}_{2}$ and $\mathrm{WO}_{3}$ agrees with the renowned oxygen deficiency of these compounds, e.g., the existence of Magneli phases $\left(\mathrm{Ti}_{n} \mathrm{O}_{2 n-1}\right)$ and numerous $\mathrm{WO}_{3-\mathrm{x}}$ phases [99]. The stability of oxygen vacancies in MOS with high $E_{\mathrm{M}-\mathrm{O}}$ can be explained by the relatively high electronegativity of the cations which can trap the loosely bound electrons, and, thus, be reduced to $\mathrm{Sn}^{2+}$ (and $\mathrm{Sn}^{3+}[100]$ ), $\mathrm{Ti}^{3+}, \mathrm{W}^{5+}$ (and $\left.\mathrm{W}^{4+}\right)$, respectively. The formation of oxygen vacancy reduces the coordination number of cations, which is favorable for stronger (more covalent) bonding of electronegative cations with oxygen anions. On the other hand, the more stable are oxygen vacancies, the less readily should they donate electrons to chemisorbed acceptor molecules like $\mathrm{O}_{2}$. Therefore, the concentration of chemisorbed oxygen (including ionosorbates $\mathrm{O}_{2}{ }^{-}$) is lower on the surface of these oxides (Figure 14b). Oxidation of gas molecules (e.g., $\mathrm{H}_{2}$ in TPR) on the surface of oxides which are prone to oxygen deficiency is likely limited by the interaction with lattice oxygen anions (Equation (6)), i.e., described by Mars-van Krevelen mechanism in heterogeneous catalysis or oxygen vacancy model of sensor response.
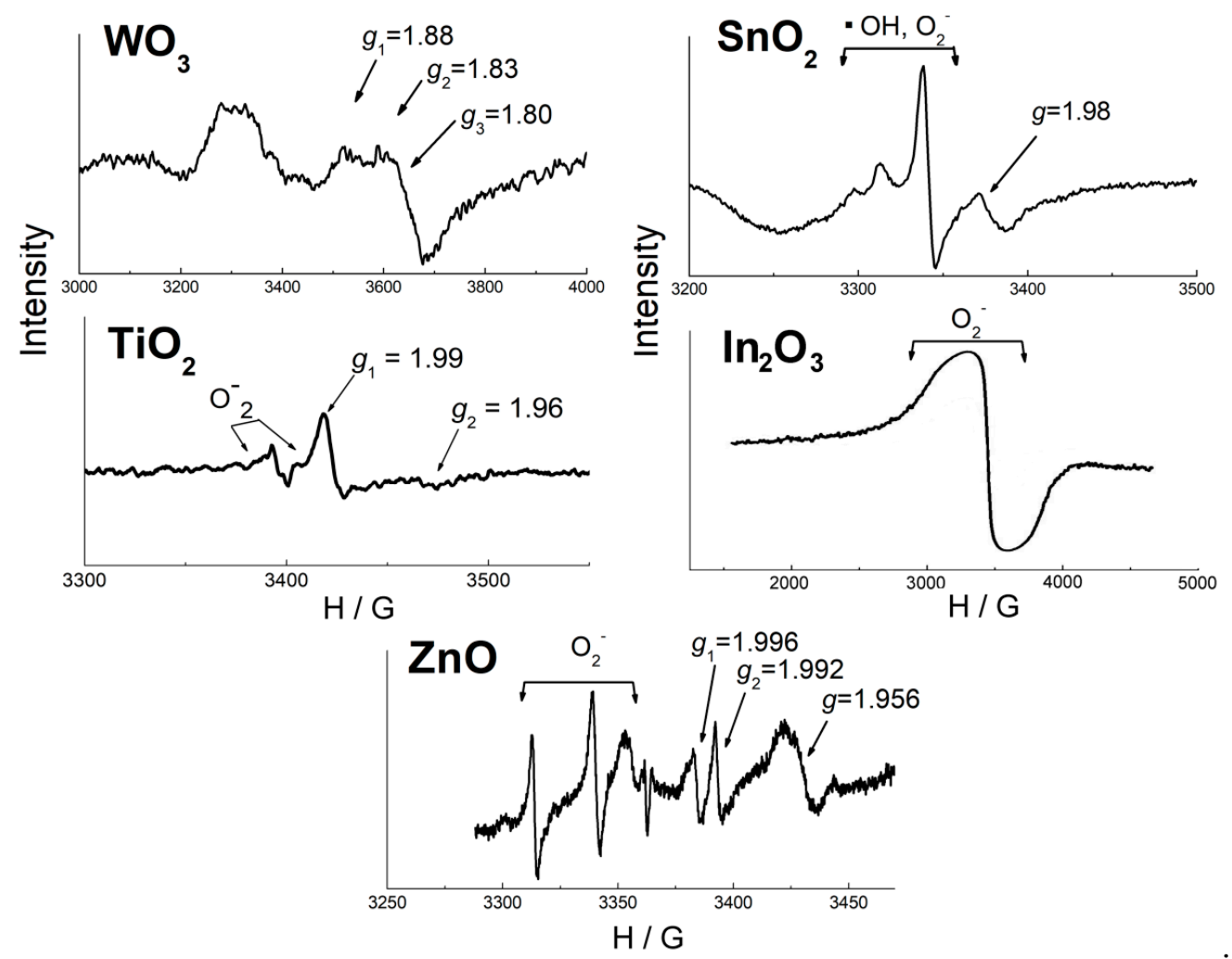

Figure 13. EPR spectra of nanocrystalline $n$-type MOS. Adapted with permissions from ref. [79] copyright 2014 American Chemical Society; ref. [95] copyright 2013 American Chemical Society; ref. [96] copyright 2021 Springer Nature; ref. [101] copyright by the authors; ref. [102] copyright 2013 Elsevier. 


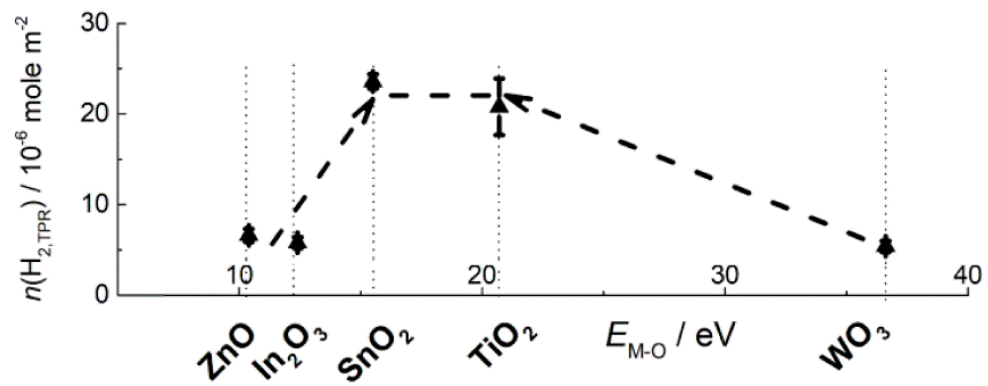

(a)

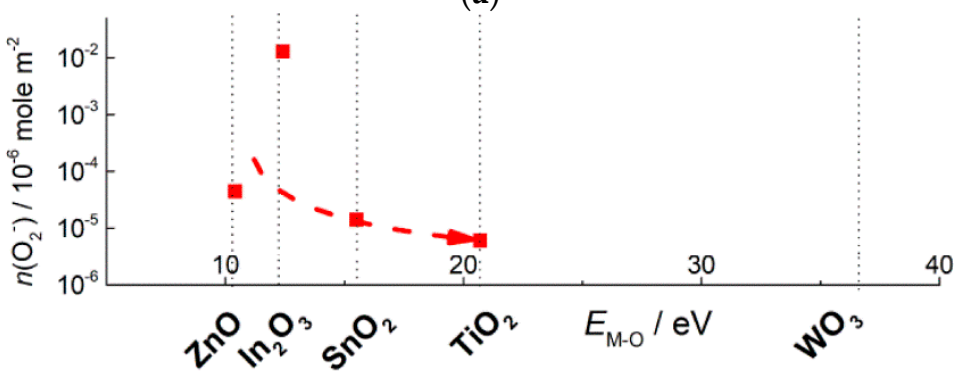

(b)

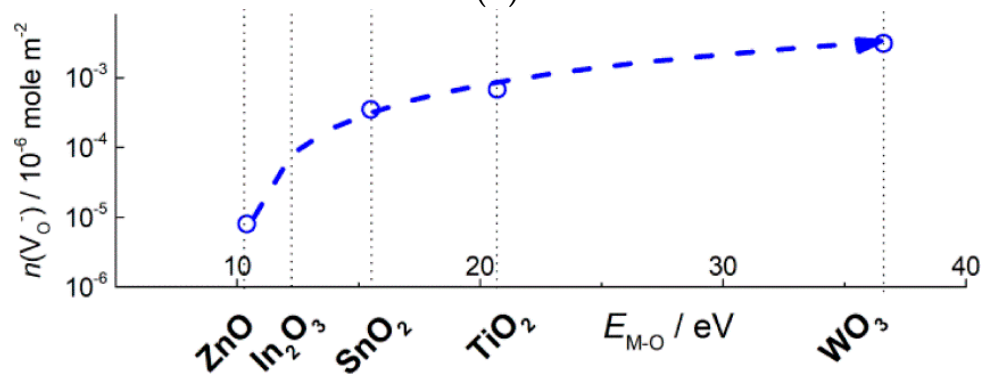

(c)

Figure 14. Concentration of active sites at the surface of nanocrystalline $n$-type MOS in relation to metal-oxygen bond energy: oxidizing sites estimated from $\mathrm{H}_{2}$ consumption in TPR at temperature below $300{ }^{\circ} \mathrm{C}(\mathbf{a})$, ionosorbed oxygen $\mathrm{O}_{2}{ }^{-}$determined by EPR $(\mathbf{b})$, and donor sites $\left(\mathrm{V}_{\mathrm{O}}{ }^{-}\right)$determined by EPR (c). The values are taken from Table 2 .

\subsection{Oxidizing Sites (Chemisorbed Oxygen)}

The paramagnetic ionosorbates $\mathrm{O}_{2}{ }^{-}$with the triplet EPR signal $\left(g_{1}=2.00, g_{2}=2.01\right.$, $\left.g_{3}=2.02-2.03[25,103]\right)$ were observed on EPR spectra of nanocrystalline $\mathrm{In}_{2} \mathrm{O}_{3}$ [94,97], $\mathrm{ZnO}$ [102], $\mathrm{SnO}_{2}$ and $\mathrm{TiO}_{2}[96,101,104]$ (Figure 13). The concentration of $\mathrm{O}_{2}{ }^{-}$at the oxides surfaces $\left(10^{-2}-10^{-5}\right.$ micromole $\left./ \mathrm{m}^{2}\right)$ was by $2-6$ orders of magnitude lower than that of oxidizing sites evaluated by TPR (Table 2). Hence, the active sites responsible for probe molecules oxidation were mainly constituted by other adsorbed and/or oxygen species and $\mathrm{OH}$-groups, rather than $\mathrm{O}_{2}{ }^{-}$. The small concentration of $\mathrm{O}_{2}{ }^{-}$is in line with Weisz limitation, which states that maximum coverage of ionosorbates at the semiconductor surface cannot exceed $10^{-3}-10^{-2}$ monolayer, i.e., $1.7 \times 10^{-2}-1.7 \times 10^{-1}$ micromole $/ \mathrm{m}^{2}$ assuming that $\mathrm{O}_{2}{ }^{-}$has normal orientation and radius close to $\mathrm{r}\left(\mathrm{O}^{-}\right)=1.76 \AA$ [8]. The concentration of $\mathrm{O}_{2}{ }^{-}$determined by EPR decreased as the metal-oxygen bond energy increased (Figure 14b). As an assumption, from the oxides with lower $E_{\mathrm{M}-\mathrm{O}}\left(\mathrm{ZnO}, \mathrm{In}_{2} \mathrm{O}_{3}\right)$ lattice oxygen anions are desorbed into gas phase (Equation (1)). Thus formed oxygen vacancies are unstable due to low electronegativity of the cations $\mathrm{In}^{3+}, \mathrm{Zn}^{2+}$ and readily adsorb oxygen, including the formation of $\mathrm{O}_{2}{ }^{-}$(Equation (2)). Noteworthy, the fraction of $\mathrm{O}_{2}{ }^{-}$in oxidizing sites concentration was larger in $\operatorname{In}_{2} \mathrm{O}_{3}: \mathrm{n}\left(\mathrm{O}_{2}{ }^{-}\right): 2 \mathrm{n}\left(\mathrm{H}_{2(\mathrm{TPR})}\right) \approx 4 \times 10^{-2}$. Thus, the donor sites (oxygen vacancies) at the surface of oxides with low $E_{\mathrm{M}-\mathrm{O}}$ are mostly blocked by chemisorbed oxygen species from air; it limits the surface population by other 
adsorbates (e.g., neutral adsorbed $\mathrm{O}_{2}, \mathrm{OH}$-groups) which could serve as the oxidizing surface sites.

Oxidizing surface sites were evaluated using TPR with hydrogen $[63,75,76,78,79]$. TPR profiles are shown in Figure 15. The oxides $\mathrm{SnO}_{2}, \mathrm{In}_{2} \mathrm{O}_{3}$ and $\mathrm{WO}_{3}$ were reduced to metals at temperature $400-900{ }^{\circ} \mathrm{C}$. Temperature of reduction rates maxima $\left(T_{\mathrm{m}}\right)$ shifted from $T_{\mathrm{m}}=500-660{ }^{\circ} \mathrm{C}$ for $\mathrm{In}_{2} \mathrm{O}_{3}$ and $\mathrm{SnO}_{2}$ to $T_{\mathrm{m}}=700-900{ }^{\circ} \mathrm{C}$ for $\mathrm{WO}_{3}$, which agrees with increasing thermodynamic stability of the oxides, as follows from increasing $E_{\mathrm{M}-\mathrm{O}}$ and decreasing formation enthalpy (Table 1). The maxima of bulk reduction rates $\mathrm{of} \mathrm{SnO}_{2}$ and $\mathrm{WO}_{3}$ also shifted to higher temperature with the increase of particle size. It can be due to higher thermodynamic stability with increasing crystallinity, as well as due slower reduction kinetics of larger MOS nanoparticles. $\mathrm{TiO}_{2}$ cannot be reduced completely by hydrogen, and the reduction of $\mathrm{ZnO}$ was not completed under the TPR conditions to prevent the evolution of $\mathrm{Zn}$ vapor. Low intense hydrogen consumption bands below $300{ }^{\circ} \mathrm{C}$ were attributed to the reduction of oxidizing surface sites like chemisorbed oxygen $\left(\mathrm{O}_{2(\mathrm{ads})}, \mathrm{O}_{2}{ }^{-}, \mathrm{O}^{-}\right)$, surface oxygen anions $\left(\mathrm{O}^{2-}\right)$ and hydroxyl species:

$$
\begin{gathered}
\mathrm{O}_{\mathrm{n}}{ }^{\mathrm{m}-} \text { (surf) }+ \\
2 n \mathrm{H}_{2(\mathrm{~g})}=2 n \mathrm{H}_{2} \mathrm{O}_{(\mathrm{g})}+m e^{-},(n=1,2 ; m=0,1,2) \\
\mathrm{OH}^{-} \text {(surf) }+1 / 2 \mathrm{H}_{2(\mathrm{~g})}=\mathrm{H}_{2} \mathrm{O}_{(\mathrm{g})}+e^{-}
\end{gathered}
$$

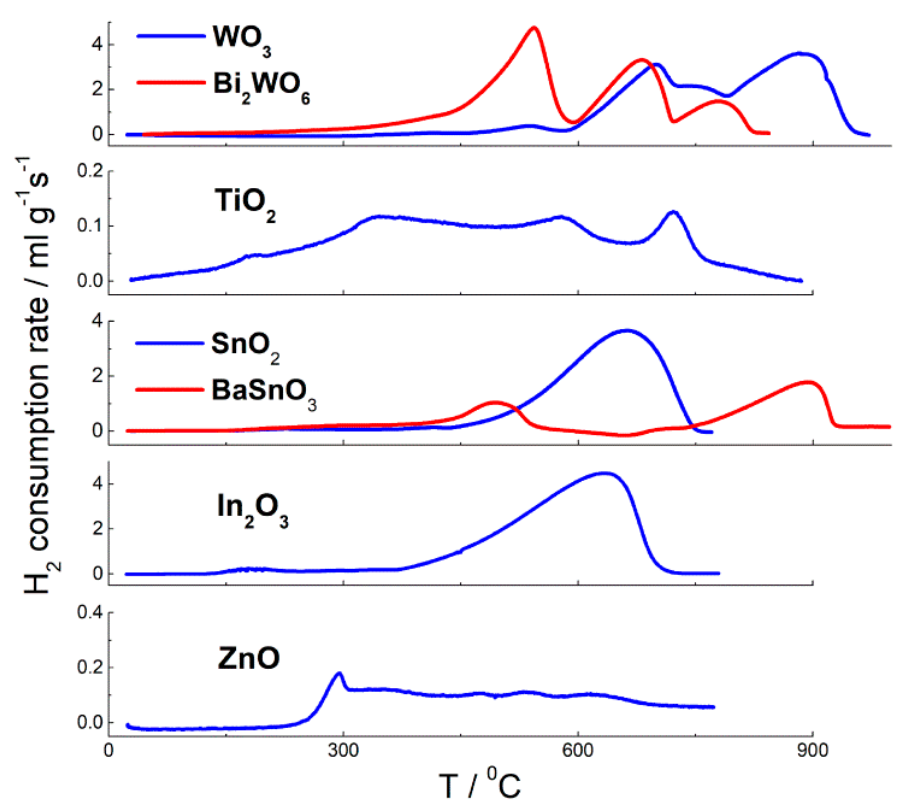

Figure 15. Temperature plots of hydrogen consumption rate during TPR of nanocrystalline $n$-type MOS. Adapted with permissions from ref. [63] copyright 2021 Elsevier; ref. [75] copyright 2018 Elsevier; ref. [76] copyright by the authors (CC BY); ref. [78] copyright 2021 Elsevier; ref. [79] copyright 2014 American Chemical Society.

Concentration of oxidizing surface sites $\mathrm{n}\left(\mathrm{H}_{2, \mathrm{TPR}}\right)$ in Table 2 was calculated equivalent to micromoles of $\mathrm{H}_{2}$ consumed per $1 \mathrm{~m}^{2}$ of surface area. It was shown to be affected by the microstructure parameters. On the examples of $\mathrm{SnO}_{2}$ or $\mathrm{TiO}_{2}$ it can be seen that the increment of particle size and decrease of BET area results in the drop of $n\left(\mathrm{H}_{2, \mathrm{TPR}}\right)$ (Table 2). It can be assumed that smaller nanoparticles possess more defect-site atoms (at the edges, steps, corners, etc.) which hold the adsorbed oxygen and $\mathrm{OH}$-groups more strongly (or, the smaller particles are more easily reducible) than regular atoms on a crystal surface, and the number of adsorbates per unit surface area increases. To estimate the effect of the metal oxide composition on the surface reducibility, the $\mathrm{n}\left(\mathrm{H}_{2(\mathrm{TPR})}\right)$ values were plotted in relation to metal-oxygen bond energies in Figure 14c. Noteworthy, the 
higher concentration of oxidizing sites was found for the oxides with intermediate $E_{\mathrm{M}-\mathrm{O}}$ $\left(\mathrm{SnO}_{2}, \mathrm{TiO}_{2}\right)$, in comparison to $\mathrm{In}_{2} \mathrm{O}_{3}$ (lower $\left.\mathrm{E}_{\mathrm{In}-\mathrm{O}}\right)$ and $\mathrm{WO}_{3}$ (higher $\mathrm{E}_{\mathrm{W}-\mathrm{O}}$ ). The origin of the volcano-shape dependence may be deduced from the trends of descending $\mathrm{O}_{2}{ }^{-}$ (Figure $14 \mathrm{~b}$ ) and growing $\mathrm{V}_{\mathrm{O}}^{-}$concentrations with increasing $E_{\mathrm{M}-\mathrm{O}}$ (Figure 14a). The enhanced surface reducibility of MOS with intermediate metal-oxygen bond energy might result from a proper balance between oxygen vacancy formation (Equation (1)) and oxygen chemisorption (Equations (2) and (3)). On the one hand, the oxides $\mathrm{ZnO}, \mathrm{SnO}_{2}, \mathrm{TiO}_{2}$ possess oxygen vacancies which are persistent in ambient air (in contrast to those in $\operatorname{In}_{2} \mathrm{O}_{3}$ ) and may serve as adsorption sites for oxygen species (including $\mathrm{O}_{2}{ }^{-}$observed by EPR) and $\mathrm{OH}$-groups. On the other hand, oxygen vacancies associated with the cations $\mathrm{Zn}^{2+}$, $\mathrm{Sn}^{4+}, \mathrm{Ti}^{4+}$ should be rather unstable and adsorptive, in comparison to those associated by electronegative $\mathrm{W}^{6+}$ cations in oxygen-deficient $\mathrm{WO}_{3}$.

\section{From Simple to Mixed-Metal Oxides: Metal-Oxygen Bond Energy and Active Sites}

The complication of chemical composition of MOS is a powerful tool for tailoring the functional properties, including gas sensing behavior. The impurities may be introduced into the bulk of metal oxides or deposited onto the surface. Bulk additives can be grouped into dopants which do not alter the phase composition (e.g., Sb-doped $\mathrm{SnO}_{2}$ [105]; Sndoped $\mathrm{In}_{2} \mathrm{O}_{3}$ [106]; $\mathrm{Nb}$-doped $\mathrm{TiO}_{2}$ [107], etc.), and second components which condition the formation of new phases. Being incorporated into crystal lattice, dopants have minor effect on surface reactivity and are used for regulation of electronic properties of MOS. In this section, we focus on the examples of mixed-metal oxides which can be considered as derivatives of simple MOS, but exists in distinct crystalline phases: $\mathrm{BaSnO}_{3}$ in relation to $\mathrm{SnO}_{2}$, and $\mathrm{Bi}_{2} \mathrm{WO}_{6}$ in relation to $\mathrm{WO}_{3}$. The mixed-metal oxides were synthesized under hydrothermal conditions starting from freshly deposited $\mathrm{SnO}_{2} \cdot \mathrm{xH}_{2} \mathrm{O}$ and $\mathrm{H}_{2} \mathrm{WO}_{4}$. The former was mixed with $\mathrm{Ba}(\mathrm{OH})_{2}$ to obtain $\mathrm{BaSnO}_{3}$, and the latter-with $\mathrm{Bi}(\mathrm{OH})_{3}$ to obtain $\mathrm{Bi}_{2} \mathrm{WO}_{6}[63,77]$.

\subsection{Crystal Structure and Metal-Oxygen Bonding}

$\mathrm{BaSnO}_{3}$ has a perovskite-like cubic structure, which differs from the tetragonal rutile structure of $\mathrm{SnO}_{2}$ (Figure 16a). The structure of Aurivillius phase $\mathrm{Bi}_{2} \mathrm{WO}_{6}$ consists of alternating fluorite-like $\left(\mathrm{Bi}_{2} \mathrm{O}_{2}\right)^{2+}$ and the perovskite-like $\left(\mathrm{WO}_{4}\right)^{2-}$ layers. The latter are comprised by corner-shared octahedra $\left\{\mathrm{WO}_{6}\right\}$, which is relative to the structure of $\mathrm{WO}_{3}$ (Figure 16b). Semiconductor properties of the pairs of compounds $\mathrm{BaSnO}_{3}-\mathrm{SnO}_{2}$ and $\mathrm{Bi}_{2} \mathrm{WO}_{6}-\mathrm{WO}_{3}$ are similar: the simple and mixed-metal oxides are $n$-type semiconductors with close bandgap widths of $E_{\mathrm{g}}=3.4-3.6 \mathrm{eV}\left(\mathrm{BaSnO}_{3}, \mathrm{SnO}_{2}\right)[61,108]$ and $E_{\mathrm{g}}=2.7-2.8 \mathrm{eV}$ $\left(\mathrm{Bi}_{2} \mathrm{WO}_{6}, \mathrm{WO}_{3}\right)[109,110]$. Thus, the introduction of cations $\mathrm{Ba}^{2+}$ or $\mathrm{Bi}^{3+}$ and the accordant change of crystalline phases when the mixed-metal oxides are formed from $\mathrm{SnO}_{2}$ and $\mathrm{WO}_{3}$, respectively, do not affect semiconductor properties. The latter are determined by the framework of interconnected octahedra $\left\{\mathrm{SnO}_{6}\right\}$ or $\left\{\mathrm{WO}_{6}\right\}$, which exist in the structures of simple oxides and mixed-metal oxides (Figure 16). Actually, DFT simulations showed that valence band maxima (VBM) in these compounds are mainly contributed by filled nonbonding $\mathrm{O} 2 \mathrm{p}$-states $[63,111,112]$. The conduction band maximum (CBM) in $\mathrm{SnO}_{2}$ is mainly due to antibonding Sn 5 s and O 2p states; and they are slightly contributed by Ba 6 s states in the $\mathrm{CBM}$ of $\mathrm{BaSnO}_{3}$. The antibonding $\mathrm{Sn} 5 \mathrm{~s}-$ and $\mathrm{Ba}$ 6s-orbitals are empty in both cases, which does not deteriorate metal-oxygen bonding in $\mathrm{SnO}_{2}$ and $\mathrm{BaSnO}_{3}$. Nevertheless, a slightly weaker Sn-O bonding in $\mathrm{BaSnO}_{3}$ can be deduced, respective to $\mathrm{SnO}_{2}$. Firstly, $\mathrm{Sn}-\mathrm{O}$ distance is a little longer in $\mathrm{BaSnO}_{3}\left(2.06 \AA\right.$ [113]), respective to $\mathrm{SnO}_{2}(2.02 \AA$ [61]). Secondly, from the TPR patterns (Figure 15) it can be inferred that bulk reduction of $\mathrm{BaSnO}_{3}$ started at a lower temperature (about $390^{\circ} \mathrm{C}$ ), than that of $\mathrm{SnO}_{2}\left(430^{\circ} \mathrm{C}\right)$, judging by the data for materials with comparable particles sizes. Tin oxide was completely reduced in one step with the maximum rate of $\mathrm{H}_{2}$ consumption at $T_{\mathrm{m}}=600-660^{\circ} \mathrm{C}$ :

$$
\mathrm{SnO}_{2(\mathrm{~s})}+2 \mathrm{H}_{2(\mathrm{~g})}=\mathrm{Sn}_{(\mathrm{l})}+2 \mathrm{H}_{2} \mathrm{O}_{(\mathrm{g})}
$$




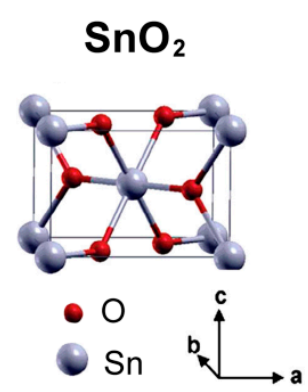

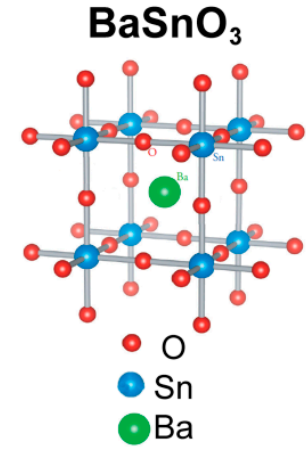

(a)

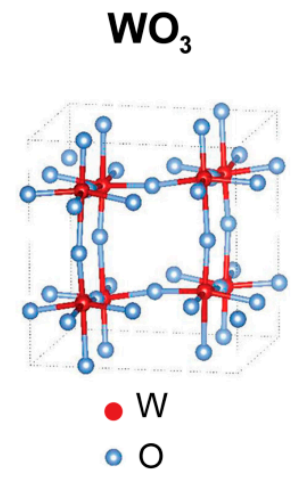

(b)

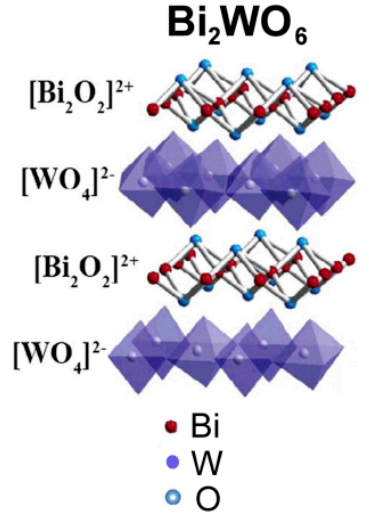

Figure 16. Unit cells of rutile-like tetragonal $\mathrm{SnO}_{2}$, perovskite-like cubic $\mathrm{BaSnO}_{3}$ (a), monoclinic $\mathrm{WO}_{3}$ and $\mathrm{Aurivillius}$ structure of $\mathrm{Bi}_{2} \mathrm{WO}_{6}(\mathbf{b})$. Adapted with permissions from references [61,63,113]. Copyrights 2013 American Physical Society, 2021 Elsevier, 2014 Elsevier.

Although $\mathrm{BaSnO}_{3}$ was incompletely reduced during TPR, the 1st hydrogen consumption peak centered at $T_{\mathrm{m}}=500{ }^{\circ} \mathrm{C}$ was due to partial reduction of the oxide and, thus, corresponded to the cleavage of $\mathrm{Sn}-\mathrm{O}$ bonds in the crystal lattice:

$$
\mathrm{BaSnO}_{3}(\mathrm{~s})+\frac{1}{2} \mathrm{H}_{2(\mathrm{~g})}=\frac{1}{2} \mathrm{Ba}_{2} \mathrm{SnO}_{4(\mathrm{~s})}+\frac{1}{2} \mathrm{SnO}_{(\mathrm{s})}+\frac{1}{2} \mathrm{H}_{2} \mathrm{O}_{(\mathrm{s})}
$$

The 2nd peak on the TPR pattern of $\mathrm{BaSnO}_{3}$ with the maximum at $890{ }^{\circ} \mathrm{C}$ was due to reduction of residual $\mathrm{SnO}$.

In $\mathrm{WO}_{3}$ and $\mathrm{Bi}_{2} \mathrm{WO}_{6}$, the CBM is equally impacted by $\mathrm{W} 5 \mathrm{~d}$ - and $\mathrm{O} 2 \mathrm{p}$-states [63]. The empty Bi 6p-states do not contribute to CBM, but the filled Bi 6 s states do affect the VMB. The Bi 6s-O 2p interaction is antibonding, which decreases the energetic stability of $\mathrm{Bi}_{2} \mathrm{WO}_{6}$ and diminishes $\mathrm{W}-\mathrm{O}$ bond energy in the structure, respective to $\mathrm{WO}_{3}$. It follows from the comparison of integral partial crystal orbital Hamilton population (-IpCOHP) as a measure of bond energy, bond lengths and partial charges (Bader charge analysis) of atoms. $\mathrm{Bi}_{2} \mathrm{WO}_{6}$ possesses lower $\mathrm{W}-\mathrm{O}$ bond energy (lower-IpCOHP), longer average $\mathrm{W}$-O distance and increased ionicity of $\mathrm{W}-\mathrm{O}$ bonds (higher partial atomic charges), in comparison to $\mathrm{WO}_{3}$ [63]. In agreement with the first-principles calculations, TPR data support the lower $\mathrm{W}-\mathrm{O}$ bond stability in $\mathrm{Bi}_{2} \mathrm{WO}_{6}$ than in $\mathrm{WO}_{3}$ (Figure 15). Reduction of $\mathrm{WO}_{3}$ proceeded sequentially $[63,75]$ :

$$
\begin{aligned}
& \mathrm{WO}_{3(\mathrm{~s})}+\mathrm{H}_{2(\mathrm{~g})}=\mathrm{WO}_{2(\mathrm{~s})}+\mathrm{H}_{2} \mathrm{O}_{(\mathrm{g})}, T_{\mathrm{m}}=700{ }^{\circ} \mathrm{C} \\
& \mathrm{WO}_{2(\mathrm{~s})}+2 \mathrm{H}_{2(\mathrm{~g})}=\mathrm{W}_{(\mathrm{s})}+2 \mathrm{H}_{2} \mathrm{O}_{(\mathrm{g})}, T_{\mathrm{m}}=880{ }^{\circ} \mathrm{C}
\end{aligned}
$$

In $\mathrm{Bi}_{2} \mathrm{WO}_{6}$, bismuth was first reduced to metallic $\mathrm{Bi}$ at temperature $T_{\mathrm{m}}=550{ }^{\circ} \mathrm{C}$ :

$$
\mathrm{Bi}_{2} \mathrm{WO}_{6(\mathrm{~s})}+3 \mathrm{H}_{2(\mathrm{~g})}=2 \mathrm{Bi}_{(\mathrm{l})}+\mathrm{WO}_{3(\mathrm{~s})}+3 \mathrm{H}_{2} \mathrm{O}_{(\mathrm{g})}
$$

The peaks of two-step reduction of residual $\mathrm{WO}_{3}$ were observed at $T_{\mathrm{m}}=680{ }^{\circ} \mathrm{C}$ and $T_{\mathrm{m}}=780^{\circ} \mathrm{C}$, i.e., at lower temperature than the respective ones for pristine $\mathrm{WO}_{3}$ (Figure 15). It indicates on the lower $\mathrm{W}-\mathrm{O}$ bonds stability in the structure of $\mathrm{Bi}_{2} \mathrm{WO}_{6}$, in comparison to $\mathrm{WO}_{3}$ [63].

\subsection{Concentration of Active Sites}

The concentration of oxidizing surface sites estimated by hydrogen consumption in the lower temperature intervals (below $300^{\circ} \mathrm{C}$ ) on TPR patterns (Table 2) was close 
for $\mathrm{SnO}_{2}$ and $\mathrm{BaSnO}_{3}$, if samples with similar particle sizes were compared. The higher surface reducibility was observed for $\mathrm{Bi}_{2} \mathrm{WO}_{6}$, respective to $\mathrm{WO}_{3}$, which agrees with lower metal-oxygen bonds energy in the former.

Surface acidity of MOS is strongly influenced by the constituent cations. The concentration of Brønsted and Lewis acid sites evaluated by TPD was lower at the surfaces of $\mathrm{BaSnO}_{3}$ and $\mathrm{Bi}_{2} \mathrm{WO}_{6}$, in comparison to $\mathrm{SnO}_{2}$ and $\mathrm{WO}_{3}$, respectively (Table 2). It was shown that microstructure had minor impact on the difference of surface acidity between $\mathrm{Bi}_{2} \mathrm{WO}_{6}$ and $\mathrm{WO}_{3}$; it was mainly due to distinct chemical composition [63]. The lower acidity of mixed-metal oxides was attributed to the presence of $\mathrm{Ba}^{2+}$ or $\mathrm{Bi}^{3+}$ cations at the surfaces of $\mathrm{BaSnO}_{3}$ and $\mathrm{Bi}_{2} \mathrm{WO}_{6}$, provided that these cations have lower charge/radius ratio and, hence, lower electronegativity and weaker Lewis acidity than $\mathrm{Sn}^{4+}$ in pristine $\mathrm{SnO}_{2}$ or, moreover, $\mathrm{W}^{6+}$ in pristine $\mathrm{WO}_{3}$.

\section{Impact of Active Sites on Gas Sensitivity of Nanocrystalline n-Type MOS}

In this section, the correlations in active sites concentrations and the sensitivities of nanocrystalline $n$-type MOS to four analyte gases $\left(\mathrm{NH}_{3}, \mathrm{CO}, \mathrm{VOCs}, \mathrm{NO}_{2}\right)$ are discussed based on our previously published research works. These correlations were deduced from the plots of sensitivity vs. metal-oxygen bond energy (Figures 17-20) compared with the relations of active sites concentrations and $E_{\mathrm{M}-\mathrm{O}}$ (Figures 12 and 14). The specific cases of improved selectivity of mixed-metal oxides to $\mathrm{SO}_{2}$ and $\mathrm{H}_{2} \mathrm{~S}$ are outlined.

The sensitivity $(S)$ was defined as the relative change of resistance in presence of reducing (Red) or oxidizing (Ox) gases:

$$
\begin{gathered}
S_{\text {Red }}=\left(R_{\text {air }}-R_{\text {Red }}\right) / R_{\text {Red }}, \\
S_{\mathrm{Ox}}=\left(R_{\mathrm{Ox}}-R_{\text {air }}\right) / R_{\text {air }}
\end{gathered}
$$

where $R_{\text {air }}$ is sensor resistance in air, $R_{\text {Red }}$-resistance in presence of reducing gases $\left(\mathrm{NH}_{3}\right.$, $\mathrm{CO}, \mathrm{VOCs}, \mathrm{SO}_{2}, \mathrm{H}_{2} \mathrm{~S}$, etc.), $R_{\mathrm{Ox}}$-resistance in presence of oxidizing gas $\left(\mathrm{NO}_{2}\right)$. It known that the sensitivity in general increases with the increment of specific surface area and the decrease of particle size $[22,23,114]$, and we also observed it on the particular examples of nanocrystalline MOS and analyte gases [42,75]. In the syntheses of nanocrystalline MOS, the microstructural parameters could not be finely matched between different materials due to distinct energetics and kinetics of oxides crystallization. Therefore, in order to uniformly compare the sensitivities we defined an effective sensitivity $\left(S_{\text {eff }}\right)$ as the sensitivity normalized per $50 \mathrm{~m}^{2} / \mathrm{g}$ of the specific surface area of each sensor material [78]:

$$
S_{\text {eff }}=S \cdot 50 / \text { SSA }
$$

where SSA is the main value of the specific surface area of materials (Table 2). The value of $50 \mathrm{~m}^{2} / \mathrm{g}$ was chosen as an average expected SSA of nanocrystalline MOS obtained by the aqueous deposition or hydrothermal routes.

The effective sensitivities of MOS to the fixed concentration of analyte gases were compared in dry air conditions and measured at optimal operation temperature, i.e., at temperature of maximum sensitivity of the sensors to the given analyte gas. The large scattering of the $S_{\text {eff }}$ data in Figures 17-20 arouse from the sets of data compared, e.g., samples with same composition and different microstructure parameters, as well as errors in BET area evaluation.

\subsection{Sensitivity to Ammonia and Surface Acidity}

The sensitivity of different MOS to ammonia tends to increase for the MOS with increasing metal-oxygen bond energy (Figure 17a). Ammonia is a reducing gas, which is oxidized on the surface of pristine MOS mainly to $\mathrm{N}_{2}$ [31,115-117]:

$$
\mathrm{NH}_{3(\text { ads })}+3 / 2 n \mathrm{O}_{\mathrm{n}}{ }^{\mathrm{m}-} \text { (surf) }=\frac{1}{2} \mathrm{~N}_{2(\mathrm{~g})}+3 / 2 \mathrm{H}_{2} \mathrm{O}_{(\mathrm{g})}+3 m / 2 n e^{-}
$$


although $\mathrm{NO}_{x}$ species were observed by mass-spectral analysis of desorbed gas in TPD of $\mathrm{NH}_{3}$ from $\mathrm{NO}_{3}$-contaminated $\mathrm{In}_{2} \mathrm{O}_{3}$ [78] or doped $\mathrm{SnO}_{2}$ [116].

DRIFT studies showed that basic $\mathrm{NH}_{3}$ molecules were chemisorbed on the acid sites and the binding with Lewis acid sites (surface cations) was strong enough, so that molecular adsorbates were predominant at the surfaces of MOS exposed to ammonia gas at elevated temperature $[75,116,118]$. Thus, the oxidation reaction (Equation (16)) which determines the sensor response is preceded by $\mathrm{NH}_{3}$ chemisorption on surface acid sites. The concentration of acid sites increases with the increment of metal-oxygen bond energy (Figure 12), which agrees with the increasing sensitivity to $\mathrm{NH}_{3}$ (Figure 17b). Thus, the sensitivity of MOS to $\mathrm{NH}_{3}$ is contributed by surface acidity that controls the chemisorption of analyte gas molecules.

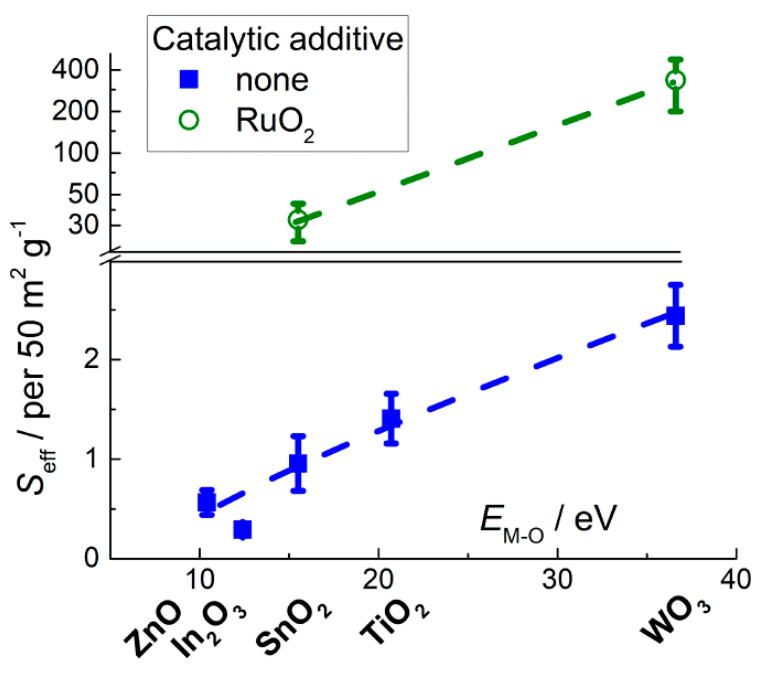

(a)

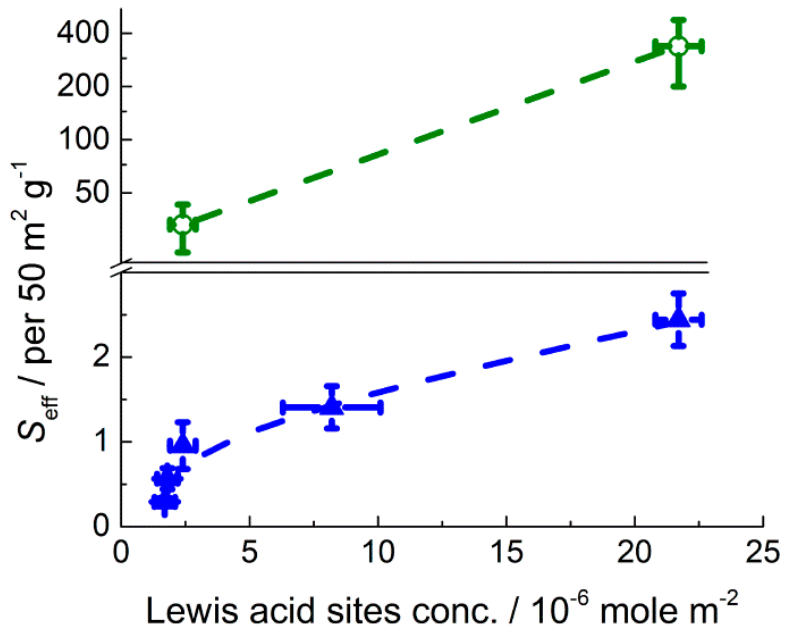

(b)

Figure 17. Sensitivity of pristine and $\mathrm{RuO}_{2}$-functionalized nanocrystalline $n$-type MOS to 20 ppm $\mathrm{NH}_{3}$ at temperature 150-250 ${ }^{\circ} \mathrm{C}$ in relation to metal-oxygen bond energy in MOS (a) and acid sites concentration at the MOS surfaces (b). Adapted with permissions from ref. [75] copyright 2018 Elsevier; ref. [98] copyright 2018 Elsevier; copyright [116] 2019 John Wiley and sons; ref. [117] copyright 2012 Elsevier.

\subsection{Sensitivity to CO and VOCs Impacted by Oxidizing Sites and Acid Sites}

The relation of CO sensitivity to metal-oxygen bond energy in MOS (Figure 18a) resembles that of oxidizing sites concentrations estimated by TPR (Figure 14c). Sensor response to $\mathrm{CO}$ is due its oxidation by surface oxygen and hydroxyl species at the surface of $\operatorname{MOS}[75,82,87]$ :

$$
\begin{aligned}
& \mathrm{CO}_{(\mathrm{g})}+1 / n \mathrm{O}_{\mathrm{n}}{ }^{\mathrm{m}-}{ }_{\text {(surf) }}=\mathrm{CO}_{2(\mathrm{~g})}+m / n e^{-} \\
& \mathrm{CO}_{(\mathrm{g})}+\mathrm{OH}_{(\text {surf })}=\mathrm{CO}_{2(\mathrm{~g})}+\mathrm{H}^{+}{ }_{\text {(surf })}+e^{-}
\end{aligned}
$$

Besides $\mathrm{CO}_{2}$, carbonate species were detected by infrared spectroscopy on the surface of $\mathrm{ZnO}, \mathrm{In}_{2} \mathrm{O}_{3}$ and $\mathrm{SnO}_{2}$ exposed to $\mathrm{CO}$ under certain conditions $[5,76,119]$. Carbon monoxide has no acid-base properties; hence, its adsorption is not influenced by surface acidity of metal oxides. Thus, it is reasonable that the sensitivity to $\mathrm{CO}$ is dependent on the surface reducibility of MOS which reflects the concentration of active species for $\mathrm{CO}$ oxidation (Equations (17) and (18)). In agreement with this is the increasing sensitivity with the concentration of oxidizing sites at the MOS surface (Figure 18b). 


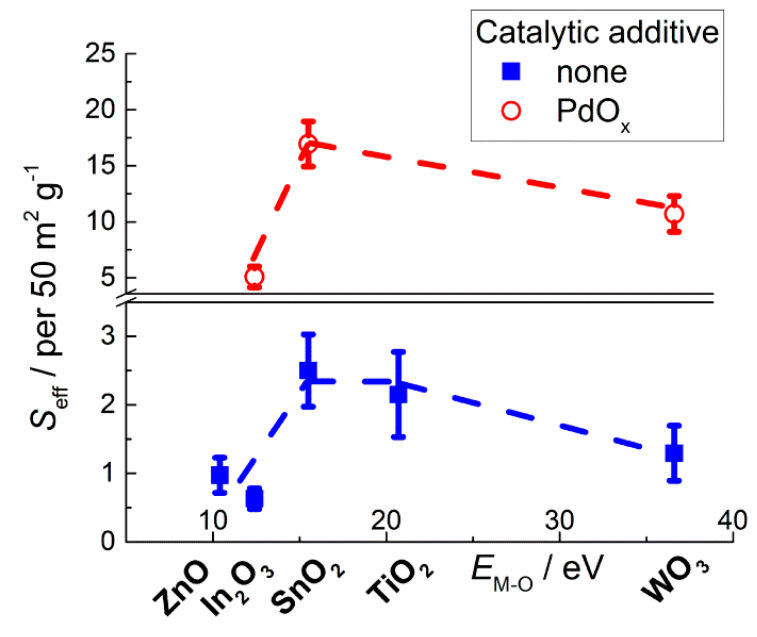

(a)

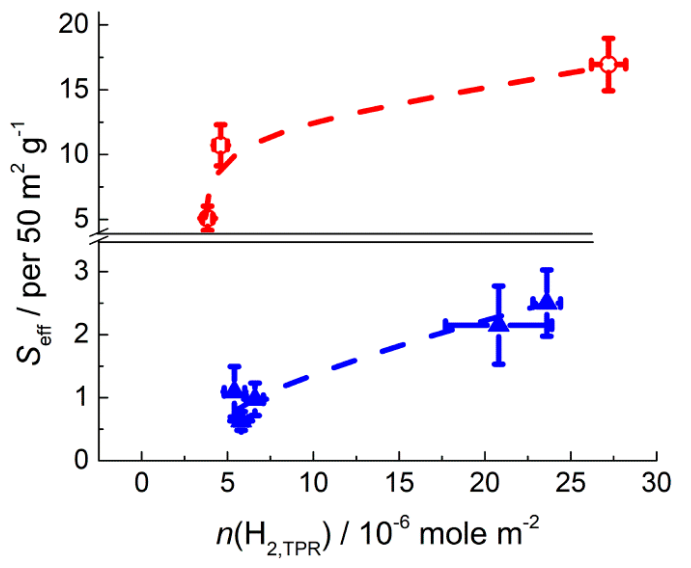

(b)

Figure 18. Sensitivity of pristine and $\mathrm{PdO}_{\mathrm{x}}$-functionalized nanocrystalline $n$-type MOS to 20 ppm $\mathrm{CO}$ at temperature 250-300 ${ }^{\circ} \mathrm{C}$ in relation to metal-oxygen bond energy in MOS (a) and acid sites concentration at the MOS surfaces (b). Adapted with permissions from ref. [75] copyright 2018 Elsevier; ref. [76] copyright 2019 by the authors (BB BY); ref. [87] copyright 2010 Elsevier; ref. [97] copyright 2018 by the authors (CC BY); ref. [120] copyright 2015 by the authors (CC BY).

The sensitivity to VOCs (methanol, acetone) increased with metal-oxygen bond energy and reached a plateau for $\mathrm{SnO}_{2}, \mathrm{TiO}_{2}$ and $\mathrm{WO}_{3}$ (Figure 19) [78]. On the one hand, it agrees with increasing concentration of oxidizing surface sites (Figure 14c). However, in contrast to the case of $\mathrm{CO}$, the sensitivity of $\mathrm{WO}_{3}$ to VOCs did not drop, in spite of lower concentration of oxidizing sites. DRIFT study of MOS interaction with methanol and acetone vapors indicated that VOCs molecules adsorbed on surface cations and the adsorption enhanced with increasing surface acidity of MOS. It is likely due to Lewis basicity of oxygen atoms in $\mathrm{CH}_{3} \mathrm{OH}$ and $\mathrm{CH}_{3} \mathrm{COCH}_{3}$. At raised temperature that corresponds to sensors operation temperature, the adsorbed VOCs molecules were oxidized with the formation of carboxylate species [78,121]:

$$
\begin{array}{r}
\mathrm{CH}_{3} \mathrm{OH}_{(\text {ads })}+5 / 2 \mathrm{O}_{\mathrm{n}}{ }^{\mathrm{m}-}{ }_{\text {(surf) }}=\mathrm{HCOO}^{-}{ }_{\text {(surf) }}+3 / 2 \mathrm{H}_{2} \mathrm{O}_{(\mathrm{g})}+5 m / 2 n e^{-} \\
\mathrm{CH}_{3} \mathrm{COCH}_{3 \text { (ads) }}+9 / 2 \mathrm{O}_{\mathrm{n}}{ }^{\mathrm{m}-}{ }_{\text {(surf) }}=\mathrm{CH}_{3} \mathrm{COO}^{-}{ }_{\text {(surf) }}+\mathrm{CO}_{2(\mathrm{~g})}+3 / 2 \mathrm{H}_{2} \mathrm{O}+9 m / 2 n e^{-}
\end{array}
$$

Thus, the sensitivity of MOS to oxygen-containing VOCs should be contributed by both processes: adsorption on Lewis acid sites and the adsorbates oxidation by oxidizing surface species (Equations (19) and (20)). The optimal sensitivity to VOCs could be expected for the oxides that have relatively high surface acidity balanced by surface reducibility, as it was observed for $\mathrm{SnO}_{2}$ and $\mathrm{TiO}_{2}$ (Figure 19). Then, the persistence of sensitivity in case of $\mathrm{WO}_{3}$ may be explained by its stronger surface acidity (Figure 12). The lower concentration of oxidizing sites at the surface of $\mathrm{WO}_{3}$ is compensated by the abundance of acid sites, which enforces the adsorption of VOCs and thus enhances the sensitivity. To illustrate this conclusion, the sensitivity to VOCs was plotted against the sum of Lewis acid sites and oxidizing sites $\mathrm{n}\left(\mathrm{H}_{2, \mathrm{TPR}}\right)$ concentrations in Figure $19 \mathrm{c}, \mathrm{d}$. 


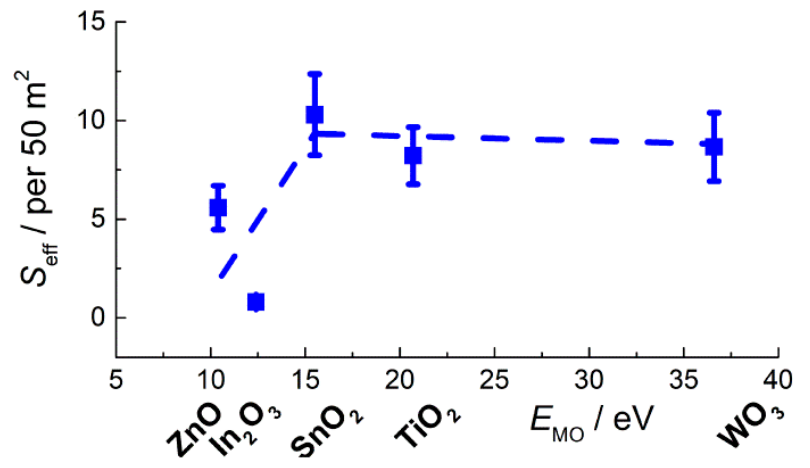

(a)

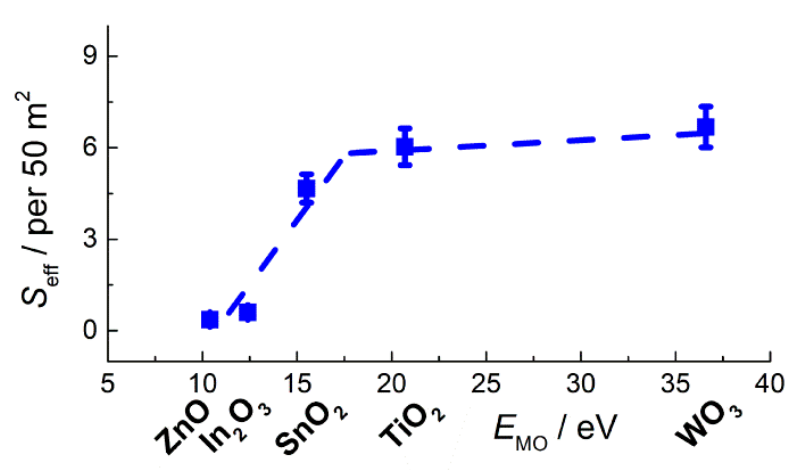

(b)

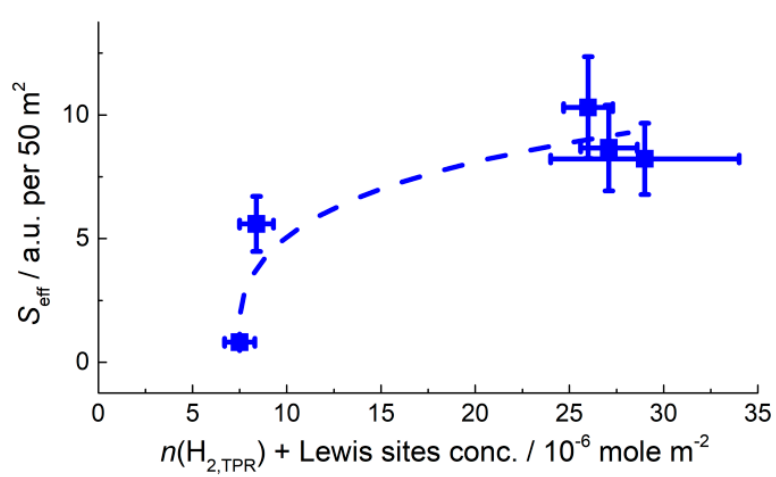

(c)

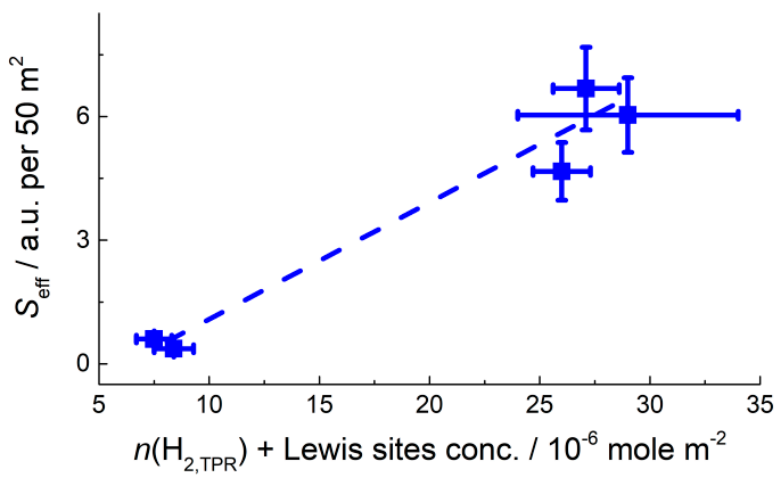

(d)

Figure 19. Sensitivity of pristine and Au-functionalized nanocrystalline $n$-type MOS to 20 ppm acetone (a,c) and 20 ppm methanol $(\mathbf{b}, \mathbf{d})$ at temperature $300{ }^{\circ} \mathrm{C}$ in relation to metal-oxygen bond energy in $\operatorname{MOS}(\mathbf{a}, \mathbf{b})$ and sum of Lewis acid sites and oxidizing sites concentration at the MOS surfaces (c,d). Adapted with permission from ref. [78]. Copyright 2021 Elsevier.

\subsection{Sensitivity to $\mathrm{NO}_{2}$ Determined by Donor Sites}

The sensitivity to $\mathrm{NO}_{2}$ was found to enhance with increasing metal-oxygen bond energy of MOS (Figure 20), i.e., following the same trend as the sensitivity to $\mathrm{NH}_{3}$ (Figure 17). It is not an issue of selectivity, since the sensor resistance changes in opposite directions when exposed to oxidizing gas $\mathrm{NO}_{2}$ or reducing gas $\mathrm{NH}_{3}$. It has been established that sensing mechanism of $\mathrm{NO}_{2}$ relies on analyte molecules ionosorption with the formation of $\mathrm{NO}_{2}^{-}$:

$$
\mathrm{NO}_{2(\mathrm{~g})}+e^{-}=\mathrm{NO}_{2}{ }^{-} \text {(ads) }
$$

which undergoes disproportionation and/or conversion resulting in $\mathrm{NO}_{3}{ }^{-}, \mathrm{NO}^{+}$, etc. $[41,42,122]$. Loosely bound electrons in $n$-type MOS are associated with oxygen vacancies (Equation (1)), the concentration of which (as suggested for $\mathrm{V}_{\mathrm{O}^{-}}$by EPR) increases in MOS with increasing $E_{\mathrm{M}-\mathrm{O}}$ (Figure 14a). Thus, the trend of increasing sensitivity to $\mathrm{NO}_{2}$ is due to higher concentration of electron donor sites in metal oxides with increasing $E_{\mathrm{M}-\mathrm{O}}$. 


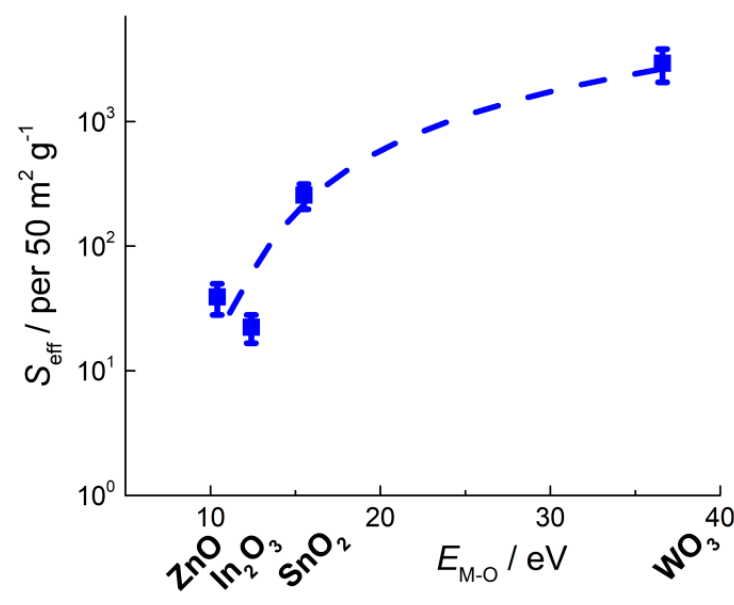

(a)

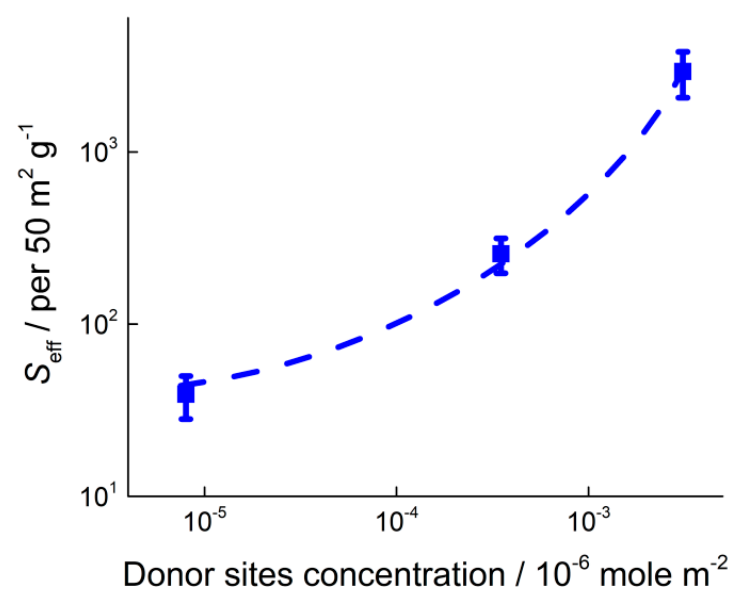

(b)

Figure 20. Sensitivity of nanocrystalline $n$-type $\mathrm{MOS}$ to $1 \mathrm{ppm} \mathrm{NO}$ at temperature $100-150{ }^{\circ} \mathrm{C}$ in relation to metal-oxygen bond energy (a) and donor sites concentration (b). Adapted with permissions from ref. [42] copyright 2019 by the authors (CC BY); ref. [63] copyright 2021 Elsevier; ref. [102] copyright 2013 Elsevier; ref. [123] copyright 2015 by the authors (CC BY).

\subsection{Effect of Cations on Sensitivity and Selectivity of Mixed-Metal Oxides}

The sensitivities of mixed-metal oxides and simple MOS to sets of various analyte gases are compared in Figure 21 for the pairs $\mathrm{BaSnO}_{3}-\mathrm{SnO}_{2}$ and $\mathrm{Bi}_{2} \mathrm{WO}_{6}-\mathrm{WO}_{3}[63,77]$. Comparing the sensitivities of $\mathrm{SnO}_{2}$ to definite concentrations of analyte gases (Figure 21a), it may noticed that tin oxide was unselective in the detection of reducing gases and the difference in sensor signals might be attributed to different concentrations of analyte gases (e.g., higher sensitivity to $100 \mathrm{ppm} \mathrm{H}_{2}$ and lower sensitivities to 2-20 ppm CO, $\mathrm{NH}_{3}, \mathrm{H}_{2} \mathrm{~S}$, etc.). On the contrary, $\mathrm{BaSnO}_{3}$ demonstrated an improved sensitivity selectively to $\mathrm{SO}_{2}$ and, to a lesser extent, to alcohols; the sensitivity of $\mathrm{BaSnO}_{3}$ to other reducing gases was comparable with that of $\mathrm{SnO}_{2}$ (Figure 21a).

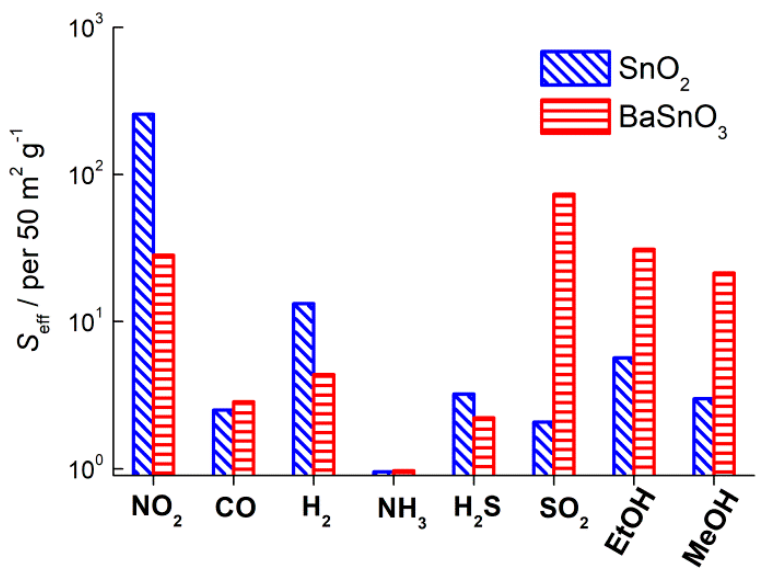

(a)

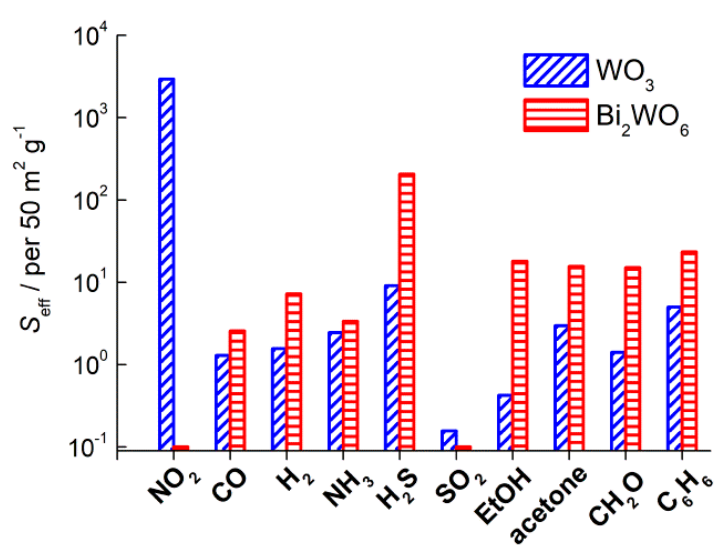

(b)

Figure 21. Sensitivity of nanocrystalline $\mathrm{SnO}_{2}$ and $\mathrm{BaSnO}_{3}$ to $\mathrm{NO}_{2}(2 \mathrm{ppm})$ at $100{ }^{\circ} \mathrm{C}, \mathrm{CO}(50 \mathrm{ppm}), \mathrm{NH}_{3}(20 \mathrm{ppm})$, $\mathrm{H}_{2} \mathrm{~S}$ (2 ppm), $\mathrm{H}_{2}$ (100 ppm), $\mathrm{SO}_{2}$ (10 ppm), ethanol (20 ppm), methanol (20 ppm) at $300{ }^{\circ} \mathrm{C}$ (a) [77]; and sensitivity of nanocrystalline $\mathrm{WO}_{3}$ and $\mathrm{Bi}_{2} \mathrm{WO}_{6}$ to $\mathrm{NO}_{2}(1 \mathrm{ppm})$ at $100{ }^{\circ} \mathrm{C}$, ethanol $(20 \mathrm{ppm})$ at $150{ }^{\circ} \mathrm{C}, \mathrm{SO}_{2}(2 \mathrm{ppm})$, formaldehyde (400 ppb), $\mathrm{H}_{2} \mathrm{~S}(2 \mathrm{ppm})$ at $250{ }^{\circ} \mathrm{C}, \mathrm{CO}(20 \mathrm{ppm}), \mathrm{H}_{2}(50 \mathrm{ppm}), \mathrm{NH}_{3}(20 \mathrm{ppm})$, acetone $(2 \mathrm{ppm})$, benzene (2 ppm) at $300{ }^{\circ} \mathrm{C}$ (b) [63]. 
DRIFT spectroscopy revealed that the selectivity of $\mathrm{BaSnO}_{3}$ to $\mathrm{SO}_{2}$ was related with specific enhancement of target molecules oxidation due to binding the produced sulfate species with the Lewis basic sites (lattice $\mathrm{O}^{2-}$ anions) associated with $\mathrm{Ba}^{2+}$ cations [77]:

$$
\mathrm{SO}_{2(\mathrm{~g})}+1 / n \mathrm{O}_{\mathrm{n}}{ }^{\mathrm{m}-} \text { (surf) }+\mathrm{Ba}^{2+}{ }_{\text {(lat) }}+\mathrm{O}^{2-}{ }_{\text {(lat) }}=\mathrm{BaSO}_{4(\text { surf })}+m / n e^{-}
$$

Comparative sensing tests of $\mathrm{Bi}_{2} \mathrm{WO}_{6}$ and $\mathrm{WO}_{3}$ demonstrated the commonly higher sensitivity of bismuth tungstate to reducing gases [63]. The improved sensitivity of $\mathrm{Bi}_{2} \mathrm{WO}_{6}$ to VOCs, including formaldehyde and benzene, may be outlined (Figure 21b). Based on DFT simulations of $\mathrm{W}-\mathrm{O}$ bonding in these structures, the higher sensitivity of $\mathrm{Bi}_{2} \mathrm{WO}_{6}$ to reducing gases was ascribed to the lower $\mathrm{W}-\mathrm{O}$ bond strength and, hence, easier $\mathrm{W}-\mathrm{O}$ cleavage on the surface during the oxidation of analyte gas molecules. On the other hand, the lack of sensitivity to $\mathrm{NO}_{2}$ was in line with the decreased concentration of donor sites (oxygen vacancies) in $\mathrm{Bi}_{2} \mathrm{WO}_{6}$, in comparison to $\mathrm{WO}_{3}$. It was evidenced by XPS evaluations that showed lower content of reduced $\mathrm{W}^{5+}$ cations in $\mathrm{Bi}_{2} \mathrm{WO}_{6}$ than in $\mathrm{WO}_{3}$ [63]. Also, the sensitivity of $\mathrm{BaSnO}_{3}$ to $\mathrm{NO}_{2}$ was lower than that of $\mathrm{SnO}_{2}$ (Figure 21a); it could be due to lower concentration of oxygen vacancies in the mixed-metal oxide. Indirectly, it was evidenced by the higher energy of oxygen vacancy $\mathrm{V}_{\mathrm{O}}$ formation in $\mathrm{BaSnO}_{3}$ (above $4 \mathrm{eV}$ [113]) than that in $\mathrm{SnO}_{2}$ (3.5 eV [124]). The other evidence for lower concentration of donor states in mixed-metal oxides is the higher baseline sensors resistance, in comparison to simple MOS $[63,77]$. Aside from the high sensitivity of $\mathrm{WO}_{3}$ to $\mathrm{NO}_{2}$, tungsten oxide displayed poor selectivity to reducing gases, as inferred from the comparable sensor signals in the range $S_{\text {Red }}=1-10$ for the $\mathrm{WO}_{3}$ sensor (Figure 21b). On the contrary, $\mathrm{Bi}_{2} \mathrm{WO}_{6}$ displayed the selectively high sensitivity to $\mathrm{H}_{2} \mathrm{~S}$, which was also in the spotlight of other works $[39,40]$. It should be due to specific $\mathrm{H}_{2} \mathrm{~S}_{-} \mathrm{Bi}^{3+}$ binding between the soft Pearson's acid (bismuth cation) and base (sulfur atom in $\mathrm{H}_{2} \mathrm{~S}$ ).

\section{Crucial Role of Catalytic Clusters in Sensitivity and Selectivity of Functionalized n-Type MOS}

Surface functionalization by catalytic noble metal (NM) clusters (Figure 22) is a powerful approach to improve sensor characteristics of MOS. Well-documented advantages of catalytically modified MOS sensors include the enhanced sensitivity, decreased operation temperature, shortened response and recovery times, and improved selectivity to analyte gases $[8,9,18,19]$. Selectivity is a major issue in the sensing of reducing gases, since most of toxic, pyrogenic, flammable or explosive impurities in air belong to this group. The oxidizing pollutants are few; these molecules that have stronger electron affinity than oxygen, e.g., $\mathrm{NO}_{2}$, ozone, halogens. Therefore, the search for selective oxidation catalysts is challenging for the functionalization of MOS sensors to improve the sensing behavior in the detection of reducing gases. Based on the Sabatier principle, a proper oxidation catalyst enables the adsorption of reactants (reducing gas and oxygen) and intermediates, as well as desorption of reaction products [64]. The optimal activity and specificity is anticipated when the binding energies with the catalyst surface are balanced between these species [125]. Platinum group metals have moderate adsorption energies for various gases, since almost completed d-shell enables chemical bonding through electron acceptation from adsorbate as well as back-donation to the adsorbate [37]. Elements with less occupied $\mathrm{d}$-orbitals as well as s-, p-, and f-elements easier donate electrons and too strongly adsorb oxygen (resulting in oxide formation) which deteriorates its oxidation activity. The adsorption capacity of elements with fully occupied d-orbitals $(\mathrm{Ag}, \mathrm{Au})$ is relatively low and is limited by the formation of electron vacancies in d-shell and nano-size effect [125-127].

The additives of NM form new (extrinsic) active sites at the surface of MOS (Figure 5), as well as influence its intrinsic active sites. The immobilized catalyst may impose the route of analyte gas conversion at the surface of MOS, which results in improved selectivity and sensitivity. The sensing mechanism in this case is dominated by the catalytic sites at the functionalized MOS surface [49]. In this section, we summarize our research on the effects of catalytic additives of $\mathrm{PdO}_{\mathrm{x}}, \mathrm{RuO}_{2}$, and $\mathrm{Au}$ on the active sites and sensitivity of $n$-type 
MOS to $\mathrm{CO}, \mathrm{NH}_{3}$, and VOCs. The concentration of noble metals was fixed at $1 \mathrm{wt} . \%$, and the additives were introduced by impregnation of MOS with alcohol solutions of $\mathrm{Pd}(\mathrm{acac})_{2}$ or $\mathrm{Ru}(\mathrm{acac})_{3}$. The impregnated materials were annealed at minimum temperature required for the decomposition of acetylacetonates to maintain the dispersion of NM clusters and prevent aggregation $[74,75,117]$. Gold was introduced via the colloid adsorption technique in aqueous suspensions of MOS [78].

\subsection{Role of $P d O_{x}$ in Room-Temperature Sensitivity to $\mathrm{CO}$}

Palladium- and platinum-based catalysts have long been known as efficient catalysts for $\mathrm{CO}$ oxidation. The adsorption energy of oxygen on these metals ( $340-360 \mathrm{~kJ} / \mathrm{mole}$ ) is comparable to that of $\mathrm{CO}$ which is favorable for co-adsorption of reacting species [128]. The additives of $\mathrm{Pd}$ and $\mathrm{Pt}$ have often been recognized to improve sensing behavior of MOS to CO $[33,75,87,129,130]$.

In our works, the nanocomposites $\mathrm{MOS} / \mathrm{PdO}_{\mathrm{x}}$ obtained after decomposition of deposited $\mathrm{Pd}(\mathrm{acac})_{2}$ consisted of agglomerated MOS nanocrystals covered by amorphous $\mathrm{PdO}_{\mathrm{x}}$ clusters and nanoparticles with the size 1-15 nm (Figure 22a). Palladium was observed in mixed oxidation states $\mathrm{PdO}+\mathrm{Pd}$, with the dominance of the oxidized form $[75,87,95]$. Investigation of the active sites by surface science techniques suggested that $\mathrm{PdO}_{\mathrm{x}}$ induced an increased concentration of aqueous species (adsorbed $\mathrm{H}_{2} \mathrm{O}, \mathrm{OH}$-groups, $\mathrm{OH}$-spin centers) at the surface of $\mathrm{SnO}_{2}$ [79]. However, no such effect was observed for $\mathrm{WO}_{3}$-based materials [75].

The notable effect of $\mathrm{PdO}_{x}$ clusters was the increased sensitivity of functionalized MOS sensors to CO (Figure 18). Valuably, the higher sensitivity was observed at room temperature $[75,120]$. Conventional MOS sensors require raised operation temperature $\left(200-500{ }^{\circ} \mathrm{C}\right)[2,4,8,12]$, because of the activation barrier for analyte gas conversion at the oxide surface (Equations (4) and (6)). At room temperature the sensitivity of MOS-based sensors is usually vanished. Therefore, the outstanding room-temperature sensitivity of $\mathrm{MOS} / \mathrm{PdO}_{\mathrm{x}}$ can be utilized to improve the selectivity of $\mathrm{CO}$ detection and, by the way, to diminish the power consumption of the sensor device. DRIFT studies revealed that $\mathrm{CO}$ was chemisorbed specifically on Pd-sites at room temperature (Figure 23). It was deduced that $\mathrm{Pd}-\mathrm{CO}$ binding loosened the interatomic bond in the adsorbate and thus catalyzed its oxidation by surface oxygen and hydroxyl species [75,118]:

$$
\begin{gathered}
\mathrm{Pd}-\mathrm{CO}_{(\text {ads })}+1 / n \mathrm{O}_{\mathrm{n}}{ }^{\mathrm{m}-}{ }_{\text {(surf) }}=\mathrm{Pd}_{(\text {surf) }}+\mathrm{CO}_{2(\mathrm{~g})}+m / n e^{-}, \\
\mathrm{Pd}^{-\mathrm{CO}_{(\text {ads })}}+\mathrm{OH}_{\text {(surf) }}=\mathrm{Pd}_{(\text {surf })}+\mathrm{CO}_{2(\mathrm{~g})}+\mathrm{H}^{+}{ }_{(\text {surf })}+e
\end{gathered}
$$

Raising temperature suppressed CO chemisorption, which explained the drop of sensitivity to $\mathrm{CO}$ with increasing temperature $[74,75,120]$. 


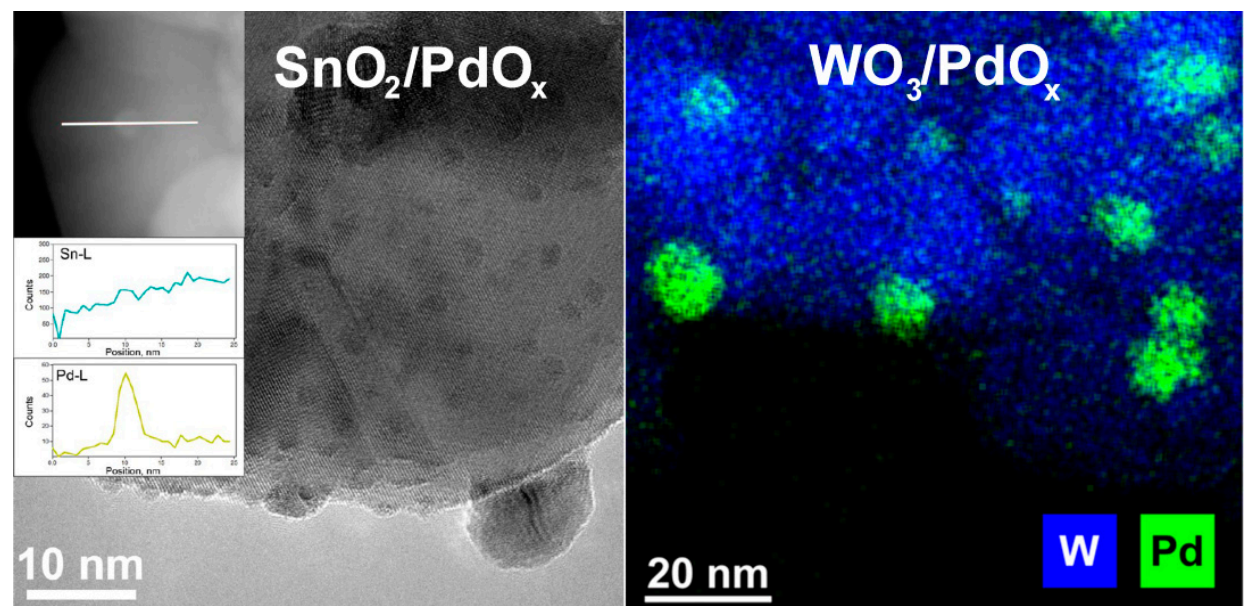

(a)

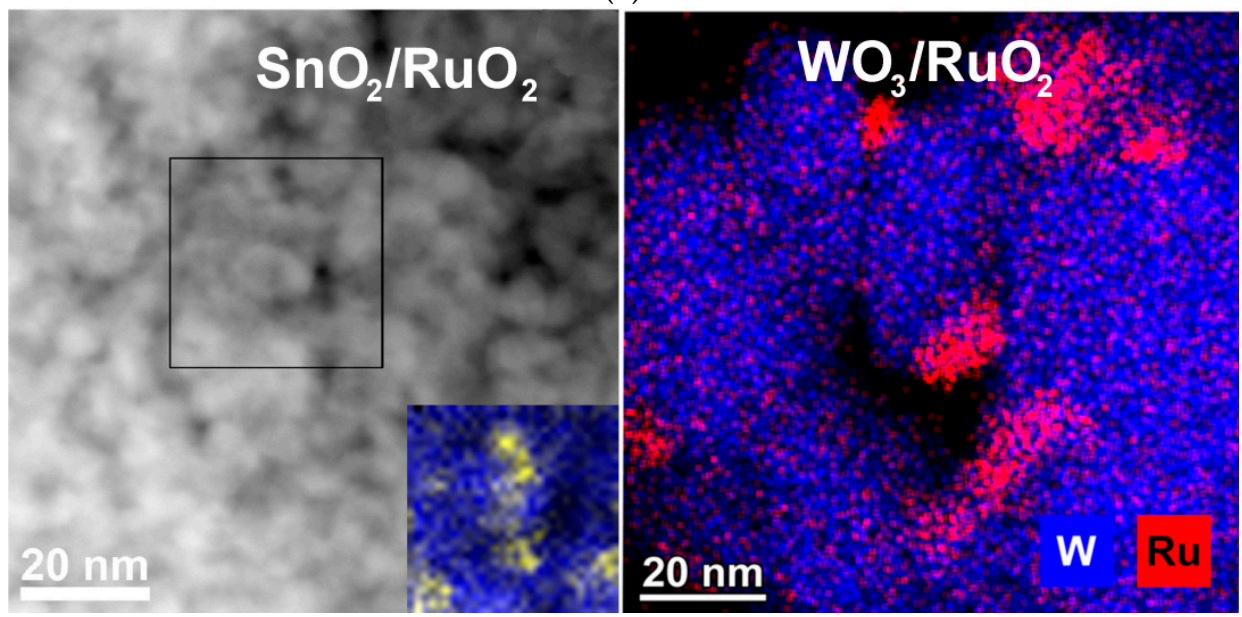

(b)
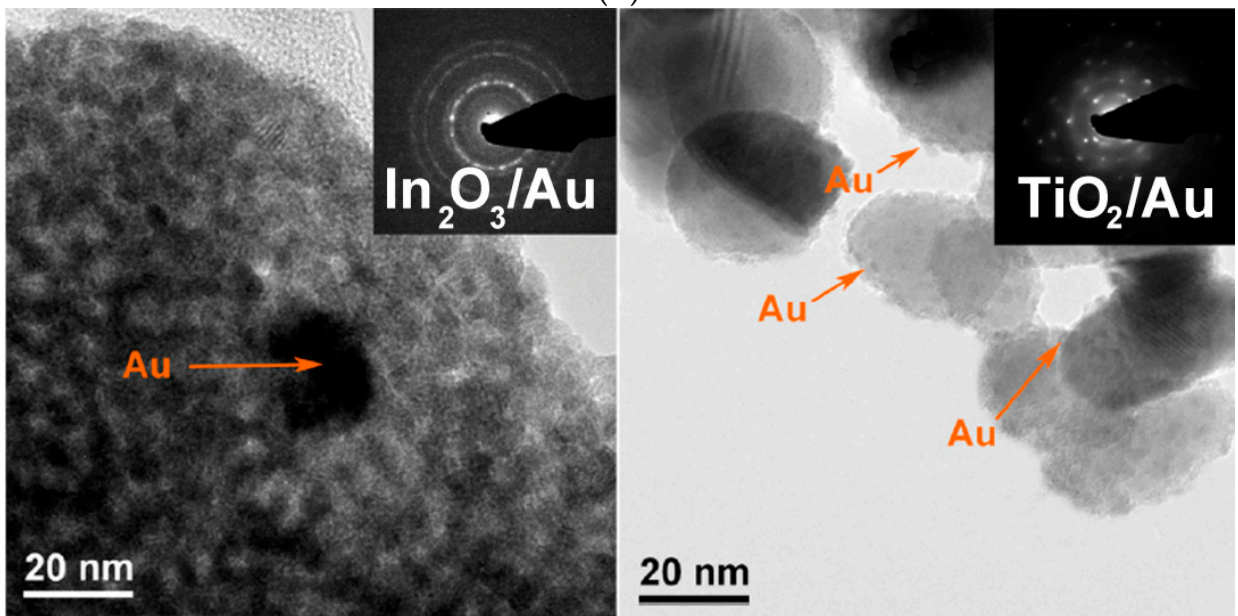

(c)

Figure 22. TEM micrographs, STEM images and EDX elemental maps of nanocrystalline $\mathrm{SnO}_{2}$ and $\mathrm{WO}_{3}$ functionalized by $\mathrm{PdO}_{\mathrm{x}}(\mathbf{a})$ and $\mathrm{RuO}_{2}(\mathbf{b})$; and TEM micrographs with electron diffraction patterns of $\mathrm{In}_{2} \mathrm{O}_{3}$ and $\mathrm{TiO}_{2}$ functionalized by Au (c). Adapted with permissions from ref. [75] copyright 2018 Elsevier; ref. [78] copyright 2021 Elsevier; ref. [95] copyright 2013 American Chemical Society. 


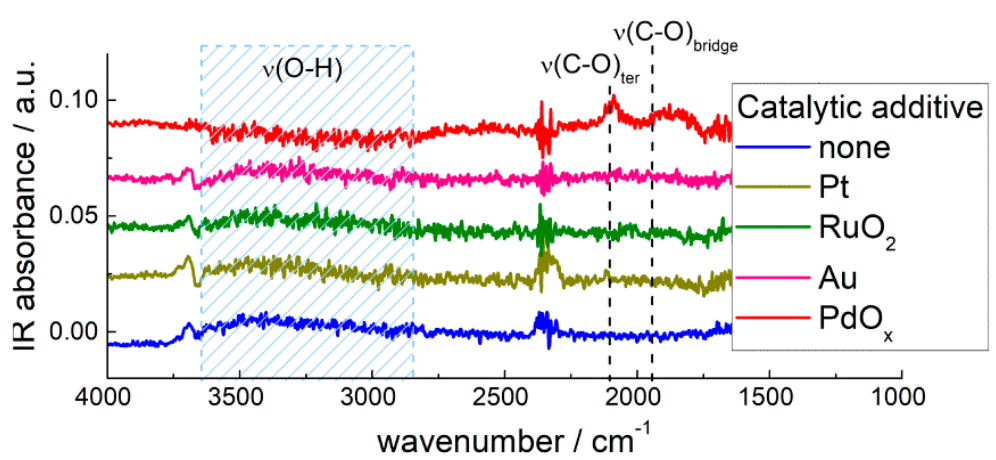

(a)

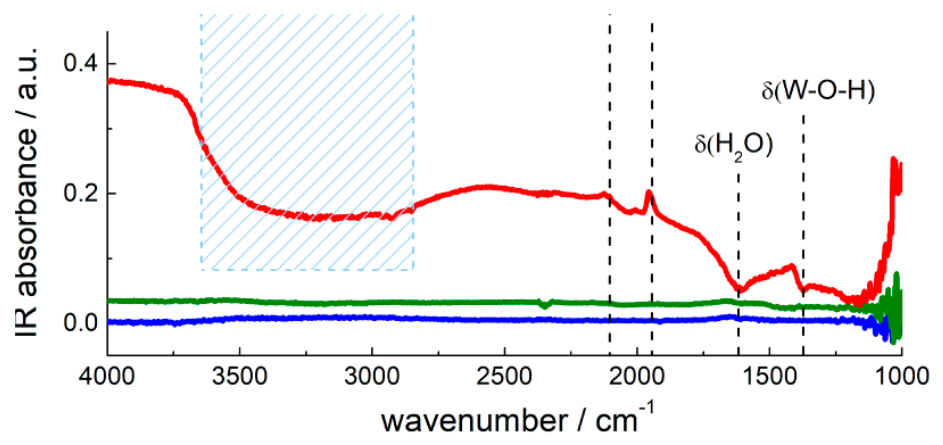

(b)

Figure 23. DRIFT spectra of pristine and functionalized by noble metal additives nanocrystalline $\mathrm{SnO}_{2}$ (a) and $\mathrm{WO}_{3}$ (b) exposed to $\mathrm{CO}(100 \mathrm{ppm}(\mathbf{a}) ; 200 \mathrm{ppm}(\mathbf{b}))$ at room temperature for $1 \mathrm{~h}$. Adapted with permissions from ref. [75] copyright 2018 Elsevier; ref. [118] copyright 2015 American Chemical Society.

\subsection{Impact of $\mathrm{RuO}_{2}$ on Sensitivity and Selectivity to $\mathrm{NH}_{3}$}

Ruthenium in the metallic $\mathrm{Ru}$ or oxidized $\mathrm{RuO}_{2}$ state is an efficient active phase of catalysts for selective processing of ammonia: synthesis, decomposition or oxidation $[125,131,132]$. DFT simulations suggested that due to moderate Ru-N bond energy, the chemisorption of $\mathrm{NH}_{3}$ is not too strong and its conversion to $\mathrm{NH}_{\mathrm{x}}$-intermediates and final products $\left(\mathrm{N}_{2}, \mathrm{NO}_{\mathrm{x}}\right)$ proceeds with low activation barriers $[125,133]$. The catalytic effect of ruthenium in the oxidation of ammonia was found promising for the improvement of sensitivity and selectivity of Ru-modified MOS sensors [134-136].

In the nanocomposites $\mathrm{MOS} / \mathrm{RuO}_{2}$ obtained via thermal decomposition of MOSimpregnated $\mathrm{Ru}(\mathrm{acac})_{3}$ at $265{ }^{\circ} \mathrm{C}$, the additive was observed in the form of randomly shaped clusters and nanoparticles with the size ranging from 2-20 nm (Figure 22b) to few hundred $\mathrm{nm}[75,95]$. Chemical state analysis indicated on the predominantly $\mathrm{RuO}_{2}$ state of ruthenium with a fraction of $\mathrm{Ru}^{3+}[74,75,95,117]$. Agreeing results were obtained by TPR of $\mathrm{SnO}_{2}$ - and $\mathrm{WO}_{3}$-based materials that the concentration of oxidizing sites increased at the surface of Ru-modified MOS [75,79].

Ru-modified MOS demonstrated substantially improved sensitivity and selectivity to $\mathrm{NH}_{3}$ at raised operation temperature $\left(150-250^{\circ} \mathrm{C}\right)[75,117,135,136]$. It was demonstrated that $\mathrm{SnO}_{2} / \mathrm{RuO}_{2}$ was capable to discriminate $\mathrm{NH}_{3}$ traces in presence of interfering $\mathrm{CO}$ gas in air [120]. Comparing different ruthenated metal oxides, an increasing sensitivity to $\mathrm{NH}_{3}$ was found with increasing $E_{\mathrm{M}-\mathrm{O}}$ and surface acidity of MOS (Figure 17). Similarly to the case of pristine MOS, this trend is explained by the increasing adsorption of $\mathrm{NH}_{3}$ on Lewis acid sites at the oxides surfaces. By DRIFT spectroscopy, the specific route of $\mathrm{NH}_{3}$ oxidation catalyzed by $\mathrm{RuO}_{2}$ was evidenced [75,118]. Although $\mathrm{NH}_{3}$ adsorption was almost unaffected by the NM additives, it was only on the Ru-modified MOS that Ru-bound 
NO species evolved from the interaction with ammonia (Figure 24) $[75,118,136]$. Nitrosyl species were further oxidized to $\mathrm{NO}_{2}$ gas [117]. Thus, the reason for improved sensitivity and selectivity to $\mathrm{NH}_{3}$ is that supported $\mathrm{RuO}_{2}$ nanoparticles specifically catalyze deep oxidation of adsorbed ammonia at the sensors surfaces, while in the absence of ruthenium the oxidation of ammonia likely stopped at the stage of $\mathrm{N}_{2}$ formation:

$$
\begin{gathered}
\mathrm{NH}_{3(\text { ads })}+5 / 2 n \mathrm{O}_{\mathrm{n}}{ }^{\mathrm{m}-}{ }_{\text {(surf) }}+\mathrm{Ru}^{4+}{ }_{\text {(surf) }}=\mathrm{Ru}^{4+}-\mathrm{NO}_{(\text {ads })}+3 / 2 \mathrm{H}_{2} \mathrm{O}_{(\mathrm{g})}+5 m / 2 n e^{-}, \\
\mathrm{Ru}^{4+}-\mathrm{NO}_{(\text {ads })}+1 / n \mathrm{O}_{\mathrm{n}}{ }^{\mathrm{m}-}{ }_{(\text {surf })}=\mathrm{NO}_{2(\mathrm{~g})}+m / n e^{-}
\end{gathered}
$$

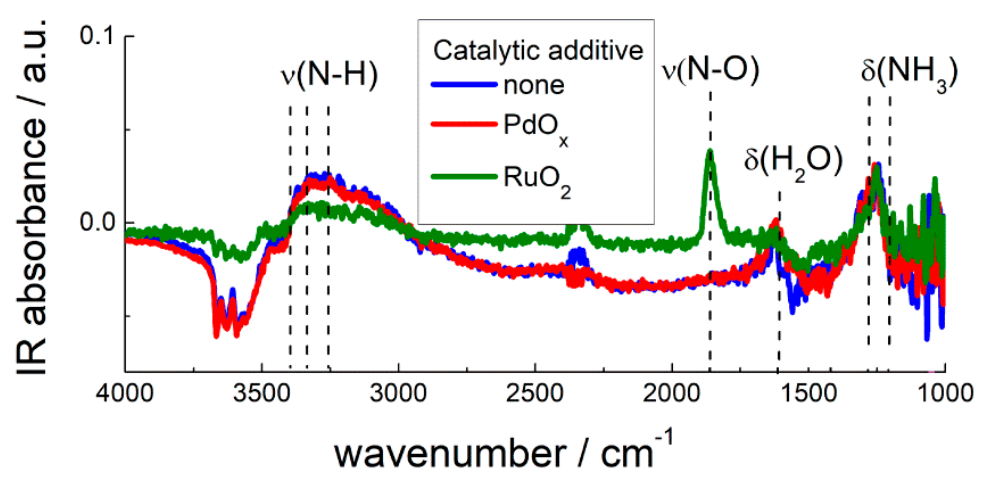

(a)

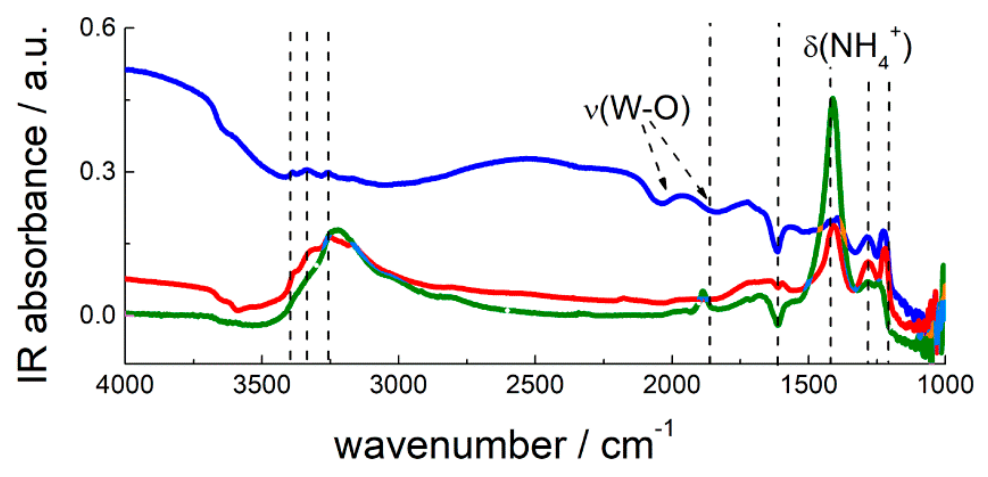

(b)

Figure 24. DRIFT spectra of pristine and functionalized by noble metal additives nanocrystalline $\mathrm{SnO}_{2}(\mathbf{a})$ and $\mathrm{WO}_{3}$ (b) exposed to $\mathrm{NH}_{3}(100 \mathrm{ppm}(\mathbf{a}) ; 200 \mathrm{ppm}(\mathbf{b}))$ at $200{ }^{\circ} \mathrm{C}$ for $1 \mathrm{~h}$. Adapted with permissions from ref. [75] copyright 2018 Elsevier; ref. [118] copyright 2015 American Chemical Society.

The distinction between the surface sites of $\mathrm{NH}_{3}$ adsorption (acid sites) and oxidation (catalytic $\mathrm{RuO}_{2}$ sites) suggested an idea of independent co-functionalization of MOS surface by acidic and catalytic species for tailoring the sensor characteristics. For this purpose, $\mathrm{SnO}_{2}$ was loaded by different amounts of sulfate $\mathrm{SO}_{4}$-groups and $\mathrm{RuO}_{2}$ clusters [98]. It was demonstrated that introducing the comparable amounts (1-3 wt.\%) of the acidic $\mathrm{SO}_{4-}$ and catalytic $\mathrm{RuO}_{2}$ additives properly enhanced the adsorption of $\mathrm{NH}_{3}$ balanced by its oxidation, resulting in the optimum sensitivity.

\subsection{Au-Promoted Oxidizing Sites and Sensitivity to VOCs}

Gold nanoparticles supported on metal oxides have been in focus of extensive research in catalysis $[37,72,126]$. Although Au itself is inactive in the bulk state, it was reported that the catalytic activity of nanosized gold exceeded that of platinum group metals in low-temperature CO oxidation [126]. Gold nano-catalysts were also shown to be efficient for total oxidation of VOCs $[137,138]$. Functionalization of MOS sensors by Au resulted in improved sensitivity to CO [139] and VOCs $[139,140]$, which was also attributed to 
catalytic activity of $\mathrm{Au}$, electronic cluster-support interaction and spillover of oxygen. Catalytic activity of Au strongly depends on cluster size and on the support. Reducible metal oxides, including MOS, are the proper supports enabling the adhesion of Au clusters and active oxygen species for the catalytic reaction cycle [141]. Among the various metal oxides, $\mathrm{TiO}_{2}$-supported $\mathrm{Au}$ catalysts have attracted the great interest $[72,92,126,142,143]$. The higher extent of surface oxygen activation on $\mathrm{TiO}_{2} / \mathrm{Au}$ was ascribed to the proper Ti-O bond energy favorable for facile interplay between oxygen vacancy formation and oxygen chemisorption from gas phase [144]. However, the origin of active sites in oxide-supported $\mathrm{Au}$ catalysts has still been questionable: periphery $\mathrm{Au}$ and $\mathrm{O}$ atoms, charged $\mathrm{Au}+$ species, $\mathrm{Au}-\mathrm{OH}$ groups, etc., were suggested [92,126,145].

Functionalization of MOS surfaces by small gold clusters is challenging, since the mobility of $\mathrm{Au}$ atoms induces the aggregation of gold in larger nanoparticles at raised operation temperature of sensors. Furthermore, chloride ions evolved from the precursor $\mathrm{HAuCl}_{4}$ decomposition promote the aggregation of gold. To minimize it, the colloid adsorption technique of MOS modification by freshly deposited $\mathrm{Au}(\mathrm{OH})_{3}$ is preferable, rather than the impregnation by $\mathrm{HAuCl}_{4}$ [126]. Recently, we reported on a comparative study of Au-modified MOS sensors obtained by colloid adsorption and thermal decomposition of $\mathrm{Au}(\mathrm{OH})_{3}$ at above $200{ }^{\circ} \mathrm{C}$ [78]. The additive was observed in the metallic state $\mathrm{Au}^{0}$ in the form of nanoparticles with the size $5-30 \mathrm{~nm}$. Investigation of active sites showed that in presence of $\mathrm{Au}$ the concentration of oxidizing sites increased at the surfaces of $n$-type MOS, and the relation $n\left(\mathrm{H}_{2, \mathrm{TPR}}-E_{\mathrm{M}-\mathrm{O}}\right.$ had the volcano shape with the maximum for $\mathrm{TiO}_{2} / \mathrm{Au}$ (Figure 25a), similarly to that for pristine MOS (Figure 14c).

The Au-functionalized sensors displayed higher sensitivity to methanol and acetone, respective to pristine MOS (Figure 25b,c). Noteworthy, the dependence of VOCs sensitivity on $\mathrm{E}_{\mathrm{M}-\mathrm{O}}$ in MOS was similar to that of oxidizing sites concentration (Figure 25a), i.e., with the maximum for $\mathrm{TiO}_{2} / \mathrm{Au}$. On the other hand, it was dissimilar to the relation VOCs sensitivity- $E_{\mathrm{M}-\mathrm{O}}$ for pristine MOS which had a plateau for $\mathrm{SnO}_{2}, \mathrm{TiO}_{2}$, and $\mathrm{WO}_{3}$ (Figure 19a,b). The plateau could be ascribed to increased adsorption of VOCs at the abundant acid sites of $\mathrm{WO}_{3}$ which compensated the lower oxidizing sites concentration at its surface. The sensitivity of Au-functionalized MOS to VOCs was less dependent on surface acidity and to a larger extent determined by the concentration of oxidizing sites (Figure 25d,e). DRIFT measurements showed no significant changes in the oxidation routes of $\mathrm{CH}_{3} \mathrm{OH}$ and $\mathrm{CH}_{3} \mathrm{COCH}_{3}$ on $\mathrm{Au}$-functionalized MOS, respective to pristine oxides (Equations (19) and (20)) [78]. Thus, in presence of Au the oxidation of VOCs by surface oxygen was enhanced leading to higher sensitivity, but the sensing mechanism was not altered. The volcano-shaped relation with the maximum for $\mathrm{TiO}_{2} / \mathrm{Au}$ allows assuming that the oxidation reactions (Equations (19) and (20)) influence the sensitivity of MOS/Au to a larger extent, than the adsorption on the acid sites of MOS. It is in line with the concept of Au-promoted surface oxygen activation, which was most noticeable on titania-supported catalysts [144]. 


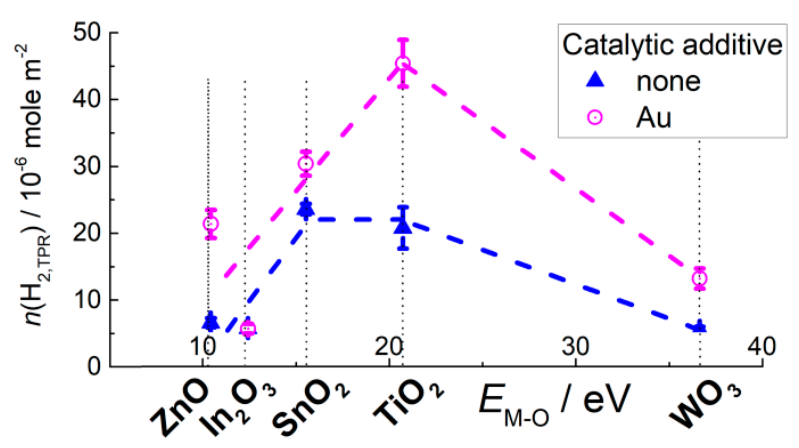

(a)

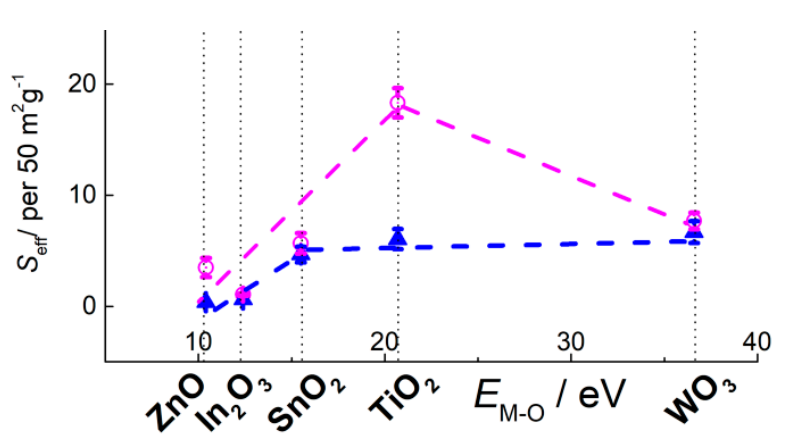

(c)

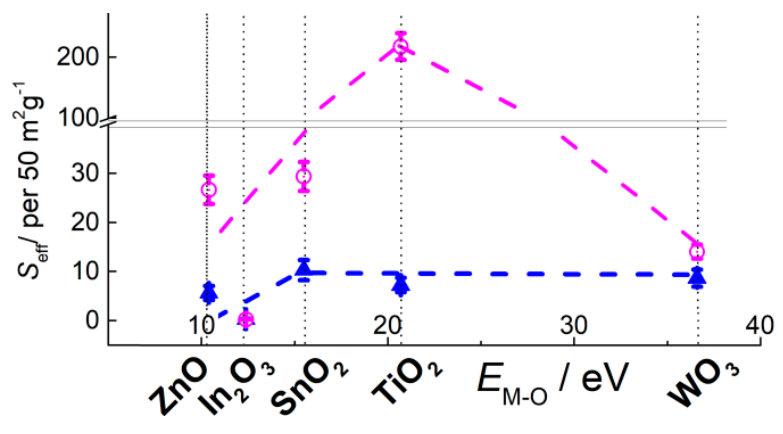

(b)

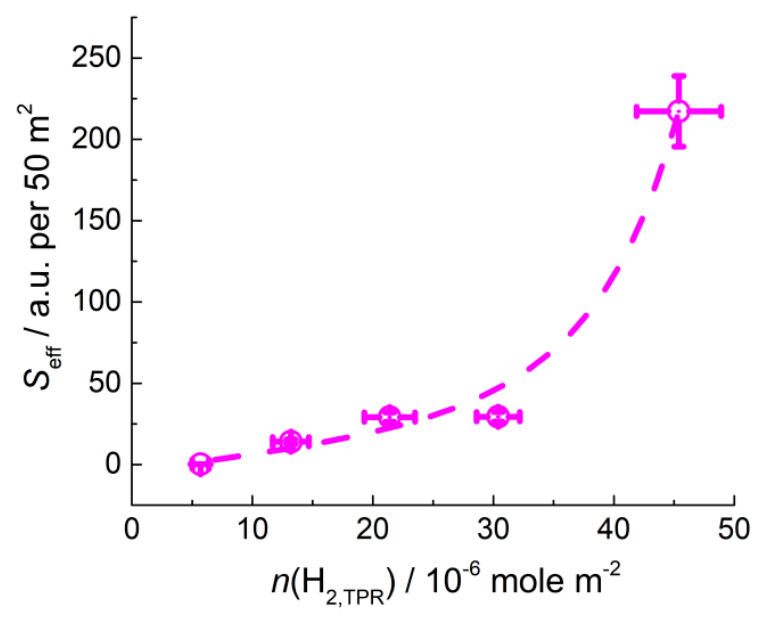

(d)

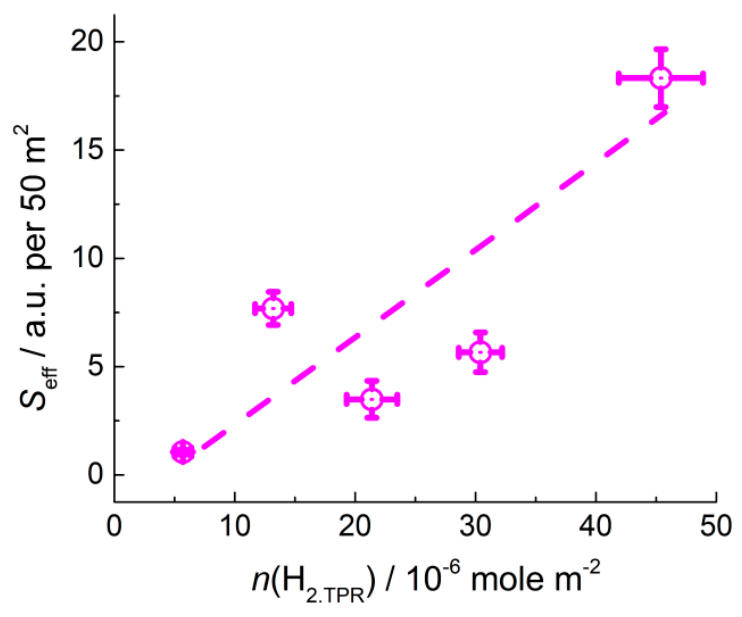

(e)

Figure 25. Concentration of oxidizing sites at the surface of pristine and Au-functionalized $n$-type MOS estimated from $\mathrm{H}_{2}$ consumption in TPR at temperature below $300{ }^{\circ} \mathrm{C}(\mathbf{a})$ in comparison with the sensitivity to 20 ppm of acetone (b) and $20 \mathrm{ppm}$ of methanol (c) as a function of metal-oxygen bond energy in MOS. Sensitivity of Au-functionalized MOS to 20 ppm of acetone (d) and $20 \mathrm{ppm}$ of methanol (e) in relation to of oxidizing sites concentration (d,e). Operation temperature of sensors was $250-300{ }^{\circ} \mathrm{C}$ for pristine MOS and $150-225^{\circ} \mathrm{C}$ for Au-functionalized MOS. Adapted with permission from ref. [78]. Copyright 2021 Elsevier. 


\section{Conclusions}

In this review of the authors' research on sensor materials based on nanocrystalline $n$-type $\mathrm{MOS}\left(\mathrm{In}_{2} \mathrm{O}_{3}, \mathrm{ZnO}, \mathrm{SnO}_{2}, \mathrm{TiO}_{2}, \mathrm{WO}_{3}\right)$ with particle sizes in the 3-50 nm range, the direct correlations between material composition, concentrations of active sites at the surface, and gas sensing behavior was substantiated. The active sites were classified as acid sites of Brønsted type (acidic OH-groups) and Lewis type (coordinately unsaturated cations), oxidizing sites (adsorbed oxygen, OH-species, and/or surface oxygen anions), and donor sites (oxygen vacancies and/or reduced cations). In line with the increment of charge/radius ratio and electronegativity of the constituent cations, the metal-oxygen bond energy reported in literature and surface acidity probed by TPD of ammonia increase in the order: $\mathrm{In}_{2} \mathrm{O}_{3}, \mathrm{ZnO}, \mathrm{SnO}_{2}, \mathrm{TiO}_{2}, \mathrm{WO}_{3}$. Concentration of oxidizing sites evaluated by TPR was higher at the surface of the oxides with moderate $E_{\mathrm{M}-\mathrm{O}}\left(\mathrm{SnO}_{2}, \mathrm{TiO}_{2}\right)$. Probably, it was due to interplay of two opposite trends: enhancing oxygen vacancies formation and decreasing oxygen chemisorption with the increase of $E_{\mathrm{M}-\mathrm{O}}$, as was shown by the concentrations of paramagnetic sites $\mathrm{V}_{\mathrm{O}}{ }^{-}$and $\mathrm{O}_{2}{ }^{-}$measured by EPR. The extrinsic catalytically active sites were formed via the functionalization of MOS surfaces by $\mathrm{PdO}_{x}$ and $\mathrm{RuO}_{2}$ clusters with the size 1-20 nm, and Au nanoparticles with the size 5-30 nm surfaces. Mixed-metal oxides $\mathrm{BaSnO}_{3}$ and $\mathrm{Bi}_{2} \mathrm{WO}_{6}$ obtained by hydrothermal synthesis were considered in comparison with $\mathrm{SnO}_{2}$ and $\mathrm{WO}_{3}$, respectively. In the pairs $\mathrm{BaSnO}_{3}-$ $\mathrm{SnO}_{2}$ and $\mathrm{Bi}_{2} \mathrm{WO}_{6}-\mathrm{WO}_{3}$ there are similar structural units and semiconductor properties determined by the $\mathrm{Sn}-\mathrm{O}$ and $\mathrm{W}-\mathrm{O}$ networks, respectively. The introduction of $\mathrm{Ba}^{2+}$ slightly elongated $\mathrm{Sn}-\mathrm{O}$ bond in $\mathrm{BaSnO}_{3}$, respective to $\mathrm{SnO}_{2}$. First-principles analysis showed that the filled 6s-level of $\mathrm{Bi}^{3+}$ deteriorates the stability of crystal structure and $\mathrm{W}-\mathrm{O}$ bonding in $\mathrm{Bi}_{2} \mathrm{WO}_{6}$, in comparison to $\mathrm{WO}_{3}$. Due to the relatively low charge/radius ratio and electronegativity of $\mathrm{Ba}^{2+}$ and $\mathrm{Bi}^{3+}$ cations, the concertation of acid sites was lower at the surfaces of mixed-metal oxides, compared with $\mathrm{SnO}_{2}$ and $\mathrm{WO}_{3}$. Due to lower $\mathrm{W}-\mathrm{O}$ bond energy, $\mathrm{Bi}_{2} \mathrm{WO}_{6}$ had higher oxidizing surface reactivity than $\mathrm{WO}_{3}$.

The trends in active sites concentration and sensitivity to different analyte gases $\left(\mathrm{NH}_{3}, \mathrm{NO}_{2}, \mathrm{CO}\right.$, VOCs) were compared for MOS using metal-oxygen bond energy as a descriptor parameter. It was shown that sensitivity of pristine and $\mathrm{RuO}_{2}$-modified MOS to $\mathrm{NH}_{3}$ increased with surface acidity reaching maximum for $\mathrm{WO}_{3}$-based sensors. Diffusereflectance infrared spectroscopy suggested that it was due to enhanced adsorption of $\mathrm{NH}_{3}$ on Lewis acid sites that favors the oxidation of adsorbed molecules and sensor response formation. The sensitivity to $\mathrm{CO}$ which has no acid-base behavior is likely determined by the oxidation reaction at the surface. The sensitivity of pristine and $\mathrm{PdO}_{\mathrm{x}}$-modified MOS to CO correlated with the concentration of oxidizing sites which was higher for $\mathrm{SnO}_{2}$ and $\mathrm{TiO}_{2}$. The sensitivity to VOCs molecules possessing Lewis-basic $\mathrm{O}$ atoms (methanol, acetone) was contributed by the processes of adsorption on acid sites and the conversion on oxidizing sites. For pristine MOS, the sensitivity to VOCs reached a plateau for $\mathrm{SnO}_{2}$, $\mathrm{TiO}_{2}, \mathrm{WO}_{3}$. The higher surface acidity of $\mathrm{WO}_{3}$ and enhanced adsorption of VOCs could compensate its lower oxidizing sites concentration, respective to $\mathrm{SnO}_{2}$ and $\mathrm{TiO}_{2}$. The sensitivity to oxidizing gas $\mathrm{NO}_{2}$ increased with the increment of donor sites concentration (oxygen vacancies) in MOS with the maximum for pristine $\mathrm{WO}_{3}$.

Changing the composition of sensor materials modifies the metal-oxygen bonding and intrinsic active sites, as well as results in the formation of specific active sites and improved selectivity. Mixed-metal oxides $\mathrm{BaSnO}_{3}$ and $\mathrm{Bi}_{2} \mathrm{WO}_{6}$ possessed lower concentration of donor sites and decreased sensitivity to $\mathrm{NO}_{2}$, respective to $\mathrm{SnO}_{2}$ and $\mathrm{WO}_{3}$. The presence of $\mathrm{Ba}^{2+}$ cations at the surface of $\mathrm{BaSnO}_{3}$ favored the oxidation of sulfur dioxide to sulfatespecies, which provided the selectively high sensitivity to $\mathrm{SO}_{2}$. The lower $\mathrm{W}-\mathrm{O}$ bond energy and higher surface reducibility of $\mathrm{Bi}_{2} \mathrm{WO}_{6}$ correlated with its improved sensitivity to reducing gases including VOCs, in comparison to $\mathrm{WO}_{3}$. The selectivity of $\mathrm{Bi}_{2} \mathrm{WO}_{6}$ to $\mathrm{H}_{2} \mathrm{~S}$ should be due to specific binding of hydrogen sulfide to $\mathrm{Bi}^{3+}$ cations.

Clusters and nanoparticles of noble metals (or noble metal oxides) with specific catalytic activity in the oxidation of certain gas molecules can significantly change the sensing 
mechanism. Pd sites specifically bind $\mathrm{CO}$ which imposes the sensitivity and selectivity of Pd-functionalized MOS to carbon monoxide at room temperature. Moreover, the lack of target molecules adsorption at raised temperature determines the drop of $\mathrm{MOS} / \mathrm{PdO}_{\mathrm{x}}$ sensitivity to $\mathrm{CO} . \mathrm{RuO}_{2}$ clusters specifically catalyze oxidation of $\mathrm{NH}_{3}$ adsorbed at the surface of MOS producing $\mathrm{NO}_{\mathrm{x}}$. It leads to a pronounced improvement in the selectivity to ammonia for $\mathrm{RuO}_{2}$-modified sensors, and the sensitivity increases with the surface acidity of MOS reaching maximum for $\mathrm{WO}_{3} / \mathrm{RuO}_{2}$. Gold nanoparticles promote oxidizing sites at the surface of MOS, likely due to activation of surface oxygen species. It results in improved sensitivity to reducing VOCs molecules. Although the route of methanol and acetone conversion did not change in presence of $\mathrm{Au}$, the sensitivity of $\mathrm{Au}$-functionalized sensors was mainly determined by the oxidation reaction and was higher for the $\mathrm{SnO}_{2} / \mathrm{Au}$ and $\mathrm{TiO}_{2} / \mathrm{Au}$ nanocomposites.

Further research is necessary to improve fundamental understanding of the interrelation "materials composition-active sites at the surface-sensing behavior". We believe that surface science techniques like TPR, TPD, infrared spectroscopy (FTIR, DRIFT) are worth being included into the portfolio of characterization tools for sensing materials. Finding out the correlations between sensitivities to analyte gases and concentrations of adsorptive (acid/base) and reactive (redox) surface sites is informative on the processes which determine the sensitivity and selectivity, and DRIFT spectroscopy sheds the light on sensing mechanisms. The possible directions of future research on the active sites and gas sensitivity of nanocrystalline MOS include but are not limited to the following ones. (i) Design of new sensor materials based on simple MOS, mixed-metal oxides, and composites possessing specific active sites at the surface. The parameters that could be varied are the chemical composition, crystal structure and facets, morphology, concentration of additives. Experimental approaches for creating and controlling the concentrations of acid sites, reactive surface oxygen and oxygen vacancies should be developed, e.g., thermal quenching, chemical etching, surface modification, etc. It is challenging to stabilize the active sites in air under heating, so as to maintain the sensors stability during long-term operation. (ii) Extending the research of mixed-metal oxides, evaluation of the effects of cationic composition on metal-oxygen bonding, active sites, semiconductor properties and selectivity of gas - solid interaction. (iii) The search for new catalytic additives with specific reactivity towards redox conversion of definite analyte gases is challenging for theoretical and experimental studies, since the catalytic functionalization of MOS sensors is a powerful approach to improve selectivity and specify the temperature regime of gas sensing. Besides the conventionally used additives of noble metals and transition metal oxides, the potentially efficient catalysts may be found among bimetallic clusters, organically hybridized complexes, metal-organic frameworks, chalcogenides, carbon-based compounds, etc. The main issue would be stability of the catalytic additives under sensors operation conditions. Metal-oxygen bonding and active sites at the surface of MOS influence the cluster/support interplay which conditions the successive catalytic functionalization of sensors. Hence, different MOS should be comparatively investigated as the gas sensitive composites with a certain catalyst. (iv) Development of in situ and operando techniques for the revelation of kinetics and energetics of gas molecules interaction which with the active sites at the MOS sensors surfaces.

Author Contributions: Conceptualization, A.M. and A.G.; methodology, A.M.; resources, A.M., M.R. and E.A.K.; data curation, A.M. and E.A.K.; writing-original draft preparation, A.M.; writingreview and editing, A.M. and M.R.; visualization, A.M.; supervision, A.G.; project administration, M.R.; funding acquisition, M.R. All authors have read and agreed to the published version of the manuscript.

Funding: This research was funded by Russian Science Foundation, grant number 19-13-00245.

Institutional Review Board Statement: Not applicable.

Informed Consent Statement: Not applicable. 
Conflicts of Interest: The authors declare no conflict of interest.

\section{Appendix A. Techniques for Determination of Active Sites}

The oxidation states and coordination environments of metal cations, oxygen anions and surface oxygen species can be obtained by standard techniques of materials characterization, e.g., X-ray photoelectron spectroscopy (XPS), electron paramagnetic resonance (EPR), X-ray absorption spectroscopy (XAS), Mossbauer spectroscopy (if applicable for given cations) $[45,100,146]$. Fourier-transformed infrared (FTIR) spectroscopy is inevitable for the detection of polar adsorbates that have the functional groups with $\mathrm{O}-\mathrm{H}, \mathrm{N}-\mathrm{O}, \mathrm{N}-\mathrm{H}$, $\mathrm{C}-\mathrm{H}, \mathrm{C}-\mathrm{O}, \mathrm{S}-\mathrm{O}$ bonds, etc. However, in most of the procedures the whole material is the subject of investigation, and the information on surface sites can hardly be extracted. Specific techniques should be used for probing the chemical reactivity and concentration of surface sites.

\section{Appendix A.1. Determination of Acid/Base Sites}

Acid sites can be determined by the adsorption of probe basic molecules: ammonia, amines, pyridine. The base sites are usually probed by the adsorption of $\mathrm{CO}_{2}$, since carbon dioxide has almost no redox behavior and does not undergo undesirable side reactions at the metal oxides surfaces. The strength and quantity of adsorption can be measured by spectrophotometric titration in presence of indicators, thermal desorption spectrometry (TDS), temperature programmed desorption (TPD) [147-149]. The strength of acid sites is characterized by a Hammett parameter $\left(H_{0}\right)$ related to acidity constant $\left(K_{a}\right)$ of the indicator: $H_{0}=\mathrm{p} K_{a}-\lg \left\{a\left(\mathrm{IH}^{+}\right) / a(\mathrm{I})\right.$, where $\mathrm{IH}^{+}$and I are the concentrations of protonated and deprotonated forms of the indicator. The concentrations are measured by spectrophotometry [150]. The experiments are performed in liquid phase with the suspensions of metal oxides. A number of indicators with different acidity constants are used to find out the distribution of acid sites by their strength. Yet, the nature of acid sites scarcely correlates with the Hammett parameter. An alternate technique is potentiometric titration using a $\mathrm{pH}$-sensitive electrode. An electrode potential scale was proposed to qualitatively discriminate the strength of acid sites: $>100 \mathrm{mV}$ - very strong, $0-100 \mathrm{mV}$-strong, $-100-0 \mathrm{mV}$ - weak, and $<-100 \mathrm{mV}$ - very weak acid sites [151]. The informative method to identify the acid/base sites is infrared spectroscopy. From the characteristic vibrational frequencies of the adsorbed probe molecules and their derivatives (Table A1), the Brønsted sites (OH-groups) and Lewis sites (surface cations) can be distinguished [98,152,153]. The adsorption of probe molecules can be detected in situ by DRIFT spectroscopy, and no heating is required in the measurements. It is applicable for the characterization of reactive surfaces (metal oxides with low $\mathrm{M}-\mathrm{O}$ bond energy or functionalized by catalytic additives), since the redox conversion of probe molecules is inactivated without at low temperature. For example, DRIFT measurements of $\mathrm{NH}_{3}$ adsorption was used to determine the acid sites at the surface of Ru-modified sulfated tin oxide. The catalytic activity of the supported ruthenium oxide clusters in the oxidation of ammonia ruled out the use of temperature-programmed techniques. From the observed evolution of vibrational peaks of adsorbed $\mathrm{NH}_{3}$ and $\mathrm{NH}_{4}{ }^{+}$it was found that Lewis and Brønsted acidity of the surface of $\mathrm{SnO}_{2} / \mathrm{Ru}$ decreased when the percentage of ruthenium increased [98]. The shift of vibrational peaks of adsorbed probe molecules to higher wavenumbers correlates with the strength of acid/base sites [154]. However, for the quantitative analysis of surface acidity/basicity by infrared spectroscopy, the extinction coefficients for the respective vibrational bands should be known. 
Table A1. Infrared vibrational wavenumbers of adsorbed probe molecules on acid/base sites at metal oxide surface.

\begin{tabular}{|c|c|c|c|c|c|}
\hline Acid/Base Site & $\begin{array}{c}\text { Probe } \\
\text { Molecule }\end{array}$ & Adsorbate & Vibration & $\begin{array}{c}\text { Wavenumber, } \\
\text { cm }^{-1}\end{array}$ & Ref. \\
\hline \multirow{3}{*}{$\begin{array}{l}\mathrm{M}^{\mathrm{n}+} \text { cation } \\
\text { (Lewis acid) }\end{array}$} & \multirow{8}{*}{$\mathrm{NH}_{3(\mathrm{~g})}$} & & $v(\mathrm{~N}-\mathrm{H})$ & $3260-3380$ & \multirow{3}{*}[152,155]{} \\
\hline & & $\mathrm{NH}_{3 \text { (ads) }}$ & $\delta_{\mathrm{as}}\left(\mathrm{NH}_{3}\right)$ & $1600-1630$ & \\
\hline & & & $\delta_{\mathrm{s}}\left(\mathrm{NH}_{3}\right)$ & $1150-1300$ & \\
\hline \multirow{3}{*}{$\begin{array}{c}\text { OH-group } \\
\text { (Brønsted acid) }\end{array}$} & & & $v(\mathrm{~N}-\mathrm{H})$ & $3170-3230$ & \multirow{3}{*}[152,155,156]{} \\
\hline & & $\mathrm{NH}_{4}{ }^{+}$ & $\delta_{\text {as }}\left(\mathrm{NH}_{4}\right)$ & $1480-1400$ & \\
\hline & & & $\delta_{\mathrm{s}}\left(\mathrm{NH}_{4}\right)$ & $1680-1670$ & \\
\hline \multirow{4}{*}{$\begin{array}{c}\mathrm{M}^{\mathrm{n}+}-\mathrm{O}^{2-} \\
\text { (Lewis } \\
\text { acid-base pair) }\end{array}$} & & \multirow{2}{*}{$\mathrm{NH}^{2-}+\mathrm{OH}^{-}$} & $\delta\left(\mathrm{NH}_{2}\right)$ & $1490-1580$ & \multirow{2}{*}{ [152] } \\
\hline & & & $v(\mathrm{O}-\mathrm{H})$ & $3600-3700$ & \\
\hline & \multirow{9}{*}{$\mathrm{CO}_{2(\mathrm{~g})}$} & \multirow{3}{*}{$\begin{array}{c}\mathrm{CO}_{3}{ }^{2-} \\
\text { bidentate }\end{array}$} & $v(\mathrm{C}=\mathrm{O})$ & $1530-1670$ & \multirow{9}{*}[153,157]{} \\
\hline & & & $v_{\mathrm{as}}(\mathrm{COO})$ & $1220-1290$ & \\
\hline \multirow{7}{*}{$\begin{array}{l}\mathrm{O}^{2-} \text { anion } \\
\text { (Lewis base) }\end{array}$} & & & $v_{\mathrm{s}}(\mathrm{COO})$ & 980-1030 & \\
\hline & & & $v(\mathrm{C}=\mathrm{O})$ & $1640-1730$ & \\
\hline & & $\mathrm{CO}_{3}$ & $v_{\text {as }}(\mathrm{COO})$ & $1280-1285$ & \\
\hline & & & $v_{\mathrm{s}}(\mathrm{COO})$ & $1000-1020$ & \\
\hline & & \multirow{3}{*}{$\begin{array}{c}\mathrm{CO}_{3}{ }^{2-} \\
\text { monodentate }\end{array}$} & $v_{\mathrm{as}}\left(\mathrm{CO}_{3}\right)$ & $1450-1530$ & \\
\hline & & & $v_{\mathrm{s}}\left(\mathrm{CO}_{3}\right)$ & 1300-1370 & \\
\hline & & & $v(\mathrm{C}-\mathrm{O})$ & 1040-1080 & \\
\hline \multirow{3}{*}{$\begin{array}{l}\text { OH-group } \\
\text { (Lewis base) }\end{array}$} & & \multirow{3}{*}{$\mathrm{HCO}_{3}{ }^{-}$} & $v_{\text {as }}(\mathrm{COO})$ & $1600-1625$ & \multirow{3}{*}{ [153] } \\
\hline & & & $v_{\mathrm{s}}(\mathrm{COO})$ & $1415-1440$ & \\
\hline & & & $\delta(\mathrm{C}-\mathrm{OH})$ & 1180-1250 & \\
\hline
\end{tabular}

Thermal desorption techniques are proper for quantitative determination of surface sites with different acidity/basicity strengths. In a typical experiment, a granulated powder is pretreated in inert gas and/or dry air to clean the surface from adsorbed humidity. Next, the probe molecules are adsorbed at room temperature. To perform the temperature-programmed desorption, the sample is heated at a constant rate in a flow of inert gas $(\mathrm{He})$ or in vacuum. The amount of desorbed probe molecules can be measured by mass-spectrometry (TDS spectrometry) or with the thermoconductivity detector (TPD measurements) $[158,159] . \mathrm{NH}_{3}$ probe is advantageous for the determination of acid sites due to small molecular size, high penetrating ability, and relative stability to oxidation, in comparison to amines. The basicity of ammonia $\left(\mathrm{p} K_{b}=4.75\right)$ is sufficient for the discrimination between strong (Lewis) and weak (Brønsted) acid sites. However, on highly acidic surfaces $\mathrm{NH}_{3}$ can be adsorbed in multilayers and the concentration of acid sites can be overestimated. Pyridine has weaker basicity $\left(\mathrm{p} K_{b}=5.2\right)$ and, therefore, is rather a probe of strong (Lewis) acid sites, and due to a larger molecule size it does not penetrate into pores with diameter less than $5 \AA$. Brønsted acid sites (OH-groups) can selectively be probed by isopropyl amine. The protonated molecules i- $\mathrm{PrNH}_{3}{ }^{+}$decompose to ammonia and propylene during thermal desorption [158].

The acid/base sites are quantitatively determined by TPD under the assumption that each site is occupied by a single probe molecule (A):

$$
\mathrm{A}_{(\mathrm{ads})} \leftrightarrow \mathrm{A}_{(\mathrm{g})}
$$

Thermodynamic condition for desorption is:

$$
\Delta G_{\text {des }}=\Delta H_{\text {des }}-T \Delta S_{\text {des }}+R T \ln p_{\mathrm{A}} \leq 0
$$

where enthalpy and entropy of desorption are positive $\Delta H_{\text {des }}>0$ and $\Delta S_{\text {des }}>0$. The enthalpy of desorption corresponds to binding energy of probe molecules A with the acid/base site $\left(E_{a d s}\right)$. It is also assumed that binding energy is independent on the surface coverage by adsorbate (the Redhead model) [160]. The residual pressure of A is due to desorption of physisorbed probe molecules and temperature-induced desorption during the TPD. The entropy is mainly contributed by the gas-phase molecules $\mathrm{A}_{(\mathrm{g})}$ and is independent on the 
adsorption sites. Thus, the desorption temperature is a characteristic of the strength of acid/base sites:

$$
T_{\text {des }} \geq E_{\text {ads }} /\left(\Delta S_{d e s}-R T \ln p_{\mathrm{A}}\right)
$$

In the analysis of acid sites by TPD of ammonia, a conditional threshold temperature for the identification of Brønsted (weak) and Lewis (strong) acid sites is about $200 \pm 50{ }^{\circ} \mathrm{C}$ depending on heating rate [161,162]. Below this temperature ammonia is desorbed from the acidic $\mathrm{OH}$-groups, and at higher temperature-from surface cations. The concentration of weak and strong acid sites (Table 2) was calculated integrating the plots in the respective temperature ranges: $30-200{ }^{\circ} \mathrm{C}$ for Brønsted acid sites; $200-600{ }^{\circ} \mathrm{C}$ for Lewis acid sites. For the accuracy of quantification, it is important to control that the thermoconductivity signal in TPD is due to desorption of $\mathrm{NH}_{3}$ and the adsorbed probe molecules are not oxidized at the surface of MOS. For this, the composition of evolved gas should be monitored by mass-spectrometry or gas-chromatography.

\section{Appendix A.2. Determination of Oxidizing Sites}

The surface species containing oxygen (adsorbed oxygen, OH-groups, lattice anions on the oxide surface) are typically regarded as the active sites for the oxidation of reducing gas molecules at the surface of sensors and catalysts. These species can be deduced from XPS data. However, due to ambiguous peaks deconvolution and ultra-high vacuum condition of XPS experiment, this method is not informative for the determination of the nature and concentration of oxidizing sites under real-life conditions. FTIR spectroscopy is proper for the detection of hydroxyl groups at the surface of metal oxides; yet, the characteristic $\mathrm{O}-\mathrm{H}$ stretching vibrational band is broad due to contributions from various adsorbed aqueous species.

The experimental observation of adsorbed oxygen species is a non-trivial challenge; in particular, atomic $\mathrm{O}^{-}$species had hardly been detected [25]. One of the reasons is high electron affinity, instability and reactivity of atomic oxygen, which is believed to take place in oxidation reactions at the surface of catalysts and sensors [88,90,163-165]. Molecular oxygen adsorbates can be detected by the vibrational stretching O-O peaks in the infrared spectral range $1050-1150 \mathrm{~cm}^{-1}[25,70,85]$. However, this peak is broad and low-intense, since the vibration of non-polar adsorbed $\mathrm{O}_{2}$ molecule has weak activity in the infrared spectra. The M-O vibrational region $\left(400-1000 \mathrm{~cm}^{-1}\right)$ in infrared and Raman spectra of metal oxides is dominated by the lattice metal-oxygen vibrations and, hence, not informative on the bonds of cations with surface oxygen species. However, in Raman spectra the peak of stretching vibration of double $\mathrm{W}=\mathrm{O}$ bond at the surface of $\mathrm{WO}_{3}$ is resolved at $960 \mathrm{~cm}^{-1}$ [166]. Electron paramagnetic resonance (EPR) is a specific spectroscopic technique which is sensitive to species with unpaired electrons. By means of EPR, the paramagnetic adsorbates $\mathrm{O}_{2}{ }^{-}$and $\cdot \mathrm{OH}$ were identified and quantified on the surfaces of $\mathrm{In}_{2} \mathrm{O}_{3}, \mathrm{SnO}_{2}$ and $\mathrm{TiO}_{2}[74,94,96,97,101,104]$.

Temperature programmed desorption of oxygen is used for quantitative determination of surface oxygen species which differ in the strength of bonding to adsorption sites and desorption temperature (Equation (A3)). Comparing the data of $\mathrm{O}_{2}$ TPD with the results of EPR measurements of chemisorbed oxygen the temperature ranges were established in which molecular $\left(\mathrm{O}_{2(\mathrm{ads})}\right)$ and ionic $\left(\mathrm{O}_{2}{ }^{-}, \mathrm{O}^{-}\right.$or $\left.\mathrm{O}^{2-}\right)$ adsorbates existed (Section 3.1) [24]. In an experiment, $\mathrm{O}_{2}$ probe molecules are adsorbed on the dehydrated metal oxide surface, and desorption is carried out in a flow of helium under heating with a constant rate. Desorbed species should be identified with a mass-spectrometer.

The oxidizing reactivity of oxides can be investigated by temperature programmed reduction (TPR). Hydrogen is the proper probe molecule, since the only product of the reaction is water:

$$
1 / x \mathrm{MO}_{\mathrm{x}(\mathrm{s})}+\mathrm{H}_{2(\mathrm{~g})}=1 / x \mathrm{M}_{(\mathrm{s} / \mathrm{l})}+\mathrm{H}_{2} \mathrm{O}_{(\mathrm{g})}
$$

This is a generalized reduction scheme. Actually, metal oxide $\left(\mathrm{MO}_{\mathrm{x}}\right)$ may be reduced via distinguishable steps, like surface species reduction, bulk oxide reduction to an interme- 
diate state and complete reduction to metal. Water vapor can be isolated from the gas flow using a cold trap or desiccant, and then hydrogen consumption can be reliably measured by thermoconductivity detector. Argon or nitrogen are used as the carrier gases, since thermoconductivity of $\mathrm{Ar}\left(\right.$ or $\mathrm{N}_{2}$ ) contrasts to that of $\mathrm{H}_{2}$. In particular works, the reactivity of metal oxides was studied by TPR using specific probe molecules (e.g., $\mathrm{CO}, \mathrm{H}_{2} \mathrm{~S}$, etc.) depending on the materials applications $[167,168]$. From thermodynamics, the reduction processes (Equations (A4) and (A5)) are possible when:

$$
\Delta G_{r}=\Delta H_{r}-T \Delta S_{r}+R \ln \left(p_{(\mathrm{H} 2 \mathrm{O})} / p_{(\mathrm{H} 2)}\right) \leq 0
$$

For the bulk oxide reduction (Equation (A4)), entropy change is:

$$
\Delta S_{r}=S \mathrm{H}_{2} \mathrm{O}_{(\mathrm{g})}-\mathrm{S} \mathrm{H}_{2(\mathrm{~g})}-\left(\mathrm{S} \mathrm{MO}_{\mathrm{x}}-\mathrm{S} \mathrm{M}\right)
$$

Since entropy is mainly contributed by gas phase, its change in Equation (A5) is usually positive $\Delta S>0$, so that Gibbs free energy for the reduction of most metal oxides by $\mathrm{H}_{2}$ decreases with increasing temperature [169]. However, metal oxides with complex compositions and/or defect-rich structures, like spinels $\mathrm{M}_{3} \mathrm{O}_{4}, \mathrm{U}_{3} \mathrm{O}_{8}$, precious metal oxides, mixed-metal oxides, can diminish significantly the reduction entropy (Equation (A6)). Reduction enthalpy in Equation (A5) depends on the oxide formation enthalpy $\left(\Delta_{f} H^{0} \mathrm{MO}_{\mathrm{x}}\right)$ and fusion enthalpy of metal if reduction completes above its melting point:

$$
\Delta H_{r}=\Delta_{f} H \mathrm{H}_{2} \mathrm{O}_{(\mathrm{g})}-1 / x \cdot\left(\Delta_{f} H \mathrm{MO}_{\mathrm{x}}-\Delta_{f} H \mathrm{M}_{(\mathrm{l})}\right)
$$

According to thermodynamic definition of metal-oxygen bond energy $E_{M-O}$ (Table 1), the oxide formation enthalpy can be reformulated:

$$
-1 / x \cdot \Delta_{f} H \mathrm{MO}_{\mathrm{x}}=E_{M-O}-1 / x \cdot \Delta_{a t} H \mathrm{M}-1 / x \cdot \sum \mathrm{IE} \mathrm{M}-\frac{1}{2} \cdot \Delta_{\text {diss }} H \mathrm{O}_{2(\mathrm{~g})}+\sum \mathrm{AE}
$$

where $\Delta_{a t} H \mathrm{M}$ is atomization energy of metal, $\sum$ (IE M) is the sum of ionization energies for the metal-to-cation transition, $\Delta_{\text {diss }} \mathrm{H}_{2}$ (g) is dissociation energy of oxygen and $\sum(\mathrm{AE} \mathrm{O})$ is the sum of electron affinities for atomic oxygen-to-oxide anion transition [55]. Thus, temperature of bulk reduction of metal oxides depends on metal-oxygen bond energy and other thermodynamic parameters:

$$
\begin{gathered}
T_{b u l k} \geq E_{M-O} /\left\{\Delta S_{r}-\mathrm{RT} \ln \left(p_{(\mathrm{H} 2 \mathrm{O})} / p_{(\mathrm{H} 2)}\right)\right\}+\left\{\Delta_{f} H \mathrm{H}_{2} \mathrm{O}_{(\mathrm{g})}+1 / x \cdot\left(\Delta_{f} H \mathrm{M}_{(\mathrm{l})}-\Delta_{a t} H \mathrm{M}-\sum \mathrm{IE} \mathrm{M}\right)-\frac{1}{2} \cdot \Delta_{\text {diss }} H \mathrm{O}_{2(\mathrm{~g})}+\right. \\
\left.\sum \mathrm{AE} \mathrm{O}\right\} /\left\{\Delta S_{r}-\mathrm{RT} \ln \left(p_{(\mathrm{H} 2 \mathrm{O})} / p_{(\mathrm{H} 2)}\right)\right\}
\end{gathered}
$$

In case that only surface oxygen is reduced, solid phases $\mathrm{MO}_{\mathrm{x}}$ and $\mathrm{M}$ in Equation (A4) are almost same (i.e., small $x$ in $\mathrm{MO}_{\mathrm{x}}$ ), and the reaction entropy may be approximated as $\Delta \mathrm{S} \approx \mathrm{S} \mathrm{H}_{2} \mathrm{O}_{\text {(gas) }}-\mathrm{S} \mathrm{H}_{2 \text { (gas) }}$ which is $58 \mathrm{~J} / \mathrm{K} \cdot \mathrm{mol}(0.6 \mathrm{meV})$ under standard conditions. Enthalpy change in this case is contributed by bond energy of metal cations with surface oxygen and, in case of atomic and/or ionosorbed species,-by dissociation energy of $\mathrm{O}_{2}$ and/or the difference in electron energy between the surface and bulk states in the semiconductor $\Delta E_{e}$ :

$$
\Delta H_{r}=\Delta_{f} H \mathrm{H}_{2} \mathrm{O}_{(\mathrm{g})}+1 / x\left(E_{\mathrm{M}-\mathrm{O}}-\frac{1}{2} \cdot \Delta_{\text {diss }} H \mathrm{O}_{2(\mathrm{~g})}+\Delta E_{e}\right)
$$

Thus, surface oxygen species would be reduced at temperature:

$$
\begin{gathered}
T_{\text {surf }} \geq E_{M-\mathrm{O}} /\left\{\Delta S_{r}-\mathrm{RT} \ln \left(p_{(\mathrm{H} 2 \mathrm{O})} / p_{(\mathrm{H} 2)}\right)\right\}+\left\{\Delta_{f} H \mathrm{H}_{2} \mathrm{O}_{(\mathrm{g})}-\frac{1}{2} \cdot \Delta_{\text {diss }} H \mathrm{O}_{2(\mathrm{~g})}+\right. \\
\Delta \mathrm{E} e\} /\left\{\Delta S_{r}-\mathrm{RT} \ln \left(p_{(\mathrm{H} 2 \mathrm{O})} / p_{(\mathrm{H} 2)}\right)\right\}
\end{gathered}
$$

Surface oxygen is reduced at lower temperature mainly due to lower bond energy $\mathrm{M}-\mathrm{O}$ at the oxide surface, in comparison to the bulk. Thus, the reduced species can be 
identified by the characteristic reduction temperature in TPR patterns. From the amounts of hydrogen consumed at lower and higher temperature ranges, the concentration of adsorbed oxygen species can be quantified and the staging of bulk reduction can be estimated. For example, $\mathrm{WO}_{3}$ is reduced to $\mathrm{WO}_{2}$ at $600-750{ }^{\circ} \mathrm{C}$ and further to metallic tungsten at higher temperature (Figure 15). Temperature of bulk reduction correlates to the energetic parameters of oxides (Table 1): higher metal-oxygen bond energy and lower formation enthalpy generally agree with higher reduction temperature (Figure 15). An exception is $\mathrm{ZnO}$, since it is reduced to volatile $\mathrm{Zn}$ metal and bulk reduction temperature increases due to addition of vaporization enthalpy in Equation (A9). Temperature of metal oxide reduction in TPR cannot be predicted from thermodynamics only (Equations (A9) and (A11)), since it is much influenced by kinetic parameters of gas-solid interaction, such as activation energy, mechanism of nucleation of the reduced phase, rate of gas diffusion, and experimental conditions (heating rate, hydrogen flowrate).

\section{Appendix A.3. Determination of Electron Donor Sites}

Partially reduced metal cations and oxygen vacancies are the intrinsic electron donor sites responsible for chemisorption of oxygen and oxidizing gases at the surface of $n$-type MOS. The techniques of chemical elemental analysis like XPS, XANES, Mess-Bauer spectroscopy, and EPR can be used to determine the oxidation states of cations; however, the distinction between surface and bulk atoms can hardly be achieved by spectroscopic investigations.

Oxygen vacancies $\left(\mathrm{V}_{\mathrm{O}^{2-}}{ }^{2-} \mathrm{V}_{\mathrm{O}}^{-}\right)$which possess loosely bound electrons have been regarded as the key surface sites in the gas sensing mechanisms (Equations (1) and (7)) [170-172]. Due to lability and accessibility for ambient molecules adsorption, surface vacancies are hardly detectable experimentally. Quantitatively the oxygen deficiency in metal oxides can be determined by thermodesorption of oxygen, thermal gravimetric analysis, coulometric titration under variable oxygen pressure [173-175]. The occurrence of intrinsic oxygen vacancies was inferred from indirect investigations by conduction measurements, optical spectroscopy, photoluminescence and cathodoluminescence [170]. Directly oxygen vacancies, i.e., missing oxygen atoms, were observed by atomically resolved scanning tunneling microscopy (STM) on single crystalline surfaces of $\mathrm{SnO}_{2}$ and $\mathrm{TiO}_{2}[176,177]$. As well as the native position of $\mathrm{O}^{2-}$ lattice anions, oxygen vacancies are adjacent with metal cations on the oxide surfaces. Therefore, facile electron exchange occurs between the cations and oxygen vacancies. The resultant reduced cations associated with oxygen vacancies have been detected in spectroscopic investigations of metal oxides. $\mathrm{Sn}^{2+}$ was detected by Mossbauer spectroscopy in $\mathrm{SnO}_{2}$ under oxygen-lean conditions [45]. Raman vibrational modes at 234, 573 and $618 \mathrm{~cm}^{-1}$ were attributed to oxygen vacancies formation in $\mathrm{SnO}_{2}$ [178]. To paramagnetic single-charged oxygen vacancies $\mathrm{V}_{\mathrm{O}}{ }^{-}$could be attributed the EPR signal with the $g$-factor 1.80-2.00 on the spectra of $\mathrm{ZnO}, \mathrm{SnO}_{2}, \mathrm{TiO}_{2}$, and $\mathrm{WO}_{3}$ (Figure 13) $[42,96,104,179-182]$. Alternatively, these EPR signals could be attributed to reduced cations $\mathrm{Sn}^{3+}, \mathrm{Ti}^{3+}, \mathrm{W}^{5+}$, respectively $[96,100] . \mathrm{Ti}^{3+}$ associated with oxygen vacancies were deduced from atmospheric pressure XPS (APXPS) study of $\mathrm{TiO}_{2}$ [183]. Since the partially reduced cations and oxygen vacancies can hardly be discriminated, in the present work the EPR signals with the $g$-factor below 2 observed in the spectra of different $n$-type MOS (Figure 13) was assigned to $\mathrm{V}_{\mathrm{O}}{ }^{-}$for the sake of quantitative comparison of donor sites concentrations (Table 2).

\section{Appendix A.4. In Situ and In Operando Investigation Techniques}

The characterization techniques discussed above are mostly performed ex situ and represent the active sites at the materials surfaces under ultra-high vacuum (XPS, STM), under ambient conditions (FTIR, EPR, Raman spectroscopy), or after pretreatment (probe molecule techniques). The roles of active sites in gas sensing can be deduced from the comparison of initial surface sites concentrations and sensor properties through a series of samples and analyte gases. More reliably the routes of gas-solid interactions can be 
established from in situ or in operando studies. The adsorption and transformation of gas molecules at the oxide surface is investigated by in situ vibrational spectroscopy: diffuse reflection infrared Fourier-transformed (DRIFT) [42,118,119] and Raman spectroscopy [41]. DRIFT is proper for tracing the adsorbates, since it is sensitive to vibrations of polar bonds (O-H, C-O, N-H, N-O, C-H, etc.) or asymmetric vibrations of nonpolar adsorbates. However, the minimum wavenumber measured in DRIFT is restricted to transmittance of the chamber window, e.g., $\mathrm{ZnSe}$-above $700 \mathrm{~cm}^{-1}, \mathrm{BaF}_{2}$-above $900 \mathrm{~cm}^{-1}, \mathrm{CaF}_{2}$-above $1300 \mathrm{~cm}^{-1}$, so that vibrations of metal-oxygen and metal-adsorbate bonds are not detected. DRIFT chamber windows of alkaline metal halides have lower transmission limits $\left(\mathrm{KBr}>400 \mathrm{~cm}^{-1}, \mathrm{KCl}>500 \mathrm{~cm}^{-1}, \mathrm{NaCl}>600 \mathrm{~cm}^{-1}\right)$, but cannot be used in presence of humidity. On the other hand, Raman spectroscopy allows for screening low vibrational wavenumbers down to $30-60 \mathrm{~cm}^{-1}$, which is suitable for screening the bulk and surface bond vibrations of metal oxides, but has low sensitivity to polar bond vibrations of the adsorbate species. Thus, Raman and DRIFT spectroscopies could be used cooperatively to get an overview of adsorbates transformation at metal oxide surfaces. Gas chromatography and mass spectrometry can be used for the analysis of gases evolved from such a reaction [134]. Through the appropriate MOS sampling the spectroscopic measurements can be performed in operando under real working conditions of gas sensors $[29,184]$. The advanced techniques were elaborated for the in situ investigations of gas-solid interactions, e.g., atmospheric pressure XPS (APXPS) [183], in situ EPR [115], in situ XAS [185].

Indirect data on the interaction of MOS with analyte gases can be obtained by in situ measurements of electric conduction, work function (Kelvin probe) and impedance $[87,118,186]$. Simultaneous work function and conduction measurements allow to distinguish between chemisorbed (dipolar uncharged adsorbates) and ionosorbed (charged adsorbates) species resultant from gas molecules adsorption on the surface of MOS [118,186]. By in situ impedance spectroscopy, the ionic current carriers like protons may be traced during the adsorption and conversion of gas molecules on the hydroxylated oxide surface [87].

\section{References}

1. Yamazoe, N. Toward innovations of gas sensor technology. Sens. Actuators B Chem. 2005, 108, 2-14. [CrossRef]

2. Dey, A. Semiconductor metal oxide gas sensors: A review. Mater. Sci. Eng. B 2018, 229, 206-217. [CrossRef]

3. Moseley, P.T. Progress in the development of semiconducting metal oxide gas sensors: A review. Meas. Sci. Technol. 2017, 28, 082001. [CrossRef]

4. Shankar, P.; Rayappan, J.B.B. Gas sensing mechanism of metal oxides: The role of ambient atmosphere, type of semiconductor and gases-A review. ScienceJet 2015, 126, 4 .

5. Barsan, N.; Schweizer-Berberich, M.; Göpel, W. Fundamental and practical aspects in the design of nanoscaled $\mathrm{SnO}_{2} \mathrm{gas} \mathrm{sensors:}$ A status report. Fresenius J. Anal. Chem. 1999, 365, 287-304. [CrossRef]

6. Liu, X.; Cheng, S.; Liu, H.; Hu, S.; Zhang, D.; Ning, H. A Survey on Gas Sensing Technology. Sensors 2012, 12, 9635-9665. [CrossRef] [PubMed]

7. Kohl, D. Function and applications of gas sensors. J. Phys. D Appl. Phys. 2001, 34, R125-R149. [CrossRef]

8. Park, C.O.; Akbar, S.A. Ceramics for chemical sensing. J. Mater. Sci. 2003, 38, 4611-4637. [CrossRef]

9. Kanan, S.M.; El-Kadri, O.M.; Abu-Yousef, I.A.; Kanan, M.C. Semiconducting Metal Oxide Based Sensors for Selective Gas Pollutant Detection. Sensors 2009, 9, 8158-8196. [CrossRef]

10. Matsubara, I.; Hosono, K.; Murayama, N.; Shin, W.; Izu, N. Organically hybridized $\mathrm{SnO}_{2}$ gas sensors. Sens. Actuators B Chem. 2005, 108, 143-147. [CrossRef]

11. Woo, H.-S.; Na, C.W.; Lee, J.-H. Design of Highly Selective Gas Sensors via Physicochemical Modification of Oxide Nanowires: Overview. Sensors 2016, 16, 1531. [CrossRef] [PubMed]

12. Wang, C.; Yin, L.; Zhang, L.; Xiang, D.; Gao, R. Metal Oxide Gas Sensors: Sensitivity and Influencing Factors. Sensors 2010, 10, 2088-2106. [CrossRef]

13. Korotcenkov, G. Gas response control through structural and chemical modification of metal oxide films: State of the art and approaches. Sens. Actuators B Chem. 2005, 107, 209-232. [CrossRef]

14. Degler, D.; Weimar, U.; Barsan, N. Current Understanding of the Fundamental Mechanisms of Doped and Loaded Semiconducting Metal-Oxide-Based Gas Sensing Materials. ACS Sens. 2019, 4, 2228-2249. [CrossRef] [PubMed]

15. Kim, H.-J.; Lee, J.-H. Highly sensitive and selective gas sensors using p-type oxide semiconductors: Overview. Sens. Actuators $B$ Chem. 2014, 192, 607-627. [CrossRef]

16. Coles, G.S.V.; Bond, S.E.; Williams, G. Metal Stannates and their Role as Potential Gas-sensing Elements. J. Mater. Chem. 1994, 4, 23-27. [CrossRef] 
17. Balamurugan, C.; Song, S.-J.; Kim, H.-S. Enhancing Gas Response Characteristics of Mixed Metal Oxide Gas Sensors. J. Korean Ceram. Soc. 2018, 55, 1-20. [CrossRef]

18. Korotcenkov, G.; Cho, B.K. Metal oxide composites in conductometric gas sensors: Achievements and challenges. Sens. Actuators B Chem. 2017, 244, 182-210. [CrossRef]

19. Cheng, J.P.; Wang, J.; Li, Q.Q.; Liu, H.G.; Li, Y. A review of recent developments in tin dioxide composites for gas sensing application. J. Ind. Eng. Chem. 2016, 44, 1-22. [CrossRef]

20. Saleh, T.A.; Fadillah, G. Recent trends in the design of chemical sensors based on graphene-metal oxide nanocomposites for the analysis of toxic species and biomolecules. Trends Anal. Chem. 2019, 120, 115660. [CrossRef]

21. Walker, J.M.; Akbar, S.A.; Morris, P.A. Synergistic effects in gas sensing semiconducting oxide nanoheterostructures: A review. Sens. Actuators B Chem. 2019, 286, 624-640. [CrossRef]

22. Korotcenkov, G.; Brinzari, V.; Pronin, I.A.; Ham, M.H.; Cho, B.K. Metal Oxides for Application in Conductometric Gas Sensors: How to Choose? Solid State Phenom. 2017, 266, 187-195. [CrossRef]

23. Yamazoe, N.; Shimanoe, K. Receptor Function and Response of Semiconductor Gas Sensor. Hindawi J. Sens. 2009, $2009,875704$. [CrossRef]

24. Yamazoe, N.; Fuchigami, J.; Kishikawa, M.; Seiyama, T. Interactions of tin oxide surface with oxygen, water, and hydrogen. Surf. Sci. 1979, 86, 335-344. [CrossRef]

25. Gurlo, A. Interplay between $\mathrm{O}_{2}$ and $\mathrm{SnO}_{2}$ : Oxygen Ionosorption and Spectroscopic Evidence for Adsorbed Oxygen. Chem. Phys. Chem. 2006, 7, 2041-2052. [CrossRef]

26. Rumyantseva, M.N.; Makeeva, E.A.; Badalyan, S.M.; Zhukova, A.A.; Gaskov, A.M. Nanocrystalline $\mathrm{SnO}_{2}$ and $\mathrm{In}_{2} \mathrm{O}_{3}$ as materials for gas sensors: The relationship between microstructure and oxygen chemisorption. Thin Solid Films 2009, 518, 1283-1288. [CrossRef]

27. Vorobyeva, N.A.; Marikutsa, A.V.; Rumyantseva, M.N.; Kozlovskii, V.F.; Filatova, D.G.; Gaskov, A.M. Effect of Ga and In doping on acid centers and oxygen chemisorption on the surface of nanocrystalline ZnO. Inorg. Mater. 2016, 52, 578-583. [CrossRef]

28. Yang, L.; Marikutsa, A.; Rumyantseva, M.; Gaskov, A. Effect of $\mathrm{WO}_{3}$ particle size on the type and concentration of surface oxygen. Mendeleev Commun. 2020, 30, 126-128. [CrossRef]

29. Gurlo, A.; Riedel, R. In Situ and Operando Spectroscopy for Assessing Mechanisms of Gas Sensing. Angew. Chem. Int. Ed. 2007, 46, 3826-3848. [CrossRef]

30. Zhang, Y.; Kolmakov, A.; Lilach, Y.; Moskovits, M. Electronic Control of Chemistry and Catalysis at the Surface of an Individual Tin Oxide Nanowire. J. Phys. Chem. B 2005, 109, 1923-1929. [CrossRef]

31. Shao, F.; Hoffmann, M.W.G.; Prades, J.D.; Morante, J.R.; Lopez, N.; Hernandez-Ramirez, F. Interaction Mechanisms of Ammonia and Tin Oxide: A Combined Analysis Using Single Nanowire Devices and DFT Calculations. J. Phys. Chem. C 2013, 117, 3520-3526. [CrossRef]

32. Stankova, M.; Vilanova, X.; Llobet, E.; Calderer, J.; Bittencourt, C.; Pireaux, J.J.; Correig, X. Influence of the annealing and operating temperatures on the gas-sensing properties of rf sputtered $\mathrm{WO}_{3}$ thin-film sensors. Sens. Actuators B Chem. 2005, 105, 271-277. [CrossRef]

33. Madler, L.; Sahm, T.; Gurlo, A.; Grunwaldt, J.-D.; Barsan, N.; Weimar, U.; Pratsinis, S.E. Sensing low concentrations of CO using flame-spray-made Pt/ $\mathrm{SnO}_{2}$ nanoparticles. J. Nanopart. Res. 2006, 8, 783-796. [CrossRef]

34. Nayak, A.K.; Ghosh, R.; Santra, S.; Guhab, P.K.; Pradhan, D. Hierarchical nanostructured $\mathrm{WO}_{3}-\mathrm{SnO}_{2}$ for selective sensing of volatile organic compounds. Nanoscale 2015, 7, 12460. [CrossRef] [PubMed]

35. Yang, F.; Guo, Z. Comparison of the enhanced gas sensing properties of tin dioxide samples doped with different catalytic transition elements. J. Colloid Interface Sci. 2015, 448, 265-274. [CrossRef]

36. Pan, Y.; Shen, X.; Yao, L.; Bentalib, A.; Peng, Z. Active Sites in Heterogeneous Catalytic Reaction on Metal and Metal Oxide: Theory and Practice. Catalysts 2018, 8, 478. [CrossRef]

37. Bond, G.C.; Louis, C.; Thompson, D.T. Catalysis by Gold; Imperial College Press: London, UK, 2006.

38. Wang, D.; Zhen, Y.; Xue, G.; Fu, F.; Liu, X.; Li, D. Synthesis of mesoporous $\mathrm{Bi}_{2} \mathrm{WO}_{6}$ architectures and their gas sensitivity to ethanol. J. Mater. Chem. C 2013, 1, 4153-4162. [CrossRef]

39. Liu, W.; Qu, Y.; Li, H.; Ji, F.; Dong, H.; Wu, M.; Chen, H.; Lin, Z. Nanostructure $\mathrm{Bi}_{2} \mathrm{WO}_{6}$ : Surfactant-assisted hydrothermal synthesis for high sensitive and selective sensing of $\mathrm{H}_{2}$ S. Sens. Actuators B Chem. 2019, 294, 224-230. [CrossRef]

40. Bunpang, K.; Wisitsoraat, A.; Tuantranont, A.; Phanichphant, S.; Liewhiran, C. Effects of reduced graphene oxide loading on gas-sensing characteristics of flame-made $\mathrm{Bi}_{2} \mathrm{WO}_{6}$ nanoparticles. Appl. Surf. Sci. 2019, 496, 143613. [CrossRef]

41. Sergent, N.; Epifani, M.; Comini, E.; Faglia, G.; Pagnier, T. Interactions of nanocrystalline tin oxide powder with $\mathrm{NO}_{2}$ : A Raman spectroscopic study. Sens. Actuators B Chem. 2007, 126, 1-5. [CrossRef]

42. Yang, L.; Marikutsa, A.; Rumyantseva, M.; Konstantinova, E.; Khmelevsky, N.; Gaskov, A. Quasi Similar Routes of $\mathrm{NO}_{2}$ and $\mathrm{NO}$ Sensing by Nanocrystalline $\mathrm{WO}_{3}$ : Evidence by In Situ DRIFT Spectroscopy. Sensors 2019, 19, 3405. [CrossRef] [PubMed]

43. Schmid, W.; Barsan, N.; Weimar, U. Sensing of hydrocarbons and CO in low oxygen conditions with tin dioxide sensors: Possible conversion paths. Sens. Actuators B Chem. 2004, 103, 362-368. [CrossRef]

44. Huebner, M.; Pavelko, R.G.; Barsan, N.; Weimar, U. Influence of oxygen backgrounds on hydrogen sensing with $\mathrm{SnO}_{2}$ nanomaterials. Sens. Actuators B Chem. 2011, 154, 264-269. [CrossRef] 
45. Safonova, O.; Bezverkhy, I.; Fabrichnyi, P.; Rumyantseva, M.; Gaskov, A. Mechanism of sensing CO in nitrogen by nanocrystalline $\mathrm{SnO}_{2}$ and $\mathrm{SnO}_{2}(\mathrm{Pd})$ studied by Mossbauer spectroscopy and conductance measurements. J. Mater. Chem. 2002, 12, 1174-1178. [CrossRef]

46. Huebner, M.; Simion, C.E.; Haensch, A.; Barsan, N.; Weimar, U. CO sensing mechanism with $\mathrm{WO}_{3}$ based gas sensors. Sens. Actuators B Chem. 2010, 151, 103-106. [CrossRef]

47. Staerz, A.; Berthold, C.; Russ, T.; Wicker, S.; Weimar, U.; Barsan, N. The oxidizing effect of humidity on $\mathrm{WO}_{3}$ based sensors. Sens. Actuators B Chem. 2016, 237, 54-58. [CrossRef]

48. Mueller, S.A.; Degler, D.; Feldmann, C.; Terk, M.; Moos, R.; Fink, K.; Studt, F.; Gerthsen, D.; Barsan, N.; Grunwaldt, J.-D. Exploiting Synergies in Catalysis and Gas Sensing using Noble Metal-Loaded Oxide Composites. ChemCatChem 2018, 10, 864-880. [CrossRef]

49. Degler, D.; Mueller, S.A.; Doronkin, D.E.; Wang, D.; Grunwaldt, J.-D.; Weimar, U.; Barsan, N. Platinum loaded tin dioxide: A model system for unravelling the interplay between heterogeneous catalysis and gas sensing. J. Mater. Chem. A 2018, 6, 2034-2046. [CrossRef]

50. Jinkawa, T.; Sakai, G.; Tamaki, J.; Miura, N.; Yamazoe, N. Relationship between ethanol gas sensitivity and surface catalytic property of tin oxide sensors modified with acidic or basic oxides. J. Mol. Catal. A Chem. 2000, 155, 193-200. [CrossRef]

51. Zaera, F. Nanostructured materials for applications in heterogeneous catalysis. Chem. Soc. Rev. 2013, 42, 2746-2762. [CrossRef]

52. Barsan, N.; Weimar, U. Conduction Model of Metal Oxide Gas Sensors. J. Electroceram. 2001, 7, 143-167. [CrossRef]

53. Barsan, N.; Simion, C.; Heine, T.; Pokhrel, S.; Weimar, U. Modeling of sensing and transduction for p-type semiconducting metal oxide based gas sensors. J. Electroceram. 2010, 25, 11-19. [CrossRef]

54. Matar, S.F.; Campet, G.; Subramanian, M.A. Electronic properties of oxides: Chemical and theoretical approaches. Prog. Solid State Chem. 2011, 39, 70-95. [CrossRef]

55. Idriss, H.; Barteau, M.A. Active sites on oxides: From single crystals to catalysts. J. Adv. Catal. Sci. Technol. 2000, 45, 261-331.

56. Dimitrov, V.; Komatsu, T. Correlation among electronegativity, cation polarizability, optical basicity and single bond strength of simple oxides. J. Solid State Chem. 2012, 196, 574-578. [CrossRef]

57. Lany, S. Semiconducting transition metal oxides. J. Phys. Condens. Matter. 2015, 27, 283203. [CrossRef] [PubMed]

58. Perkins, J.D.; Ginley, D.S. Handbook of Transparent Conductors; Ginley, D.S., Ed.; Springer: New York, NY, USA, 2010.

59. Shannon, R.D. Revised effective ionic radii and systematic studies of interatomic distances in halides and chalcogenides. Acta Cryst. 1976, A32, 751-767. [CrossRef]

60. Proffit, D.E.; Ma, Q.; Buchholz, D.B.; Chang, R.P.H.; Bedzyk, M.J.; Mason, T.O. Structural and Physical Property Studies of Amorphous Zn-In-Sn-O Thin Films. J. Am. Ceram. Soc. 2012, 95, 3657-3664. [CrossRef]

61. Das, S.; Jayaraman, V. $\mathrm{SnO}_{2}$ : A comprehensive review on structures and gas sensors. Prog. Mater. Sci. 2014, 66, 112-255. [CrossRef]

62. Burdett, J.K.; Hughbanks, T.; Miller, G.J.; Richardson, J.W.; Smith, J.V. Structural-Electronic Relationships in Inorganic Solids: Powder Neutron Diffraction Studies of the Rutile and Anatase Polymorphs of Titanium Dioxide at 15 and 295 K. J. Am. Chem. Soc. 1987, 109, 3639-3646. [CrossRef]

63. Marikutsa, A.; Yang, L.; Kuznetsov, A.N.; Rumyantseva, M.; Gaskov, A. Effect of W-O bonding on gas sensitivity of nanocrystalline $\mathrm{Bi}_{2} \mathrm{WO}_{6}$ and $\mathrm{WO}_{3}$. J. Alloy. Compd. 2020, 856, 158159. [CrossRef]

64. Zaera, F. The Surface Chemistry of Heterogeneous Catalysis: Mechanisms, Selectivity, and Active Sites. Chem. Rec. 2005, 5, 133-144. [CrossRef] [PubMed]

65. Kulkarni, D.; Wachs, I.E. Isopropanol oxidation by pure metal oxide catalysts: Number of active surface sites and turnover frequencies. Appl. Catal. A Gen. 2002, 237, 121-137. [CrossRef]

66. Vedyagin, A.A.; Volodin, A.M.; Stoyanovskii, V.O.; Mishakov, I.V.; Medvedev, D.A.; Noskov, A.S. Characterization of active sites of $\mathrm{Pd} / \mathrm{Al}_{2} \mathrm{O}_{3}$ model catalysts with low Pd content by luminescence, EPR and ethane hydrogenolysis. Appl. Catal. B Environ. 2011, 103, 397-403. [CrossRef]

67. Zotov, R.A.; Molchanov, V.V.; Volodin, A.M.; Bedilo, A.F. Characterization of the active sites on the surface of $\mathrm{Al}_{2} \mathrm{O}_{3}$ ethanol dehydration catalysts by EPR using spin probes. J. Catal. 2011, 278, 71-77. [CrossRef]

68. Ross-Medgaarden, E.I.; Wachs, I.E.; Knowles, W.V.; Burrows, A.; Kiely, C.J.; Wong, M.S. Tuning the Electronic and Molecular Structures of Catalytic Active Sites with Titania Nanoligands. J. Am. Chem. Soc. 2009, 131, 680-687. [CrossRef]

69. Morrison, S.R. The Chemical Physics of Surfaces, 1st ed.; Springer: New York, NY, USA, 1990.

70. Davydov, A. Molecular Spectroscopy of Oxide Catalyst Surfaces; Wiley: Chichester, UK, 2003.

71. Bukhtiyarov, V.I.; Slinko, M.G. Metallic nanosystems in catalysis. Russ. Chem. Rev. 2001, 70, 147-159. [CrossRef]

72. Chen, M.; Goodman, D.W. Catalytically Active Gold: From Nanoparticles to Ultrathin Films. Acc. Chem. Res. 2006, 39, 739-746. [CrossRef]

73. Castellarin-Cudia, C.; Surnev, S.; Schneider, G.; Podlucky, R.; Ramsey, M.G.; Netzer, F.P. Strain-induced formation of arrays of catalytically active sites at the metal-oxide interface. Surf. Sci. 2004, 554, L120-L126. [CrossRef]

74. Marikutsa, A.V.; Rumyantseva, M.N.; Gaskov, A.M.; Konstantinova, E.A.; Grishina, D.A.; Deygen, D.M. CO and NH 3 sensor properties and paramagnetic centers of nanocrystalline $\mathrm{SnO}_{2}$ modified by Pd and Ru. Thin Solid Films 2011, 520, 904-908. [CrossRef]

75. Marikutsa, A.; Yang, L.; Rumyantseva, M.; Batuk, M.; Hadermann, J.; Gaskov, A. Sensitivity of nanocrystalline tungsten oxide to $\mathrm{CO}$ and ammonia gas determined by surface catalysts. Sens. Actuators B Chem. 2018, 277, 336-346. [CrossRef] 
76. Marikutsa, A.; Rumyantseva, M.; Gaskov, A.; Batuk, M.; Hadermann, J.; Sarmadian, N.; Saniz, R.; Partoens, B.; Lamoen, D. Effect of Zinc Oxide Modification by Indium Oxide on Microstructure, Adsorbed Surface Species, and Sensitivity to CO. Front. Mater. 2019, 6, 1-11. [CrossRef]

77. Marikutsa, A.; Rumyantseva, M.; Baranchikov, A.; Gaskov, A. Nanocrystalline $\mathrm{BaSnO}_{3}$ as an Alternative Gas Sensor Material: Surface Reactivity and High Sensitivity to $\mathrm{SO}_{2}$. Materials 2015, 8, 6437-6454. [CrossRef] [PubMed]

78. Marikutsa, A.; Novikova, A.; Rumyantseva, M.; Khmelevsky, N.; Gaskov, A. Comparison of Au-functionalized semiconductor metal oxides in sensitivity to VOC. Sens. Actuators B Chem. 2021, 326, 128980. [CrossRef]

79. Marikutsa, A.V.; Rumyantseva, M.N.; Konstantinova, E.A.; Shatalova, T.B.; Gaskov, A.M. Active Sites on Nanocrystalline Tin Dioxide Surface: Effect of Palladium and Ruthenium Oxides Clusters. J. Phys. Chem. C 2014, 118, 21541-21549. [CrossRef]

80. Abee, M.W.; Cox, D.F. $\mathrm{NH}_{3}$ chemisorption on stoichiometric and oxygen deficient $\mathrm{SnO}_{2}(110)$ surfaces. Surf. Sci. 2002, 520, 65-77. [CrossRef]

81. Bordes-Richard, E.; Courtine, P. Optical basicity: A scale of acidity/basicity of solids and its application to oxidation catalysis. In Metal Oxides: Chemistry and Application; Fierro, J.L.S., Ed.; Taylor \& Francis: Boca Raton, FL, USA, 2006; pp. $319-352$.

82. Barsan, N.; Weimar, U. Understanding the fundamental principles of metal oxide based gas sensors; the example of CO sensing with $\mathrm{SnO}_{2}$ sensors in the presence of humidity. J. Phys. Condens. Matter. 2003, 15, 813-839. [CrossRef]

83. Pavelko, R.G.; Daly, H.; Hardacre, C.; Vasiliev, A.A.; Llobet, E. Interaction of water, hydrogen and their mixtures with $\mathrm{SnO}_{2}$ based materials: The role of surface hydroxyl groups in detection mechanisms. Phys. Chem. Chem. Phys. 2010, 12, 2639-2647. [CrossRef] [PubMed]

84. Marikutsa, A.V.; Vorobyeva, N.A.; Rumyantseva, M.N.; Gaskov, A.M. Active sites on the surface of nanocrystalline semiconductor oxides $\mathrm{ZnO}$ and $\mathrm{SnO}_{2}$ and gas sensitivity. Rus. Chem. Bull. 2017, 66, 1728-1764. [CrossRef]

85. Guo, Y.; Zeng, L.; Xu, X.; Liu, Y.; Liu, Y.; Fu, X.; Gao, Z.; Qian, Z.; Xu, J.; Fang, X.; et al. Regulating SnO 2 surface by metal oxides possessing redox or acidic properties: The importance of active $\mathrm{O}_{2}{ }^{-} / \mathrm{O}_{2}{ }^{2-}$ and acid sites for toluene deep oxidation. Appl. Catal. Ageneral 2020, 605, 117755. [CrossRef]

86. Roberts, M.W. The Role of Short-lived Oxygen Transients and Precursor States in the Mechanisms of Surface Reactions; A Different View of Surface Catalysis. Chem. Soc. Rev. 1996, 6, 437-445. [CrossRef]

87. Marikutsa, A.V.; Rumyantseva, M.N.; Yashina, L.V.; Gaskov, A.M. Role of surface hydroxyl groups in promoting room temperature $\mathrm{CO}$ sensing by Pd-modified nanocrystalline $\mathrm{SnO}_{2}$. J. Solid State Chem. 2010, 183, 2389-2399. [CrossRef]

88. Haber, J. Selectivity in Heterogeneous Catalytic Oxidation of Hydrocarbons. In Heterogeneous Hydrocarbon Oxidation; Warren, B., Ed.; ACS Symposium Series; American Chemical Society: Washington, DC, USA, 1996; pp. 20-34.

89. Royer, S.; Duprez, D. Catalytic Oxidation of Carbon Monoxide over Transition Metal Oxides. ChemCatChem. 2011, 3, 24-65. [CrossRef]

90. Habgood, M.; Harrison, N. An ab initio study of oxygen adsorption on tin dioxide. Surf. Sci. 2008, 602, 1072-1079. [CrossRef]

91. Sahm, T.; Gurlo, A.; Barsan, N.; Weimar, U. Basics of Oxygen and $\mathrm{SnO}_{2}$ Interaction; Work Function Change and Conductivity Measurements. Sens. Actuators B Chem. 2006, 118, 78-83. [CrossRef]

92. Kung, M.C.; Davis, R.J.; Kung, H.H. Understanding Au-Catalyzed Low-Temperature CO Oxidation. J. Phys. Chem. C 2007, 111, 11767-11775. [CrossRef]

93. Wachs, I.E. Molecular Structures of Surface Metal Oxide Species: Nature of Catalytic Active Sites in Mixed Metal Oxides. In Metal Oxides: Chemistry and Application; Fierro, J.L.S., Ed.; Taylor \& Francis: Boca Raton, FL, USA, 2006; pp. 1-26.

94. Forsh, E.A.; Abakumov, A.M.; Zaytsev, V.B.; Konstantinova, E.A.; Forsh, P.A.; Rumyantseva, M.N.; Gaskov, A.M.; Kashkarov, P.K. Optical and photoelectrical properties of nanocrystalline indium oxide with small grains. Thin Solid Films 2015, 595, 25-31. [CrossRef]

95. Marikutsa, A.; Rumyantseva, M.; Frolov, D.; Morozov, I.; Boltalin, A.; Fedorova, A.; Petukhov, I.; Yashina, L.; Konstantinova, E.; Sadovskaya, E.; et al. Role of $\mathrm{PdO}_{\mathrm{x}}$ and $\mathrm{RuO}_{\mathrm{y}}$ Clusters in Oxygen Exchange between Nanocrystalline Tin Dioxide and the Gas Phase. J. Phys. Chem. C 2013, 117, 23858-23867. [CrossRef]

96. Konstantinova, E.A.; Zaitsev, V.B.; Kytina, E.V.; Marikutsa, A.V. Photoaccumulating Nanoheterostructures Based on Titanium Dioxide. Semiconductors 2021, 55, 219-227. [CrossRef]

97. Naberezhnyi, D.; Rumyantseva, M.; Filatova, D.; Batuk, M.; Hadermann, J.; Baranchikov, A.; Khmelevsky, N.; Aksenenko, A.; Konstantinova, E.; Gaskov, A. Effects of Ag Additive in Low Temperature CO Detection with $\operatorname{In}_{2} \mathrm{O}_{3}$ Based Gas Sensors. Nanomaterials 2018, 8, 801. [CrossRef]

98. Marikutsa, A.; Sukhanova, A.; Rumyantseva, M.; Gaskov, A. Acidic and catalytic co-functionalization for tuning the sensitivity of sulfated tin oxide modified by ruthenium oxide to ammonia gas. Sens. Actuators B Chem. 2018, 255, 3523-3532. [CrossRef]

99. Wrledt, H.A. The O-W (Oxygen-Tungsten) System. Bull. Alloy Phase Diagr. 1989, 10, 368-384. [CrossRef]

100. Ivanovskaya, M.I.; Branitskiy, G.A.; Orlik, D.R.; Malchenko, S.I.; Vrublevskiy, A.I. Nature of paramagnetic centers in tin dioxide. Rus. J. Inorg. Chem. 1992, 37, 1147-1152.

101. Le, N.T. Influence of the Synthesis Conditions of Nanocrystalline Titanium Dioxide on the Nature and Parameters of Spin Centers. Ph.D. Thesis, Moscow State University, Moscow, Russian, 2017.

102. Vorobyeva, N.; Rumyantseva, M.; Filatova, D.; Konstantinova, E.; Grishina, D.; Abakumov, A.; Turner, S.; Gaskov, A. Nanocrystalline $\mathrm{ZnO}(\mathrm{Ga})$ : Paramagnetic centers, surface acidity and gas sensor properties. Sens. Actuators B Chem. 2013, 182, 555-564. [CrossRef] 
103. Iwamoto, M.; Yoda, Y.; Yamazoe, N.; Seiyama, T. Study of Metal Oxide Catalysts by Temperature Programmed Desorption. 4. Oxygen Adsorption on Various Metal Oxides. J. Phys. Chem. 1978, 82, 2564-2570. [CrossRef]

104. Konstantinova, E.A.; Pentegov, I.S.; Marikutsa, A.V.; Rumyantseva, M.N.; Gaskov, A.M.; Kashkarov, P.K. EPR study of nanocrystalline tin dioxide. Phys. Status Solidi C 2011, 8, 1957-1960. [CrossRef]

105. Liu, J.; Liu, X.; Zhai, Z.; Jin, G.; Jiang, Q.; Zhao, Y.; Luo, C.; Quan, L. Evaluation of depletion layer width and gas-sensing properties of antimony-doped tin oxide thin film sensors. Sens. Actuators B Chem. 2015, 220, 1354-1360. [CrossRef]

106. Neri, G.; Bonavita, A.; Micali, G.; Rizzo, G.; Pinna, N.; Niederberger, M.; Ba, J. Effect of the chemical composition on the sensing properties of $\mathrm{In}_{2} \mathrm{O}_{3}-\mathrm{SnO}_{2}$ nanoparticles synthesized by a non-aqueous method. Sens. Actuators B Chem. 2008, 130, 222-230. [CrossRef]

107. Guidi, V.; Carotta, M.C.; Ferroni, M.; Martinelli, G.; Paglialonga, L.; Comini, E.; Sberveglieri, G. Preparation of nanosized titania thick and thin films as gas-sensors. Sens. Actuators B Chem. 1999, 57, 197-200. [CrossRef]

108. Larramona, G.; Gutierrez, C.; Pereira, I.; Rosa Nunes, M.; da Costa, F.M.A. Characterization of the mixed perovskite BaSn1-xSbxO3 by electrolyte electroreflectance, diffuse reflectance, and X-ray photoelectron spectroscopy. J. Chem. Soc. Faraday Trans. 1 1989, 85 , 907-916. [CrossRef]

109. Punginsang, M.; Wisitsoraat, A.; Tuantranont, A.; Phanichphant, S.; Liewhiran, C. Ultrafine $\mathrm{Bi}_{2} \mathrm{WO}_{6}$ nanoparticles prepared by flame spray pyrolysis for selective acetone gas-sensing. Mater. Sci. Semicond. Process. 2019, 90, 263-275. [CrossRef]

110. Gonzalez-Borrero, P.P.; Sato, F.; Medina, A.N.; Baesso, M.L.; Bento, A.C.; Baldissera, G.; Persson, C.; Niklasson, G.A.; Granqvist C.G.; Ferreira da Silva, A. Optical band-gap determination of nanostructured $\mathrm{WO}_{3}$ film. Appl. Phys. Lett. 2010, 96, 061909. [CrossRef]

111. Mizoguchi, H.; Eng, H.W.; Woodward, P.M. Probing the Electronic Structures of Ternary Perovskite and Pyrochlore Oxides Containing $\mathrm{Sn}^{4+}$ or $\mathrm{Sb}^{5+}$. Inorg. Chem. 2004, 43, 1667-1680. [CrossRef] [PubMed]

112. Moreira, E.; Henriques, J.M.; Azevedo, D.L.; Caetano, E.W.S.; Freire, V.N.; Fulco, U.L.; Albuquerque, E.L. Structural and optoelectronic properties, and infrared spectrum of cubic $\mathrm{BaSnO}_{3}$ from first principles calculations. J. Appl. Phys. 2012, 112, 043703. [CrossRef]

113. Scanlon, D.O. Defect engineering of $\mathrm{BaSnO}_{3}$ for high-performance transparent conducting oxide applications. Phys. Rev. B 2013, 87, 161201(R). [CrossRef]

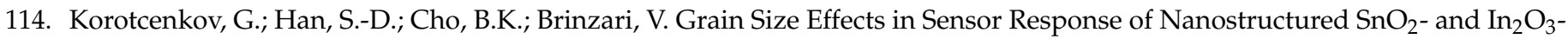
Based Conductometric Thin Film Gas Sensor. Crit. Rev. Solid State Mater. Sci. 2009, 34, 1-17. [CrossRef]

115. Morazzoni, F.; Scotti, R.; Origoni, L.; Arienzo, M.; Jimenez, I.; Cornet, A.; Morante, J.R. Mechanism of $\mathrm{NH}_{3}$ interaction with transition metal-added nanosized $\mathrm{WO}_{3}$ for gas sensing: In situ electron paramagnetic resonance study. Catal. Today 2007, 126, 169-176. [CrossRef]

116. Garshev, A.V.; Ivanov, V.K.; Krotova, A.A.; Filatova, D.G.; Konstantinova, E.A.; Naberezhnyi, D.O.; Khmelevsky, N.O.; Marikutsa,

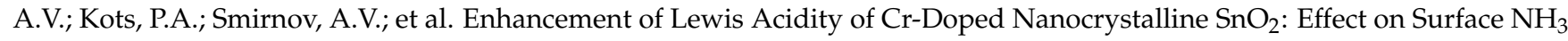
Oxidation and Sensory Detection Pattern. ChemPhysChem 2019, 20, 1985-1996. [CrossRef]

117. Marikutsa, A.; Krivetskiy, V.; Yashina, L.; Rumyantseva, M.; Konstantinova, E.; Ponzoni, A.; Comini, E.; Abakumov, A.; Gaskov, A. Catalytic impact of $\mathrm{RuO}_{x}$ clusters to high ammonia sensitivity of tin dioxide. Sens. Actuators B Chem. 2012, 175, 186-193. [CrossRef]

118. Marikutsa, A.; Rumyantseva, M.; Gaskov, A. Specific Interaction of $\mathrm{PdO}_{\mathrm{x}}$ - and $\mathrm{RuO}_{\mathrm{y}}-\mathrm{Modified}_{\text {Tin }} \mathrm{Dioxide}$ with $\mathrm{CO}$ and $\mathrm{NH}_{3}$ Gases: Kelvin Probe and DRIFT Studies. J. Phys. Chem. C 2015, 119, 24342-24350. [CrossRef]

119. Koziej, D.; Thomas, K.; Barsan, N.; Thibault-Starzyk, F.; Weimar, U. Influence of annealing temperature on the CO sensing mechanism for tin dioxide based sensors-Operando studies. Catal. Today 2007, 126, 211-218. [CrossRef]

120. Marikutsa, A.; Rumyantseva, M.; Gaskov, A. Selectivity of Catalytically Modified Tin Dioxide to $\mathrm{CO}_{\text {and }} \mathrm{NH}_{3}$ Gas Mixtures. Chemosensors 2015, 3, 241-252. [CrossRef]

121. Vaishanv, V.S.; Patel, P.D.; Patel, N.G. Indium Tin Oxide Thin-Film Sensor for Detection of Volatile Organic Compounds (VOCs). Mater. Manuf. Process. 2006, 21, 257-261. [CrossRef]

122. Sivachandiran, L.; Thevenet, F.; Rousseau, A.; Bianchi, D. $\mathrm{NO}_{2}$ adsorption mechanism on $\mathrm{TiO}_{2}$ : An in-situ transmission infrared spectroscopy study. Appl. Catal. B Environ. 2016, 198, 411-419. [CrossRef]

123. Ilin, A.; Martyshov, M.; Forsh, E.; Forsh, P.; Rumyantseva, M.; Abakumov, A.; Gaskov, A.; Kashkarov, P. UV effect on $\mathrm{NO}_{2}$ sensing properties of nanocrystalline $\mathrm{In}_{2} \mathrm{O}_{3}$. Sens. Actuators $B$ Chem. 2016, 231, 491-496. [CrossRef]

124. Tanaka, I.; Oba, F.; Tatsumi, K.; Kunisu, M.; Nakano, M.; Adachi, H. Theoretical Formation Energy of Oxygen-Vacancies in Oxides. Mater. Trans. 2002, 43, 1426-1429. [CrossRef]

125. Hellman, A.; Baerends, E.J.; Biczysko, M.; Bligaard, T.; Christensen, C.H.; Clary, D.C.; Dahl, S.; van Harrevelt, R.; Honkala, K.; Jonsson, H.; et al. Predicting Catalysis: Understanding Ammonia Synthesis from First-Principles Calculations. J. Phys. Chem. B 2006, 110, 17719-17735. [CrossRef]

126. Haruta, M. Catalysis of gold nanoparticles deposited on metal oxides. CatTech 2002, 6, 102-115. [CrossRef]

127. Santra, A.K.; Goodman, D.W. Oxide-supported metal clusters: Models for heterogeneous catalysts. J. Phys. Condens. Matter 2002, 14, R31-R62.

128. Grabow, L.C.; Hvolbek, B.; Norskov, J.K. Understanding Trends in Catalytic Activity: The Effect of Adsorbate-Adsorbate Interactions for CO Oxidation Over Transition Metals. Top. Catal. 2010, 53, 298-310. [CrossRef] 
129. Cabot, A.; Arbiol, J.; Morante, J.R.; Weimar, U.; Barsan, N.; Gopel, W. Analysis of the noble metal catalytic additives introduced by impregnation of as obtained $\mathrm{SnO}_{2}$ sol-gel nanocrystals for gas sensors. Sens. Actuators B Chem. 2000, 70, 87-100. [CrossRef]

130. Korotcenkov, G.; Brinzari, V.; Boris, Y.; Ivanov, M.; Schwank, J.; Morante, J. Influence of surface Pd doping on gas sensing characteristics of $\mathrm{SnO}_{2}$ thin films deposited by spray pyrolysis. Thin Solid Film. 2003, 436, 119-126. [CrossRef]

131. Yin, S.F.; Xu, B.Q.; Zhou, X.P.; Au, C.T. A mini-review on ammonia decomposition catalysts for on-site generation of hydrogen for fuel cell applications. Appl. Catal. A 2004, 277, 1-9. [CrossRef]

132. Wang, Y.; Jacobi, K.; Scholne, W.-D.; Ertl, G. Catalytic Oxidation of Ammonia on $\mathrm{RuO}_{2}(110)$ Surfaces: Mechanism and Selectivity. J. Phys. Chem. B 2005, 109, 7883-7893. [CrossRef] [PubMed]

133. Jones, G.; Bligaard, T.; Abild-Pedersen, F.; Norskov, J.K. Using scaling relations to understand trends in the catalytic activity of transition metals. J. Phys. Condens. Matter 2008, 20, 064239. [CrossRef]

134. Krivetskiy, V.V.; Rumyantseva, M.N.; Gaskov, A.M. Chemical modification of nanocrystalline tin dioxide for selective gas sensors. Russ. Chem. Rev. 2013, 82, 917-941. [CrossRef]

135. Wagh, M.S.; Jain, G.H.; Patil, D.R.; Patil, S.A.; Patil, L.A. Modified zinc oxide thick film resistors as $\mathrm{NH}_{3}$ gas sensor. Sens. Actuators B Chem. 2006, 115, 128-133. [CrossRef]

136. Boccuzzi, F.; Guglielminotti, E. IR study of $\mathrm{TiO}_{2}$-based gas-sensor materials: Effect of ruthenium on the oxidation of $\mathrm{NH}_{3}$, $\left(\mathrm{CH}_{3}\right)_{3} \mathrm{~N}$ and NO. Sens. Actuators B Chem. 1994, 21, 27-31. [CrossRef]

137. Scire, S.; Liotta, L.F. Supported gold catalysts for the total oxidation of volatile organic compounds. Appl. Catal. B Environ. 2012, 125, 222-246. [CrossRef]

138. Carabineiro, S.; Chen, X.; Martynyuk, O.; Bogdanchikova, N.; Avalos-Borja, M.; Pestryakov, A.; Tavares, P.; Orfao, J.; Pereira, M.; Figueiredo, J. Gold supported on metal oxides for volatile organic compounds total oxidation. Catal. Today 2015, 244, 103-114. [CrossRef]

139. Yao, M.-S.; Cao, L.-A.; Hou, G.-L.; Cai, M.-L.; Xiu, J.-W.; Fang, C.-H.; Yuan, F.-L.; Chen, Y.-F. Gold-tin co-sensitized ZnO layered porous nanocrystals: Enhanced responses and antihumidity. RSC Adv. 2017, 7, 20273. [CrossRef]

140. Seo, M.-H.; Yuasa, M.; Kida, T.; Kanmura, Y.; Huh, J.-S.; Yamazoe, N.; Shimanoe, K. Gas sensor using noble metal-loaded TiO 2 nanotubes for detection of large-sized volatile organic compounds. J. Ceram. Soc. Jpn. 2011, 119, 884-889. [CrossRef]

141. Gardner, S.D.; Hoflund, G.B. Catalytic behavior of noble metal/reducible oxide materials for low-temperature CO oxidation. 1. Comparison of catalyst performance. Langmuir 1991, 7, 2135-2139. [CrossRef]

142. Gao, F.; Wood, T.E.; Goodman, D.W. The Effects of Water on CO Oxidation over $\mathrm{TiO}_{2}$ Supported Au Catalysts. Catal. Lett. 2010, 134, 9-12. [CrossRef]

143. Okazaki, K.; Ichikawa, S.; Maeda, Y.; Haruta, M.; Kohyama, M. Electronic structures of Au supported on TiO 2 . Appl. Catal. A Gen. 2005, 291, 45-54. [CrossRef]

144. Fujita, T.; Horikawa, M.; Takei, T.; Murayama, T.; Haruta, M. Correlation between catalytic activity of supported gold catalysts for carbon monoxide oxidation and metal-oxygen binding energy of the support metal oxides. Chin. J. Catal. 2016, 37, 1651-1655. [CrossRef]

145. Okumura, M.; Kitagawa, Y.; Haruta, M.; Yamaguchi, K. The interaction of neutral and charged Au clusters with $\mathrm{O}_{2}, \mathrm{CO}_{\text {and }} \mathrm{H}_{2}$. Appl. Catal. A Gen. 2005, 291,37-44. [CrossRef]

146. Gaggiotti, G.; Galdikas, A.; Kacilius, S.; Mattogno, G.; Setkus, A. Surface chemistry of tin oxide based gas sensors. J. Appl. Phys. 1994, 76, 4467-4471. [CrossRef]

147. Shali, N.B.; Sugunan, S. Influence of transition metals on the surface acidic properties of titania prepared by sol-gel route. Mater. Res. Bull. 2007, 42, 1777-1783. [CrossRef]

148. Noei, H.; Qiu, H.; Wang, Y.; Loeffler, E.; Woell, C.; Muhler, M. The identification of hydroxyl groups on ZnO nanoparticles by infrared spectroscopy. Phys. Chem. Chem. Phys. 2008, 10, 7092-7099. [CrossRef]

149. Rodriguez-Gonzalez, V.; Gomez, R.; Moscosa-Santillan, M.; Amouroux, J. Synthesis, characterization, and catalytic activity in the n-heptane conversion over Pt/In- $\mathrm{Al}_{2} \mathrm{O}_{3}$ sol-gel prepared catalysts. J. Sol-Gel Sci. Technol. 2007, 42, 165-171. [CrossRef]

150. Tanabe, K. Solid Acids and Bases: Their Catalytic Properties; Kodansha Ltd.: Tokyo, Japan, 1970.

151. Khalaf, H.A.; Mansour, S.E.; El-Madani, E.A. The influence of sulfate contents on the surface properties of sulfate-modified tin(IV) oxide catalysts. J. Assoc. Arab Univ. Basic Appl. Sci. 2011, 10, 15-20. [CrossRef]

152. Hadjiivanov, K.I. Identification of Neutral and Charged $\mathrm{N}_{\mathrm{x}} \mathrm{O}_{\mathrm{y}}$ Surface Species by IR Spectroscopy. Catal. Rev. Sci. Eng. 2000, 42, 71-144. [CrossRef]

153. Hadjiivanov, K.I.; Vayssilov, G.N. Characterization of oxide surfaces and zeolites by carbon monoxide as an IR probe molecule. Adv. Catal. 2002, 47, 307-511.

154. Trombetta, M.; Ramis, G.; Busca, G.; Montanari, B.; Vaccari, A. Ammonia Adsorption and Oxidation on Cu/Mg/Al Mixed Oxide Catalysts Prepared via Hydrotalcite-Type Precursors. Langmuir 1997, 13, 4628-4637. [CrossRef]

155. Morimoto, T.; Yanal, H.; Nagao, M. Infrared Spectra of Ammonia Adsorbed on Zinc Oxide. J. Phys. Chem. 1976, 80, 471-475. [CrossRef]

156. Belokopytov, Y.V.; Kholyavenko, K.M.; Gerei, S.V. An Infrared Study of the Surface Properties of Metal Oxides 2. The Interaction of Ammonia with the Surface of $\mathrm{Fe}_{2} \mathrm{O}_{3}, \mathrm{ZnO}, \mathrm{MoO}_{3}$, and $\mathrm{V}_{2} \mathrm{O}_{5}$. J. Catal. 1979, 60, 1-7. [CrossRef]

157. Nakamoto, K. Infrared and Raman Spectra of Inorganic and Coordination Compounds: Part A: Theory and Applications in Inorganic Chemistry, 6th ed.; Wiley: Hoboken, NJ, USA, 1986. 
158. De Jong, A.M.; Niemantsverdriet, J.W. Thermal desorption analysis: Comparative test of ten commonly applied procedures. Surf. Sci. 1990, 233, 355-365. [CrossRef]

159. Rumyantseva, M.; Kovalenko, V.; Gaskov, A.; Makshina, E.; Yuschenko, V.; Ivanova, I.; Ponzoni, A.; Faglia, G.; Comini, E. Nanocomposites $\mathrm{SnO}_{2} / \mathrm{Fe}_{2} \mathrm{O}_{3}$ : Sensor and catalytic properties. Sens. Actuators B Chem. 2006, 118, 208-214. [CrossRef]

160. Redhead, P.A. Thermal desorption of gases. Vacuum 1962, 12, 203-211. [CrossRef]

161. Rumyantseva, M.N.; Gaskov, A.M. Chemical modification of nanocrystalline metal oxides: Effect of the real structure and surface chemistry on the sensor properties. Rus. Chem. Bull. Int. Ed. 2008, 57, 1106-1125. [CrossRef]

162. Hunger, B.; Hoffmann, J.; Heitzsch, O.; Hunger, M. Temperature Programmed Desorption (TPD) of Ammonia from Hzsm-5 Zeolites. J. Therm. 1990, 36, 1379-1391. [CrossRef]

163. Yamaguchi, Y.; Tabata, K.; Suzuki, E. Density functional theory calculations for the interaction of oxygen with reduced $\mathrm{M} / \mathrm{SnO}_{2}(110)(\mathrm{M}=\mathrm{Pd}, \mathrm{Pt})$ surfaces. Surf. Sci. 2003, 526, 149-158. [CrossRef]

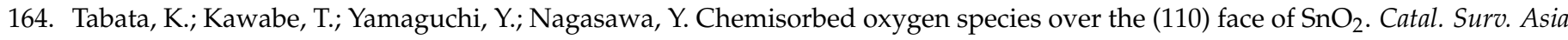
2003, 7, 251-259. [CrossRef]

165. Panov, G.I.; Uriarte, A.K.; Rodkin, M.A.; Sobolev, V.I. Generation of active oxygen species on solid surfaces. Opportunity for novel oxidation technologies over zeolites. Catal. Today 1998, 41, 365-385. [CrossRef]

166. Boulova, M.; Gaskov, A.; Lucazeau, G. Tungsten oxide reactivity to $\mathrm{CH}_{4}, \mathrm{CO}$, and $\mathrm{NO}_{2}$ molecules studied by Raman spectroscopy. Sens. Actuators B Chem. 2001, 81, 99-106. [CrossRef]

167. Moulijn, J.A.; van Leeuwen, P.W.N.M.; van Santen, R.A. (Eds.) Temperature programmed reduction and sulphiding. In Studies in Surface Science and Catalysis; Elsevier: Amsterdam, The Netherlands, 1993; Volume 79, pp. 401-417.

168. Slavinskaya, E.M.; Gulyaeva, R.V.; Zadesenets, A.V.; Stonkusa, O.A.; Zaikovskiia, V.I.; Shubin, Y.V.; Korenev, S.V.; Boronin, A.I. Low-temperature $\mathrm{CO}$ oxidation by $\mathrm{Pd} / \mathrm{CeO}_{2}$ catalysts synthesized using the coprecipitation method. Appl. Catal. B Environ. 2015, 166-167, 91-103. [CrossRef]

169. Hurst, N.W.; Gentry, S.J.; Jones, A.; McNicol, B.D. Temperature Programmed Reduction. Catal. Rev.-Sci. Eng. 1982, 24, 233-309. [CrossRef]

170. Al-Hashem, M.; Akbar, S.; Morris, P. Role of Oxygen Vacancies in Nanostructured Metal-Oxide Gas Sensors: A Review. Sens. Actuators B Chem. 2019, 301, 126845. [CrossRef]

171. Zhang, C.; Liu, G.; Geng, X.; Wu, K.; Debliquy, M. Metal oxide semiconductors with highly concentrated oxygen vacancies for gas sensing materials: A review. Sens. Actuators A Phys. 2020, 309, 112026. [CrossRef]

172. Hernandez-Ramirez, F.; Prades, J.D.; Tarancon, A.; Barth, S.; Casals, O.; Jimenez-Diaz, R.; Pellicer, E.; Rodriguez, J.; Morante, J.R.;

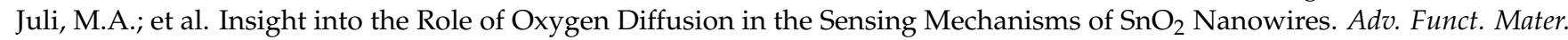
2008, 18, 2990-2994. [CrossRef]

173. Maier, J.; Gopel, W. Investigation of the bulk defect chemistry of polycrystalline tin(IV) oxide. J. Solid State Chem. 1988, 72, $293-302$. [CrossRef]

174. Mizusaki, J.; Koinuma, H.; Shimoyama, J.I.; Kawasaki, M.; Fueki, K. High temperature gravimetric study on nonstoichometry and oxygen adsorption of $\mathrm{SnO}_{2}$. J. Solid State Chem. 1990, 8, 443-450. [CrossRef]

175. Li-Zi, Y.; Zhi-Tong, S.; Chan-Zheng, W. A thermodynamic study of tin oxides by coulometric titration. J. Solid State Chem. 1994, 113, 221-224. [CrossRef]

176. Setvin, M.; Wagner, M.; Schmid, M.; Parkinson, G.S.; Diebold, U. Surface point defects on bulk oxides: Atomically-resolved scanning probe microscopy. Chem. Soc. Rev. 2017, 46, 1772-1784. [CrossRef] [PubMed]

177. Batzill, M. Surface Science Studies of Gas Sensing Materials: $\mathrm{SnO}_{2}$. Sensors 2006, 6, 1345-1366. [CrossRef]

178. Rumyantseva, M.N.; Gaskov, A.M.; Rosman, N.; Pagnier, T.; Morante, J.R. Raman Surface Vibration Modes in Nanocrystalline $\mathrm{SnO}_{2}$ : Correlation with Gas Sensor Performances. Chem. Mater. 2005, 17, 893-901. [CrossRef]

179. Smith, J.M.; Vehse, W.E. ESR of electron irradiated ZnO: Confirmation of the F+ center. Phys. Lett. A 1970, 31, 147-148. [CrossRef]

180. Kappers, L.A.; Gilliama, O.R.; Evans, S.M.; Halliburton, L.E.; Giles, N.C. EPR and optical study of oxygen and zinc vacancies in electron-irradiated ZnO. Nucl. Instrum. Meth. B 2008, 266, 2953-2957. [CrossRef]

181. Canevali, C.; Chiodini, N.; Morazzoni, F.; Scotti, R. Electron paramagnetic resonance characterization of rutheniumdispersed tin oxide obtained by sol-gel and impregnation methods. J. Mater. Chem. 2000, 10, 773-778. [CrossRef]

182. Konstantinova, E.; Weidmann, J.; Dittrich, T. Influence of Adsorbed Water and Oxygen on the Photoluminescence and EPR of Por- $\mathrm{TiO}_{2}$ (Anatase). J. Porous Mater. 2000, 7, 389-392. [CrossRef]

183. Hamlyn, R.C.E.; Mahapatra, M.; Grinter, D.C.; Xu, F.; Luo, S.; Palomino, R.M.; Kattel, S.; Waluyo, I.; Liu, P.; Stacchiola, D.J.; et al. Imaging the ordering of a weakly adsorbed two-dimensional condensate: Ambient pressure microscopy and spectroscopy of $\mathrm{CO}_{2}$ molecules on rutile $\mathrm{TiO}_{2}(110)$. Phys. Chem. Chem. Phys. 2018, 20, 13122-13126. [CrossRef]

184. Barsan, N.; Koziej, D.; Weimar, U. Metal oxide-based gas sensor research: How to? Sens. Actuators B Chem. 2007, 121, 18-35. [CrossRef]

185. Koziej, D.; Hubner, M.; Barsan, N.; Weimar, U.; Sikorazc, M.; Grunwaldt, J.-D. Operando X-ray absorption spectroscopy studies on $\mathrm{Pd}-\mathrm{SnO}_{2}$ based sensors. Phys. Chem. Chem. Phys. 2009, 11, 8620-8625. [CrossRef] [PubMed]

186. Oprea, A.; Barsan, N.; Weimar, U. Work function changes in gas sensitive materials: Fundamentals and applications. Sens. Actuators B Chem. 2009, 142, 470-493. [CrossRef] 